\title{
OCCUPATIONAL HEALTH AND SAFETY FOR \\ SIGN LANGUAGE INTERPRETERS
}

\section{KATHRYN WOODCOCK, PhD, PEng}

School of Occupational and Public Health

Ryerson University, Toronto Canada

\section{STEVEN L. FISCHER, MSc, CK}





\section{ACKNOWLEDGMENTS}

The Occupational Health and Safety Guide for Sign Language Interpreters was prepared with the financial assistance of the Workplace Safety and Insurance Board of Ontario. The Association of Visual Language Interpreters, and in particular the task force for interpreter health and safety initiated and provided substantial input on the project. Kerry Grandfield, Penny Schincariol, and Angi Tippet advised on the preparation of the material. Numerous other interpreters have provided valued insights, not the least of these being the 314 members of AVLIC who responded to the survey conducted in connection with this project.

The images of interpreting postures and exercises are to the credit of the patience, good humour, and generosity of Miguel Aguayo in the photo studio and post-production, as well as to "models" Penny Schincariol, Angi Tippet and Kelly Ferguson. The creation of the companion materials in ASL using the Sign-Link Studio resource was assisted by Ryerson University PhD student Ellen Hibbard, MS, and her colleagues in the Centre for Learning Technologies.

The expert review of Dr. Richard Wells of the Centre for Research Expertise in Musculoskeletal Disorders (CRE-MSD) at the University of Waterloo, and Dr. Matthew Marshall of the Kate Gleason College of Engineering at Rochester Institute for Technology is also much valued in assuring the technical merits of this Guide. Any errors that remain are ours. 



\section{OCCUPATIONAL HEALTH AND SAFETY FOR \\ SIGN LANGUAGE INTERPRETERS}

\section{CONTENTS}

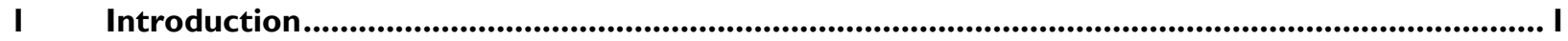

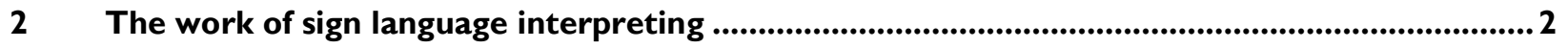

2.I An ergonomic system model of interpreting......................................................................................

$2.2 \quad$ Inside the cognitive process ............................................................................................................

2.3 Interpreting from the macroergonomic perspective: The employment situation and compensation

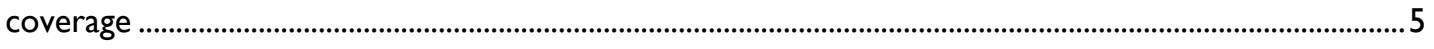

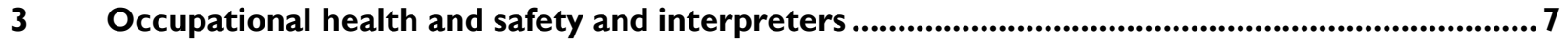

3.1 Types of hazards, and risk reduction examples ...................................................................................

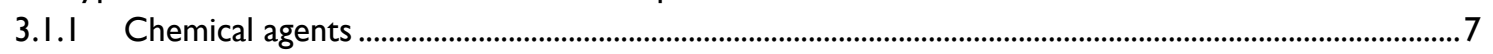

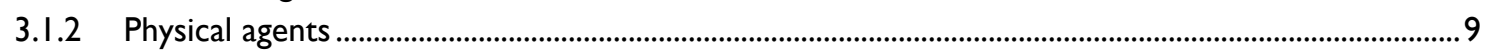

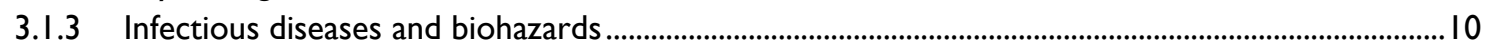

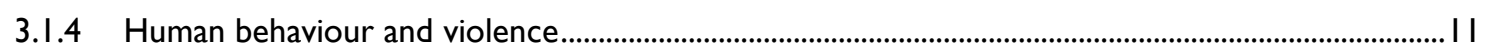

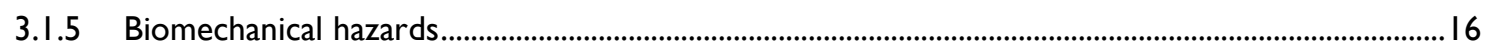

3.1.6 Voice strain ............................................................................................................................. 19

3.2 Occupational health program: A unified approach to eliminating, controlling, and managing

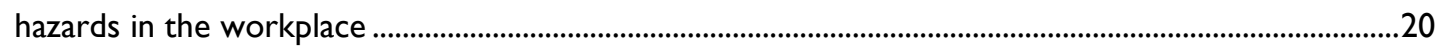

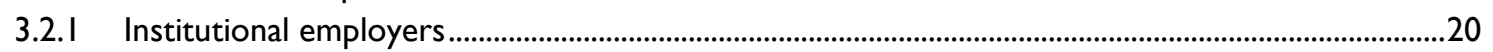

3.2.2 Self-employed interpreters.......................................................................................................

3.2.3 Reporting and surveillance ................................................................................................................

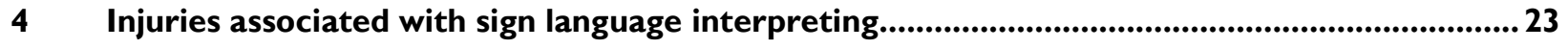

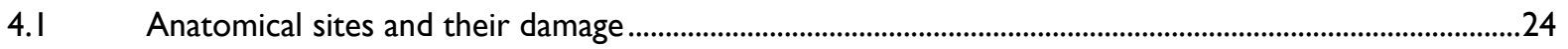

4.1.I The joint.

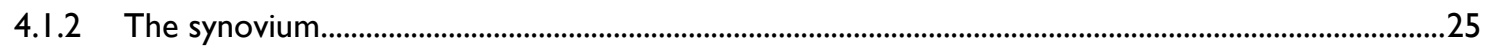

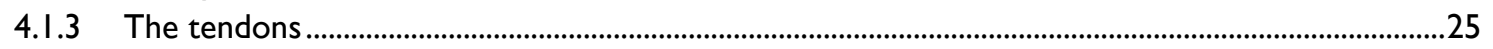

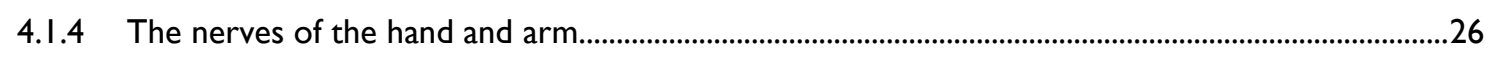

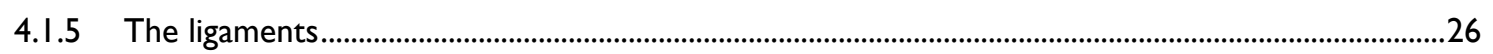

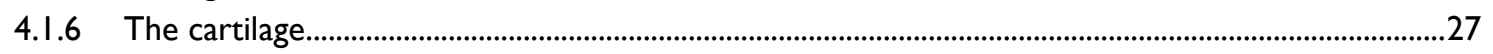

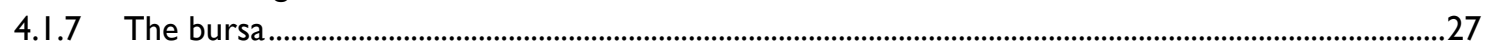

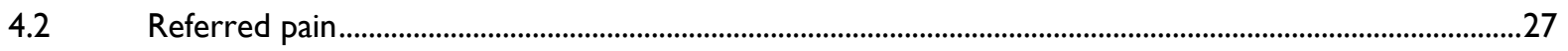

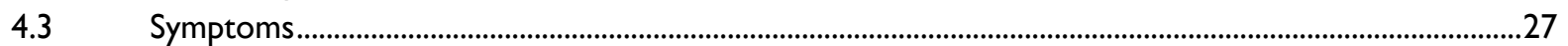

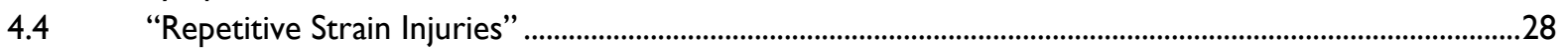

5 Factors associated with injury development in sign language interpreters: Model of

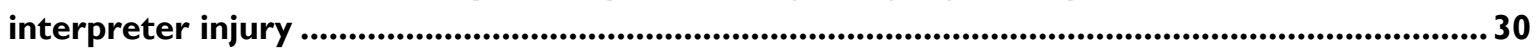

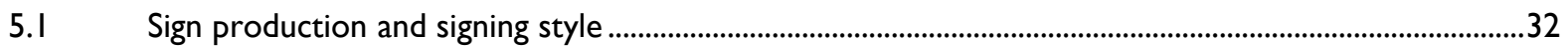

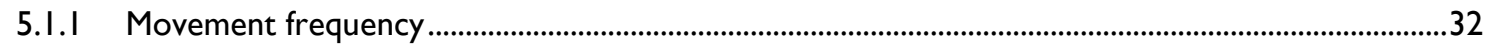

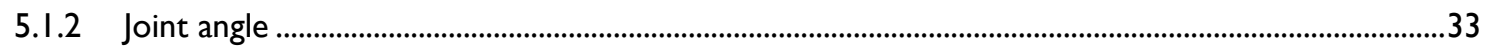




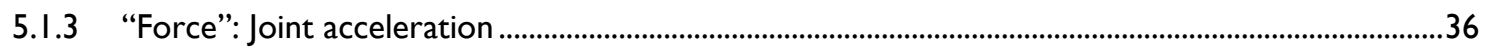

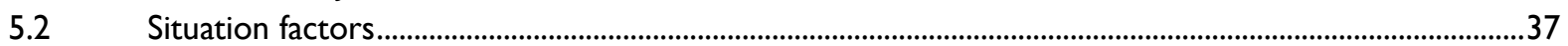

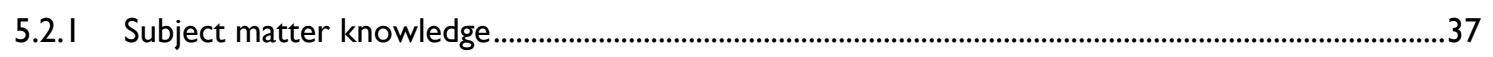

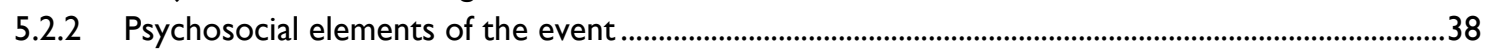

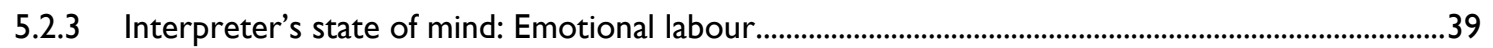

5.2.4 Physical effects of non-physical work: Interpreting from sign language to spoken language...........40

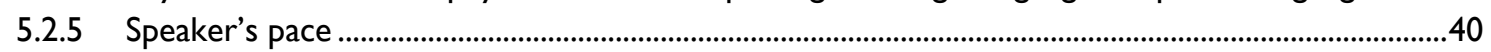

5.2.6 Interpreting duration ...................................................................................................................... I

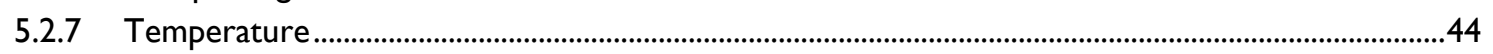

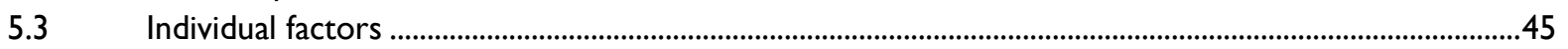

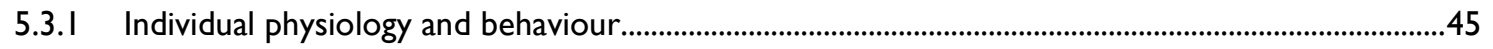

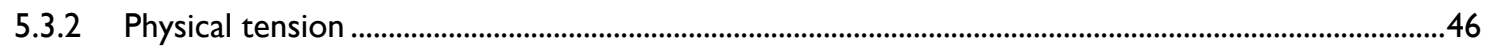

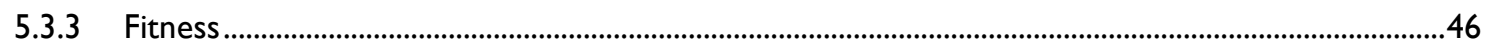

6 Treatment and rehabilitation of musculoskeletal injuries of sign language production ............ 47

6.I Injury and disability .....................................................................................................................................4

6.1.I Theoretical framework of health and disability ..............................................................................

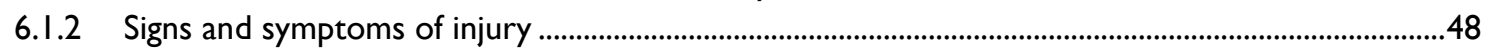

6.I.3 Monitoring and evaluating symptoms ..............................................................................................49

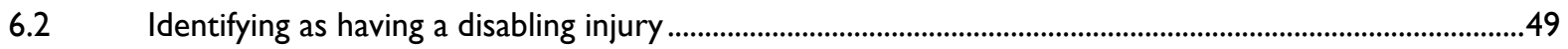

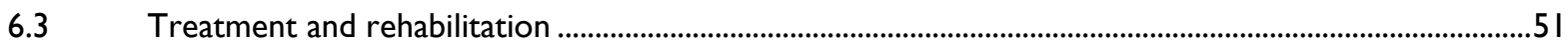

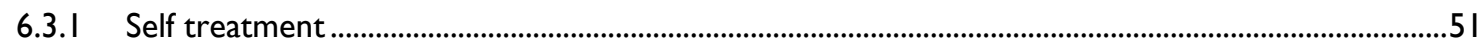

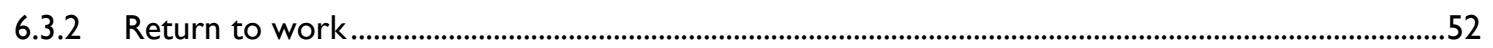

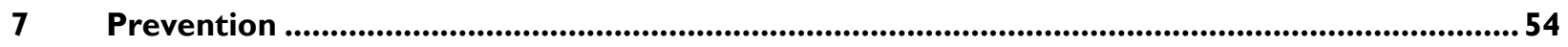

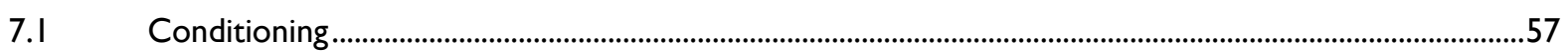

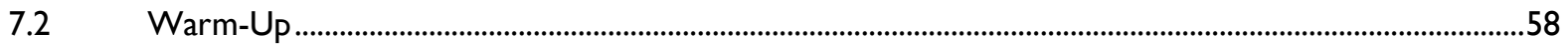

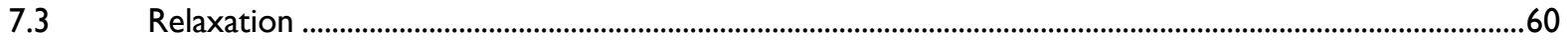

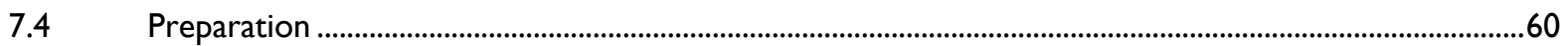

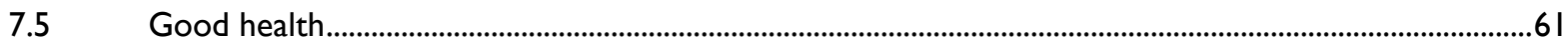

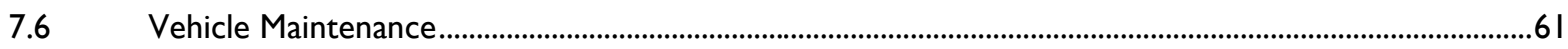

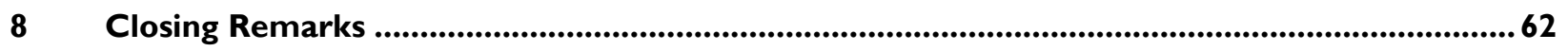

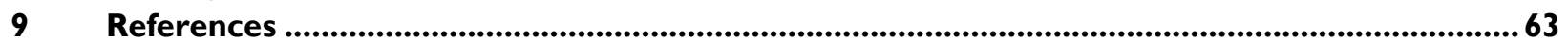

10 Appendix I. Quick DASH to assess disorders of the arm and shoulder.......................................68

II Appendix 2. Model Health and Safety Policy for Sign Language Interpreter providing services on short term contract.................................................................................................................... 7 I

12 Appendix 3. Canada's Food Guide..................................................................................................... 72 


\section{List of figures}

Figure I. A system model of interpreting........................................................................................................

Figure 2. A model of interpreter's information processing work …………………………………............................

Figure 3. Symbols used on WHMIS labelling and MSDSs......................................................................................

Figure 4. Dynamic sitting posture examples .................................................................................................................. 17

Figure 5. Prevalence of pain at eight sites among Canadian interpreters ..................................................................23

Figure 6. Prevalence of musculoskeletal injury by age group, compared with the general Canadian

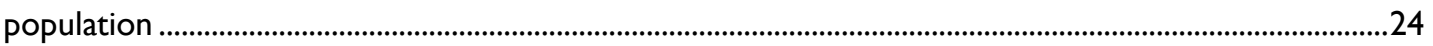

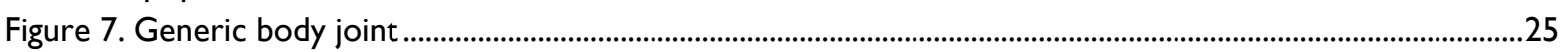

Figure 8. Vicious cycle of progressive injury resulting from high repetition, long duration, and rapid postural

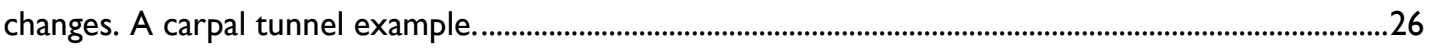

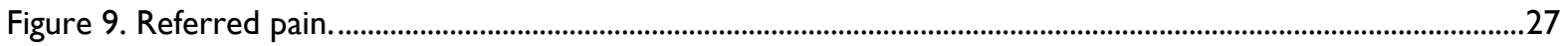

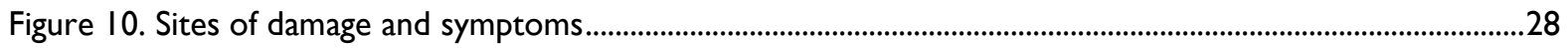

Figure II. Model of interpreter injury .............................................................................................................. I

Figure 12. Proposed model of trade-off between message equivalence and physical work in relation to time

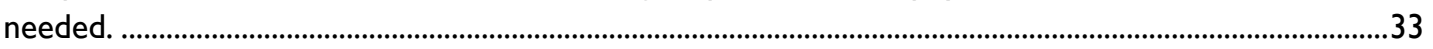

Figure 13. Initiation and completion positions of sign PUSH ....................................................................................

Figure 14. Keep signs within $25 \mathrm{~cm}$ area around neutral hand position......................................................................34

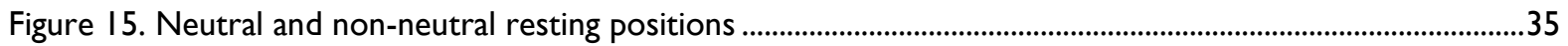

Figure 16. Examples of signs using hand-to-hand impacts .......................................................................................

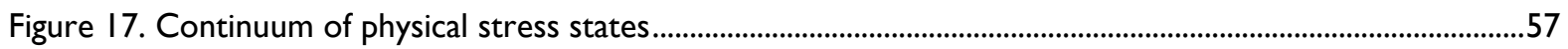

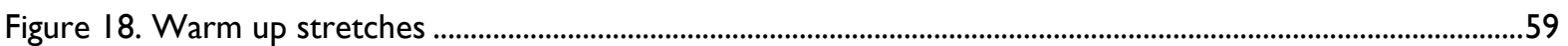

\section{List of tables}

Table I. Maximum WBGT temperature $\left({ }^{\circ} \mathrm{C}\right)$ for work-rest schedules of different intensity.................................. 9

Table 2. Factors increasing and decreasing Work-Rest durations............................................................................42

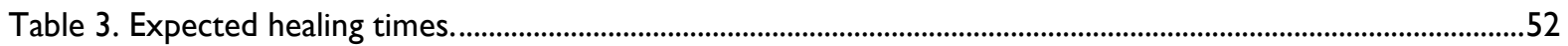

Table 4: Successful interventions to help reduce musculoskeletal injuries in sign language interpreters ..............54

Table 5. Example of a safely organized work week of 20.5 hours with "hands in the air" .......................................56

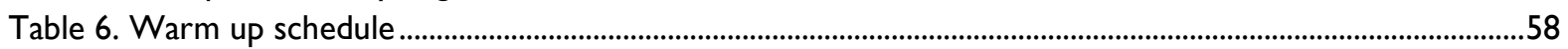




\section{INTRODUCTION}

In 1700, "De Morbis Artificum Diatriba" (A Treatise on the Diseases of Workers) by Bernardo Ramazzini, showed the link between diseases and the work environment and activities of some 40 occupations. Today, exposures to occupation-specific hazards are recognized as an important element of individual health, and many occupations are recognized as having unique occupational health syndromes.

Occupational health is critical to every worker, whether salaried, casual, self-employed, volunteer or trainee. Particularly in human service occupations, it is sometimes easier to see the work that needs to be done than to see the needs of the provider. The professional must recognize that occupational injuries and diseases can bring a career to a premature end. Occupational health requires full awareness of occupational hazards and personal efforts to curtail excessive exposure to hazards.

Awareness of the occupational health issues associated with sign language interpreting has been focussed foremost on musculoskeletal injuries of the arms, shoulders and hands. In 1995, the Association for Visual Language Interpreters of Canada (AVLIC) published the Resource Guide RSI for Sign Language Interpreters. This new resource expands upon that guide to consider other occupational health issues affecting some interpreters, and approaches to prevention and management.

This Guide is intended for working interpreters, interpreting students and educators, and those who employ or purchase the services of interpreters. Occupational health education is essential for professionals in training, to avoid early attrition from practice. "Sign language interpreting" is considered to include interpretation between American Sign Language (ASL) and English, other spoken languages and corresponding sign languages, and between sign languages (e.g., Deaf Interpreters). Some of the occupational health issues may also apply equally to Communication Access Realtime Translation (CART) reporters, oral interpreters, and intervenors. The reader is encouraged to make as much use as possible of the information provided here.

This Guide should not be used for self-diagnosis or self-treatment. If a condition is apparent, the interpreter should consult an appropriate clinician or health practitioner.

The Guide is structured to provide background information about a range of occupational health hazards, and guidance on management of occupational health in the profession. It can be read in order as a whole, or the reader may jump to the sections of most interest. Because occupational health and ergonomics are closely aligned, an ergonomic model of the task of interpreting will be used as a unifying framework for discussing the occupational health hazards of sign language interpreting.

The Guide has incorporated findings of recent research on interpreting health and safety and scientific literature of musculoskeletal injury in general.

The term "client" is used to refer to the business that purchases interpretation services. "Consumer" is used to refer to the deaf person that is participating in the interpreted event. Each interpreted event is referred to as an "appointment". "Team interpreting" is the provision of interpretation by two or more interpreters working collaboratively during the same appointment, usually but not exclusively by alternating active interpretation with rest and team support. An interpreter working alone on the appointment is referred to as a "solo" interpreter. To be general, both ASL and la Langue des Sourds du Québec (LSQ, formerly la Langue des Signes Québécoises) are referred to as "signed languages" or sign language and English and French are referred to as spoken languages. Although AVLIC is the national professional association representing interpreters whose working languages are English and ASL, examples that specifically refer to ASL and English should apply equally to LSQ and French. Use of male or female pronouns in hypothetical examples throughout the Guide is not intended to limit the example to that gender, but simply to avoid the usage of "he/she" or "they" when referring to individuals. Unless otherwise indicated, the point of the examples could pertain to either male or female interpreters. 


\section{THE WORK OF SIGN LANGUAGE INTERPRETING}

"Interpretation" bridges communication between two or more people who do not use the same language. It occurs in real time, in contrast with "translation" which is done with printed materials or other media for delivery at a later time. When one or more of those people uses sign language, an interpreter interprets the spoken message into sign language and the signed message into a spoken language to enable the participants to understand one another. Deaf Interpreters, as part of a team of interpreters, will interpret between participants including those with regional sign dialects, non-standard signs, foreign sign language and for those with emerging language use. In Canada, most sign language interpreters work between English and ASL or between French and LSQ, although interpretation between French/ASL or English/LSQ is theoretically possible and a small number of interpreters have this capability.

To place the occupational health analysis in its ergonomic framework, this section will discuss the interpretation from a both a micro ergonomic perspective (task of interpreting), and a macro ergonomic perspective (employment situation).

\section{I AN ERGONOMIC SYSTEM MODEL OF INTERPRETING}

A "task" is an activity that is performed to accomplish some goal that has been chosen, assigned, or is inherent in a job. The task of interpretation from spoken language to sign language is illustrated in Figure I. The task of interpretation from sign language to spoken language is equivalently performed in the reverse direction.

The system model (Figure I) reveals several areas where performance interference could occur. If the interpreter cannot clearly hear or see the participants, interpretation will be virtually impossible. The work performed within the interpreter is as important as the work performed at the interpreter-participant interface. If the interpreter lacks content knowledge about the subject matter of the communication event, if the interpreter does not comprehend the source message or does not know the linguistic equivalent in the target language, or is subject to any interference with motor processing, the interpretation will be degraded. Prior training, knowledge, and experience will affect linguistic and contextual knowledge available to the interpreter. Environmental factors not only interfere with seeing and hearing the participants, but heat, humidity, dust, cold, odours, and other conditions can be distracting and may even affect physical endurance. The social and motivational

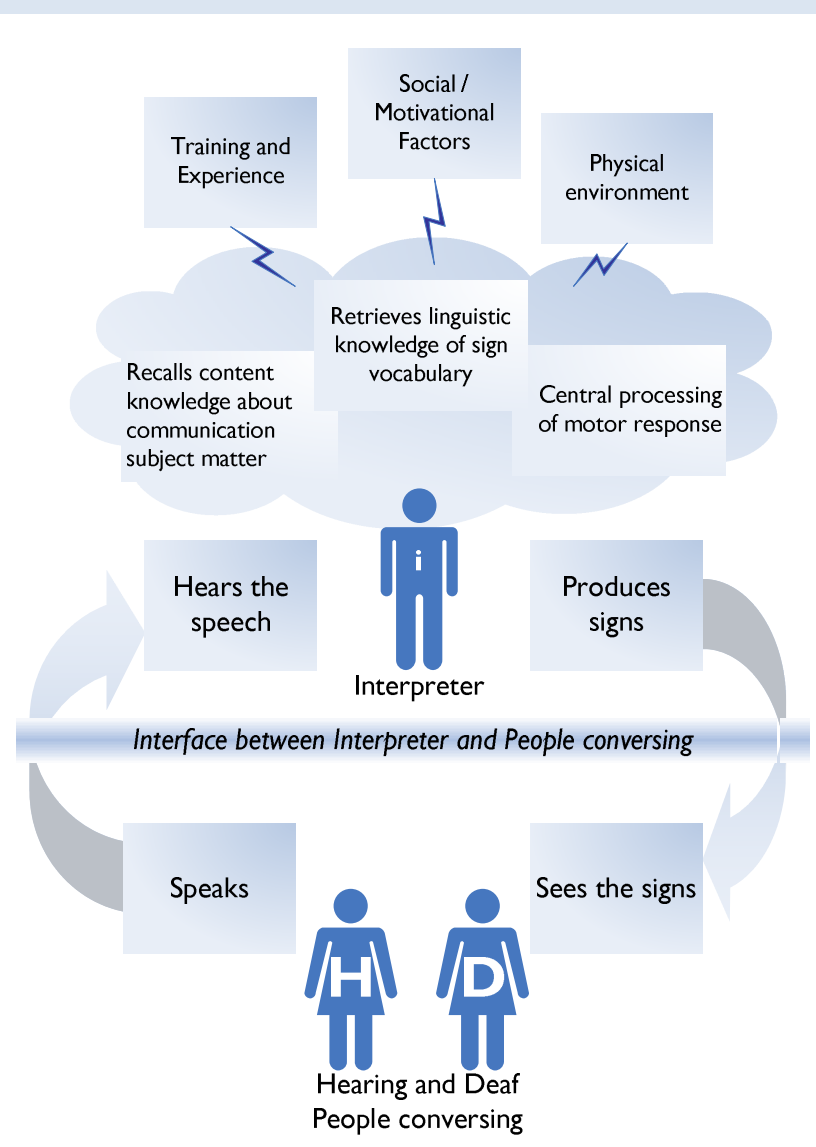

Figure I. A system model of interpreting environment of the communication event, the employment situation, or external factors can either support or hinder the interpretation. For instance, unconscious reactions in an objectionable situation may inhibit linguistic retrieval of the target language or the interpreter may consciously resist the subject matter and express this in sign, body language, linguistic choices, or intonation. Conversely, an interpreter may find the situation or subject matter compelling, and continue interpreting despite physical hindrances, adverse environments, fatigue or discomfort. 


\subsection{INSIDE THE COGNITIVE PROCESS}

Figure 2 shows an ergonomic model of how the work is performed in the interpreter's information processing system. As the sound or visual perceptions are recognized semantically, the meaning is held in working memory (WM) while the interpreter retrieves the message equivalent signs or words from long-term memory (LTM). The interpreter produces the message and monitors the response, both by feedback from her own body sensations (proprioceptive feedback) and by reactions of the participants (such as their observed expressions, body language, spoken or signed interjections). If participants have unexpected reactions, the interpreter might check and correct her interpretation.

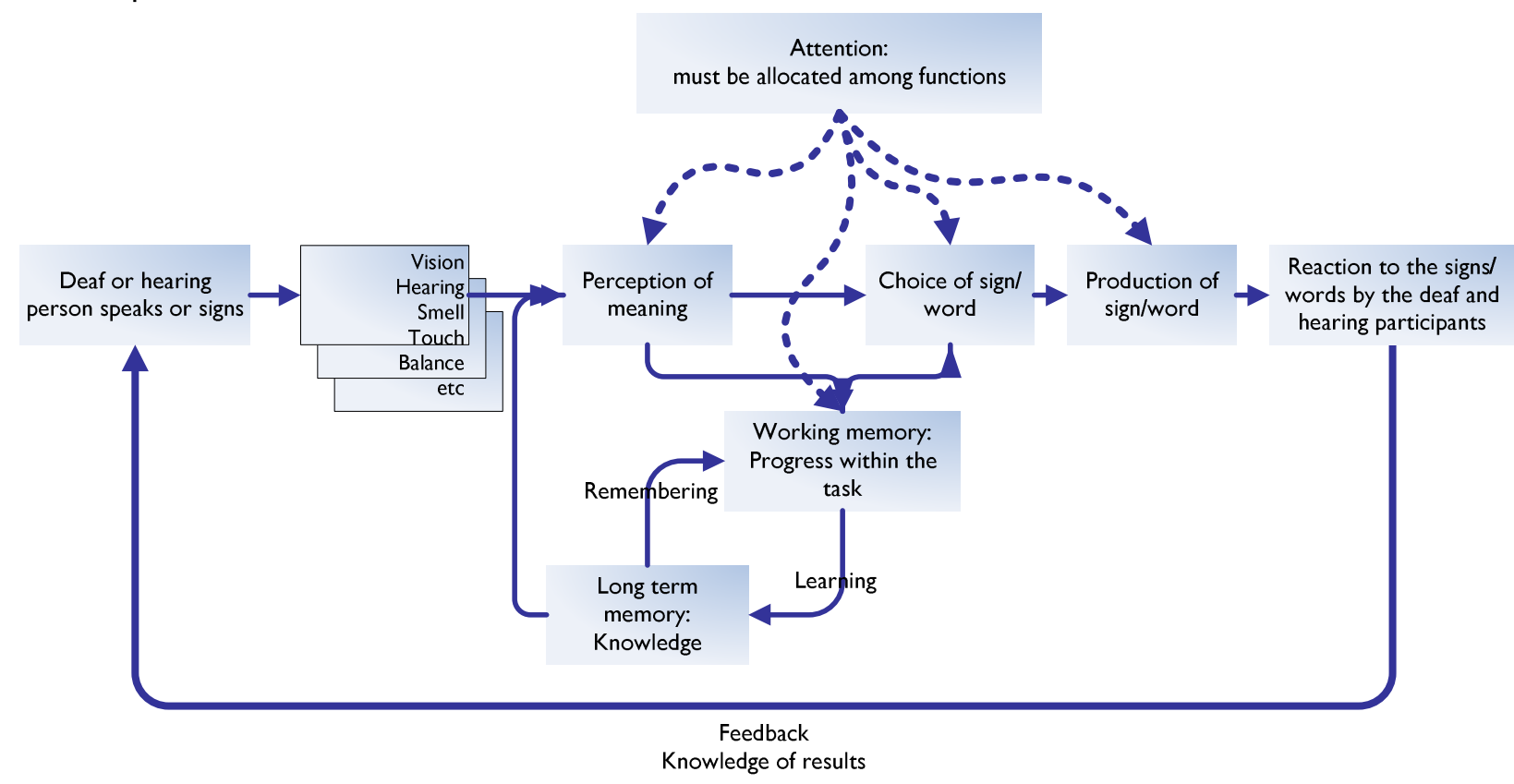

Figure 2. A model of interpreter's information processing work

It is critical to recognize that interpretation does not occur on a sign-to-word substitution basis, but only one word or sign can be received or uttered at a time. Interpretation often requires the interpreter to accumulate units of the source language (words or signs) in WM until a certain conceptual unit has been formed, then commence output in the target language.

Figure I and Figure 2 represent discrete and continuous tasks alike. In discrete tasks, the activity is performed once and is completed because the goal has been accomplished. For instance, hammering in a nail to hang a picture on the wall is a discrete task. In continuous work, the information is not processed once and an action taken in response once, but rather the activity is performed over and over for the duration of the task, for example repeatedly adjusting the position of a steering wheel to keep a car on a winding road. Sign language interpreting is obviously a continuous task. As information is received and processed, the action response is chosen but cannot be activated until its turn in the message. The WM holds the communication in a queue. In order of output, the WM contains:

I. Item currently expressing

2. Oldest interpreted item not yet expressed, to be expressed next

3. Next oldest, interpreted, but waiting for output of 2 to be completed

4. Next oldest, interpreted, but waiting for output of 3 to be completed

5. ...the remainder of the items in WM, in order ...

6. Item currently searching for interpretation in LTM 
7. Item with meaning understood, needs interpretation, waiting on availability of LTM

8. Item currently being semantically understood

9. Item currently being perceived by the senses

In WM, the interpreter must retain all of the uninterpreted content, unexpressed interpreted content, and the order of the queue. If the queue is not processed in order, the interpretation will not be true to the source. A portion of the interpreter's attentional resource is allocated to keeping the information in order. Some attention is spent on monitoring comprehension of new content received. If the interpreter realizes the message content is unfamiliar, or the required linguistic equivalent does not exist in LTM, some attention must be spent on searching LTM for an alternative strategy. A common response is to produce a target language message that carries over elements of the source language. For example, the interpreter working from English to ASL will produce an ASL message with English elements interspersed in the message. These miscues along with deletions or omissions degrade the interpretation. Interpreters faced with difficulty will fingerspell English words, paraphrase, and interrupt and ask the participants for meaning. Some of the interpreter's attention also monitors the accuracy of the physical production of signs or words, and physical slips or pronunciation.

Just managing the attention based workload in a complex interpreting situation can be a demanding cognitive activity. Compared with computerized translation systems, the human information processing system is remarkably versatile and robust. However it has limitations. Working memory is not unlimited. It can be understood as a pipeline, and when the pipeline is full, nothing else can be added until the pipeline content flows out in an orderly way, or the pipe leaks.

Task pacing is a factor. In so-called "self-paced" activities, the WM limitations may be of no consequence because the person can choose not to take in any new input until the pipe is clear. Hand-washing dishes at home is an example of a self-paced task. If one dish needs extra time, the person simply completes the dish before taking the next dish. The next action starts after completion of the previous one.

In "task-paced" activity (sometimes called "forced pacing") the next action starts a fixed amount of time after the start of the previous one. Delays in performing an action do not slow down the arrival of more work inflow. If inflow rate exceeds output rate, it is only a matter of time before the pipeline leaks. Interpreters familiar with 1950s television will remember the classic "I Love Lucy" chocolate factory sequence where Lucy resorts to eating chocolates and hiding them in her blouse to keep up with the conveyor belt of chocolates to be boxed. Inexperienced interpreters may find that forced vs. self pacing explains why they are fluent in signed conversation (self-paced) but become entangled in the interpretation process where the speaker sets the pace.

Attention is also not unlimited. Attention is a resource that acts as "traffic director" for cognitive work. Divided attention is possible, but it is vulnerable to breakdowns when there are several simultaneous demands of the same type: a backlog of incoming information not yet interpreted, for example, or overlap of target language output while receiving source language input as a response or interjection. Under high workload, people often focus their attention on the perceived source of stress and block out other demands on attention in order to successfully manage the priority demand. This may mean that to complete the production of a complicated passage in spoken language or sign language, or to retrieve the appropriate signs or words for an infrequently used or complex principle, the interpreter may lose her place, omit or produce inaccurate output, or fail to take in new input.

The attentional demand and time spent in WM for each concept is increased if retrieval of the linguistic equivalent from LTM is difficult. In any discipline, expertise is characterized by effective knowledge organization. As information is received, the expert rapidly matches it to a response from LTM because experience has enabled her to finely tune LTM organization to correspond to the most common retrieval cues. Another strategy used by experts is chunking of information. If incoming information can be recognized as a big unit instead of several small units, and if LTM has been organized to correspond to the big units, then the WM can hold more content. For example, "London is the largest city in England" can be understood as a single geographical fact. If the expert has organized her knowledge such that all geopolitical signs and words are linked, retrieval of the interpretation will be equally efficient and mental workload will be relatively light. Although this sentence consists of $3 \mathrm{I}$ letters in seven 
words, it is not 31 units or even seven units. If the interpreter can relate incoming information in this way and send an entire chunk to LTM at once, it frees up a great deal of WM space compared with searching for the interpretation word by word.

The novice interpreter may possess the same knowledge, but lacks the organization to retrieve it as rapidly. Instead, he must search through his knowledge following more deliberate rules for retrieval. The longer the delay in the LTM retrieval stage, the greater will be the demand on attention and WM content. Incoming material will continue to pile up as the earliest word is being retrieved. Or, the novice interpreter may lack the WM capacity to take in a whole string so that it could be interpreted as a chunk, obliging him to interpret a few words or signs at a time. This will cause grammatical conflicts between spoken and sign language that create attention distractions or negative feedback from participants, which of course adds to the incoming information to process.

Under stress, as the attentional "traffic director" notes that WM capacity is filling up and LTM retrieval is too slow, focussed attention and possible data loss, or WM leaks occur. Another response is a "strategic shift". Strategic shifts under heavy workload usually favour speed rather than accuracy. This occurs in many stressful jobs and can result in harmful actions being taken in haste. In fact, designers of high-hazard control systems may intentionally "lock out" operator input for a short period after an emergency alert, to prevent operators from making things worse. Under similar high stress, the interpreter's response is to delete significant amounts of the source message or insert source language elements in the interpretation. In situations where pace or stress seems possible, one precaution is to negotiate with the participants in advance what will happen should the pace be too fast.

The previous section described in cognitive ergonomics terms what is also known and discussed among interpreting researchers in relation to linguistic and interpretation quality. The ergonomic version of this process was described here to serve as the foundation for taking an ergonomics approach to this Guide. Ergonomics routinely examines the connection between cognitive and physical demands of a task, subjective stress, and the physical effects of workload, which we will see to be meaningful in the context of interpreting.

TIP: Developing ways to organize information in the working-
memory "pipeline" will be the cornerstone of interpreting
expertise, as it will alleviate stress and make interpreting more
efficient.

\subsection{INTERPRETING FROM THE MACROERGONOMIC PERSPECTIVE: THE EMPLOYMENT SITUATION AND COMPENSATION COVERAGE}

Although the interpretation activity is fairly consistently structured at the level depicted in Figure $I$ and 2 earlier, interpretation is performed in a variety of employment formats. This section will focus on the aspects of the employment situations that can affect occupational health and safety management.

Some interpreters work in staff positions where they are paid a straight salary. Ordinarily, regardless of other fringe benefits, a salaried employee interpreter has access to salary continuance for sickness absence and would be covered for occupational injuries under provincial compensation programs. Workers' compensation is a program that insures employees from loss of income and medical expenses related to workplace injury or disease, and in return, protects the employer from being sued by the injured employee. It is a "no fault" compensation scheme. Depending on the province, some employers are excluded from workers' compensation coverage (e.g., financial institutions in Ontario). Exclusion from workers' compensation programs is referred to as employer "self insurance", whereby the employer covers losses itself. "Workers' compensation" benefits will not be allowed for work-related injuries if the employer is not covered by a worker's compensation policy. However, the injured worker is in effect compensated through the employer's sick-leave or disability plan, as she would be during healthrelated absence for other reasons, or is entitled to sue for those damages. Salaried interpreters may obtain support and information from their employer and union about their coverage status and to advocate in case of an injury claim. In a non-union workplace, employees may often obtain information from an independent ombuds 
organization. Most provinces have Workers' Advisor or Advocate Offices to assist non-union workers with workers' compensation questions and appeals.

TIP: As of March 2008, the web page
http://www.labour.gov.bc.ca/wab/location_can.htm listed
Workers' Advisor and Advocate offices serving non-union
workers with workers' compensation concerns.

AVLIC members work in a variety of salaried and freelance positions. Results from a recent survey of the membership suggests that $75 \%$ of interpreters work in full time roles, while $25 \%$ work in part time or selfemployed roles, providing interpretation as a series of short-term contracts. However many split their time between regularly scheduled salaried work and self-employment to fill the remainder of their schedule.

Some interpreters work in staff positions in a part-time or casual work arrangement, where they are paid for hours worked but are responsible for their own benefits. In these cases, they would typically be covered for workers' compensation (unless the employer was not in a covered industry) but would not receive wages for hours not worked for other reasons, such as sick time.

Many interpreters work as freelance or self-employed practitioners. Self-employed interpreters may have part time or, less frequently, full time contracts while remaining independent contractors responsible for their own benefits and insurance against liability, illness, long term disability, and occupational injury. Only workers covered by the provincial compensation board can be compensated for wages and medical expenses in the event of a work related injury or disease. Because their income is so precarious and depends on being available to work, selfemployed people often purchase disability insurance policies. In addition to private insurance providers, in some provinces discretionary coverage is available from the provincial compensation board at an economical premium rate. A self-employed interpreter who hires an employee must register as an employer. Coverage for the business owner remains optional but premiums must be paid to cover the employee unless the specific province exempts that occupation. Some business clients may require as part of their contractor safety programs that interpreters have workers' compensation coverage before working on the premises. The interpreter can obtain a certificate verifying coverage status from the compensation board.

TIP: The self-employed interpreter should contact the provincial
workers' compensation board or commission to obtain
information on voluntary or discretionary coverage, as an
"employer by application".

Occupational health researchers have long noted that self-employment and piece work (payment by units of work output produced) often lead to voluntary overwork. Although casual workers may have contracted limitations on overwork, recent research has indicated that being paid only for actual worked hours discourages taking time off when the worker is unhealthy. Similarly, self-employed workers not only have considerable incentive to work through illness and injury but also no limit on the amount of hours they may choose to work in order to earn more income. In response, they may choose to work past the point of fatigue and expose themselves to injury or stress-related ill-health.

Salaried interpreters may also seek or accept additional work, or "moonlight" in response to economic necessity or compelling appeals from consumers, for instance in an under-serviced area, or both.

TIP: Careful budgeting and financial planning are encouraged to
help manage income needs, reducing the necessity to interpret for
financial reasons when your body has not adequately rested or
recovered from previous work.




\section{OCCUPATIONAL HEALTH AND SAFETY AND INTERPRETERS}

This Guide builds on previous occupational health guides for interpreters related to musculoskeletal injury of the hands, arms and shoulders. There are other potential occupational health concerns. This section will expand the discussion to introduce these other areas.

Any discussion of occupational health must begin with identifying the "workplace" and responsibilities for control of the conditions in the workplace. Few interpreters actually work at their employer's workplace. Most interpreters, whether salaried or self-employed, perform their services at a workplace provided by others. Like other workers who travel to the client, the interpreter may have little knowledge of the work environment prior to arriving for the appointment. For practical purposes, situations could be classified on a continuum of appointments in someone's workplace or institutional environment to appointments in a public place or small private office, to appointments in someone's private home. When the interpreter is interpreting for an employee or visitor at some function or meeting in a workplace, such as a school or manufacturing, service, health care, retail and other workplaces, the workplace is expected to comply with applicable health and safety regulations and have occupational health and safety programs for employees, which often benefits the interpreter.

In public events, such as vigils or community forums, and in private homes, there may be no "Management" on site to take responsibility for providing these arrangements. In this case, the interpreter may need to use more initiative to find all of the information needed to protect herself from hazards.

TIP: A valuable resource for service providers who visit clients at
their homes is available at the website of the Ontario Workplace
Safety and Insurance Board, www.wsib.on.ca. At time of
publication of this Guide, the document is available at the link:
http://tinyurl.com/yrjoft).

Some interpreting appointments fall in between, such as worship services and theatrical events. These events may be covered by an organization's health and safety policies and resources. In other cases, however, the responsible organization may never have been prompted to develop a health and safety program. Independent of the work environment however, you are ultimately responsible for your health and safety and should understand what hazards may be present, how they might produce injury, and how they can be eliminated or reduced to minimize injury risk.

\section{I TYPES OF HAZARDS, AND RISK REDUCTION EXAMPLES}

A workplace hazard is a source of danger that may cause injury or trauma to an exposed individual. A variety of workplace hazards are present in all work environments, however careful control and management of hazards using due diligence can greatly reduce the risk of danger them may cause. The following subsections detail five hazard categories that might affect the risk of developing an injury while performing sign language interpretation.

\section{I.I CHEMICAL AGENTS}

Chemical exposure can contribute to a variety of diseases, some of which may not appear for many years. Although interpreters are not likely to have skin exposure from intentional handling of any chemical agents, they may be exposed to hazardous air quality in the form of particles, mists, and gases, which can result in inhalation or ingestion. Ingestion occurs when airborne particles or molecules are swallowed with saliva after being inhaled into the mouth or landing on food materials or cigarettes. Hazardous air quality is not always detectable by odour (and strong "chemical" odour may be nothing worse than a distraction). Some chemicals are harmful on the basis of the accumulated dose of exposure while others are harmful on the basis of the concentration of the exposure at one time, and some chemicals are harmful in both manners. The health hazard of a particular brief exposure, therefore, depends on what the chemical is, what form it is in and how it could harmfully enter the body, how long and often the exposure is, and for inhaled mists, dusts, gases, and particles, the concentration of the contaminant in the air. 
As part of a normal contemporary health and safety management program, the workplace should have done an assessment of the chemicals in the workplace and a more thorough assessment including air sampling for those substances where there is a likelihood of exposure. Interpreters' exposure to this environment is of shorter duration and lower frequency than workers in the workplace, and the interpreter is not handling the chemical. Therefore, any protective equipment that is adequate for the employees will almost certainly be adequate for the interpreter. Where appropriate, lab coats and overalls can protect the interpreter while in the hazardous environment, and also prevent bringing contaminants home on clothing. Unless the business has established that the interpreter has and will bring certain gear or apparel to the appointment, the business client should provide the necessary protection. The interpreter should have the same protective equipment as employees in similar proximity to the substances.

TIP: Purchase your own comfortable protective eyewear or other
PPE if you commonly interpret in environments requiring that
form of protection.

Workplace Hazardous Materials Information Systems (WHMIS) makes use of standardized symbols (Figure 3). Many interpreters are already familiar with WHMIS as a result of interpreting workplace training for deaf employees. Interpreters may request to see Material Safety Data Sheets (MSDSs) for any chemical agents in the workplace. To meet its WHMIS obligation, a workplace would have readily available collections of MSDSs no older than three years on all chemicals that are not packaged for sale directly to consumers. While MSDS information is not always complete, it may answer many questions about the danger of different exposure levels and the protective equipment required, what to do in case of unplanned exposure (e.g., splashing) and any reproductive implications. MSDSs can also be searched on the Internet. Some interpreters will have special concerns, such as pregnancy or asthma. Any questions not answered by the MSDS could be directed to the business client or her health and safety officer.

Class A Class B Compressed GasCombustible Materials
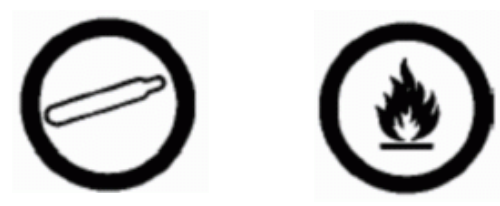

Class D

Poisonous and Infectious Materials

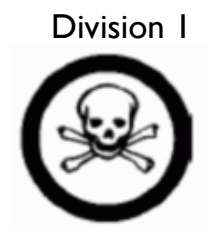

Class E Corrosive

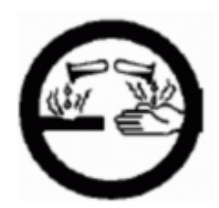

Class C Oxidizing Materials

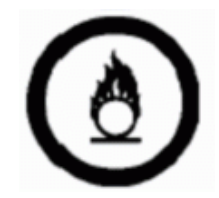

\section{Poisonous and Infectious Materials}




\subsubsection{PHYSICAL AGENTS}

Physical agents include radiation, noise, heat, cold, humidity and transfer of various other forms of energy.

An obvious form of radiation is found in medical situations. Interpreters attending a medical appointment should make certain that they are in a safe location when radiation is released (for taking X-rays etc.) Eye protection should be used near welding. Working outdoors entails exposure to UV radiation. Health and safety regulations may oblige the use of sunscreen to prevent skin cancer. If the work is not in the shade, outdoor workers should wear a hat and protective eyewear that blocks UV.

Heat and cold may be health hazards. There may be regulations governing minimum temperatures for indoor workplaces (other than cold storage facilities and sometimes the first few hours of a shift, to allow machinery to give off heat). Working in high heat is usually managed by respite to cooler premises for a break or to do other types of work. The fraction of time spent in the heat depends on how hot it is. Determining the recommended work-rest regimen is based on the temperature measured by the "WBGT" method (wet bulb globe temperature, which combines the effect of humidity and air movement with actual air temperature and radiant heat sources). This is not readily available to the interpreter, unfortunately, unless the workplace temperature has already been measured by an industrial hygiene consultant or government inspector. The following guideline may be most useful as an illustration of the trade-off between temperature and exposure duration.

The American Conference of Governmental Industrial Hygiene (ACGIH, http://www.acgih.org/home.htm) is a body of industrial hygiene consultants whose recommendations on a wide range of chemical and physical agents are considered authoritative. ACGIH recommends work-rest intervals in different thermal environments according to the heaviness of the physical work (Table I). The ACGIH defines "light work" as sitting or standing to control machines or performing light hand or arm work. "Moderate work" is defined as walking around with moderate lifting and pushing. "Heavy work" is defined as, for example, working with a pick and shovel. Then an adjustment is made for clothing. Ordinarily, interpreters would be able to use the work-rest intervals in the light work columns.

Table I. Maximum WBGT temperature $\left({ }^{\circ} \mathrm{C}\right)$ for work-rest schedules of different intensity.

\begin{tabular}{ccccc}
\hline Work-Rest Regimen & $\begin{array}{c}\text { Light Work, } \\
\text { Light Clothing }\end{array}$ & $\begin{array}{c}\text { Light Work, } \\
\text { Overalls }\end{array}$ & $\begin{array}{c}\text { Moderate } \\
\text { Work }\end{array}$ & $\begin{array}{c}\text { Heavy } \\
\text { Work }\end{array}$ \\
\hline Continuous work & 30 & 28 & 26.7 & 25 \\
$75 \%$ Work, 25\% Rest each hour & 30.6 & 28.6 & 28 & 25.9 \\
$50 \%$ Work, 50\% Rest each hour & 31.4 & 29.4 & 29.4 & 27.9 \\
25\% Work, 75\% Rest each hour & 32.2 & 30.2 & 31.1 & 30 \\
\hline
\end{tabular}

TIP: Dress in layers to help you accommodate a variety of
temperatures, ensuring you remain comfortable independent of
the temperature around you.

Another physical hazard is the transfer of energy. Transfer of energy can occur due to slipping on a surface, tripping, and falling down or falling off platforms, striking against an object or being struck by a moving object or part of an object, or being caught in machinery. Walking around a construction site or factory presents numerous hazards to the feet, from stepping on sharp objects or having a foot crushed. The most common hazard of falling for interpreters would be the use of a precarious platform, box, or even a chair or stool in lieu of a stage or dais to enhance visibility of the interpreter. A fall resulting in arm injuries could threaten the interpreter's livelihood. Those who drive from appointment to appointment may find themselves unable to drive with a leg in a cast. It is prudent, therefore, to avoid these mundane hazards. 
Protective equipment is available and should be used where appropriate: safety glasses, hard hat, long sleeves and pant legs or protective aprons. Feet can be protected from a variety of hazards by safety shoes with protection from crushing, penetration of the sole, chemical, slipping, or combinations of these. CSA approved safety footwear in both ladies' and men's styles are readily available at workwear retailers. Each shoe's resistance to different hazards is indicated on its labelling. Even when "safety shoes" are not required, footwear should be suited to the interpreter's mobility needs. Travelling between appointments and possibly walking around during appointments dictates that footwear hazards should be avoided. High heels can lead to twisted ankles, so moderate heels for women are safer choices. Closed toe and heel are safer in more situations than open-toe mule styles. The closed toe provides some protection against falling objects or other transfer of energy to the toe, and the closed heel or secure ankle strap will ensure the shoe stays on the foot. Most people know that smooth leather soles can be slippery. At the other extreme, crepe soled shoes can be hazardous on carpeted floors as the soles can grip the carpet and result in a fall.

TIP: Avoid slips, trips, and falls and foot injuries with appropriate

footwear.

Electricity is a powerful form of energy that can cause serious harm and even death, but is invisible. It will not be apparent if a piece of equipment is improperly grounded or if a metal structure has become energized by a short circuit. Interpreters should be vigilant in the workplace, as they would be at home, for frayed cords and spills around electrical equipment. Poor "housekeeping" may be an indicator that maintenance is substandard.

Noise is a serious physical hazard to everyone, and almost no one appreciates the interpersonal complications of deafness better than interpreters. The deaf community appreciates interpreters having a deafpositive outlook. However, experiencing an acquired hearing loss could force a career change on an interpreter. Whether in a workplace appointment or a loud social function with the deaf community, the interpreter must protect his hearing. Measuring the decibel level of the noise is likely impractical, but it is safer to avoid any noise level that requires shouting in order to be heard, or any exposure duration that causes temporary subjective muffling of sound afterwards. Earplugs and earmuffs may be purchased at safety supply companies and workwear retailers, or may be issued by the workplace where the interpreting appointment occurs. If purchasing ear protection, the Noise Reduction Rating (NRR) of earplugs and earmuffs should be listed on the package. The highest possible NRR should be chosen for the maximum protection. Earmuffs normally provide higher NRR and both earplugs and earmuffs can be used together, but in many situations, earmuffs will not be practical. One of the reasons many workers disregard hearing protection is the need to hear speech. For interpreters, hearing speech is essential to interpretation. For any workers who need to listen to speech and filter background noise, earmuffs with intercom/radio connection are available. These are similar to the FM system of assistive listening system often used with deaf children in the classroom. Interpreters working often in noisy factories may use this option.

TIP: Protect hearing in noisy environments using earplugs,

earmuffs or any other noise filtering devices.

\section{I.3 INFECTIOUS DISEASES AND BIOHAZARDS}

Anyone working with other people is at risk of infectious diseases. Cold and flu can spread easily in environments where many people interact indoors, sharing surfaces and objects and potentially transferring pathogens to nose, mouth, or eyes by hand contact, or from inhaling pathogens on aerosol droplets produced by people speaking and coughing. Some diseases are contagious before the person appears symptomatic, therefore one cannot simply avoid "sick people". In addition to up-to-date immunization, interpreters should practice regular handwashing with soap. Antibacterial hand sanitizer is effective when washing with soap and water is not practical. Use of hand lotion can avoid the drying of skin on the hands that creates broken skin and allows pathogens to enter.

Most health care facilities have now determined that blood and body fluids should all be treated as biohazardous. Patients with serious communicable diseases may be admitted for unrelated trivial concerns, or indeed may not have been diagnosed. Whether in a health care facility or elsewhere, the interpreter is wise to also 
treat blood and body fluids (urine, feces, emesis, saliva, and contaminated clothing and other objects) as biohazardous. For interpreting appointments in hospitals and medical centres, additional infection control precautions may be needed. Prior to interpreting, obtain information and equipment from the health care personnel on site. Agencies or institutions that promote the use of interpreting services in medical settings are obliged to educate hospital staff on sharing workplace hazard information with interpreters. They are also responsible for the health and safety of the interpreters they deploy.

Outdoor appointments and appointments in private homes may entail exposure to dogs and other domestic animals and insects. Bites, including exposure to insect and animal borne viruses, and allergies may be aggravated. Interpreters with allergies may also find that poor air quality, pollen and other allergens cause respiratory distress and should consider outdoor appointment requests and the need to travel to appointments in light of their health condition.

TIP: Frequent hand-washing is one of the most effective methods of avoiding harm from pathogens.

\section{I.4 HUMAN BEHAVIOUR AND VIOLENCE}

\section{Violence and crime}

Most people are conscious of the possibility of harm when working in dangerous neighbourhoods, walking from parking or transit to an appointment location through an isolated route, and the like. Anyone could be a victim of criminal behaviour, and criminal inclination is not always indicated by a criminal record or criminal accusation. Among the self-protective measures that people may take is working in adequately supervised environments, since the presence of others may deter inappropriate behaviours. Any worker who must provide services in unsupervised environments such as private homes is at risk for human behaviour and violence. At $15 \%$ of occupational fatalities, violent acts and assaults are the third most common cause of workplace death in the U.S., where statistics are compiled nationally by the Bureau of Labor Statistics.

Interpreters must make contingency plans for appointments involving isolated locations, private homes, and precarious travel routes, such as having someone aware of the location and expected completion time. If visiting a private home to interpret for a visit by a case worker or similar appointment, arrange to arrive and leave with the case worker. In case of emergency, the case worker's office will know where the interpreting appointment took place and would be able to call for assistance. Interpreters can ensure their safety while protecting confidential information.

Working with people who are confused, disoriented or agitated due to substance abuse, or dementia and similar conditions may also lead to exposure to violence. In these cases, the violence may be an uncontrollable physical action without intent to harm. These actions are common in health care venues such as hospitals, nursing homes and homes for the aged as well as educational environments where a student may have inadequate impulse control.

Violence is also possible when one or both parties is angry with the situation, such as a negotiation or legal situation. An interpreter may be exposed as a bystander, or may attract some of the animosity by being the person who conveys the offensive message. The interpreter must guard against retaliation from such misunderstandings.

For protection from physical violence, the interpreter needs to be aware of their surroundings and exit routes, and have a safety plan. Those who frequently work in volatile surroundings should take self-defense training. Agencies and associations should sponsor basic training to give confidence to staff and member interpreters. Training should include recognizing early warning signs of violence.

TIP: Take precautions when providing services in a private home
or the confines of an interview room. Team up with others and
have a backup plan to quickly summon assistance.

While a mobile telephone is an occupational necessity for the interpreter, and particularly useful to keep in touch with people looking out for one's well-being, driving while using the telephone is not a safe behaviour. Calls should 
be placed from a safe stopped location. Using a GPS navigation device in the car can reduce the potential to need to phone for route directions or indeed get stranded in an unfamiliar area.

TIP: Using cell phone and GPS can help avoid becoming lost or
stranded, but avoid collisions by inputting destination information
and making calls while in a safe stopped location.

\section{Emotional trauma}

Emotional trauma is another form of violence. It may occur when the interpreter is the direct recipient of emotional insult, or it may occur indirectly as a vicarious trauma (Pearlman \& Saakvitne 1995) due to empathizing from one of the parties, often a vulnerable deaf consumer.

This subject of "vicarious trauma" has been raised and discussed among interpreters (Harvey, 200I) although still lacks consensus, likely due to individual differences in reactions to these situations. Various elements contribute to the interpreter's emotional experience. Different personality types combine empathy and rationality in different proportions in interpersonal interaction. Interpreters who are unable to leave the trauma behind after the appointment are not "irrational" any more than unaffected interpreters are "heartless". An interpreter who is unavoidably empathetic may also blame herself for being unable to control her feelings and set boundaries to protect herself from feelings about the bad situations she interprets, or she may set boundaries and come to feel guilty for not caring.

Interpretation plays an essential role in clinical and legal settings for deaf victims of crime, assault, substance abuse, family violence and the like. The interpretation makes it possible for the deaf person to access remedies for their suffering. Unfortunately, it also brings the interpreter into each of these conversations, which they may suffer vicariously. Perhaps because sign language can make description so tangible, concrete, and vivid, witnessing or being exposed to accounts of traumatic events and intentional cruelty may impose considerable emotional and psychological strain for an interpreter who may be vulnerable.

The interpreter may experience suddenly and all at once the traumatic information that the victims themselves may have experienced gradually and incrementally over time, and often in the past. Through therapy and other remedies, the victims may have moved beyond their experiences and have started to heal, but the interpreter may just be beginning to process the consumer's trauma. The interpreted discussion may be shocking. It may represent familiar third-party individuals or organizations in a new and disturbing light, which may jeopardize her worldview and belief systems. Furthermore, until the shock and trauma have been resolved, the interpreter may struggle with being reminded of the situation each time she encounters the same consumer or third party in other settings.

It should be remembered that the interpreter's trauma in these cases is unintended "collateral damage" in a larger traumatic situation. These traumas are unlikely to be remedied through alerting the parties to develop awareness and consideration for the interpreter. Interpretation is essential to address the larger traumatic situation, but no individual interpreter is obliged to participate in an appointment that would be unhealthy. Like social workers and other professionals in similar situations, an interpreter who knows that she is adversely affected by empathy should make an "intake" assessment part of her appointment booking routine.

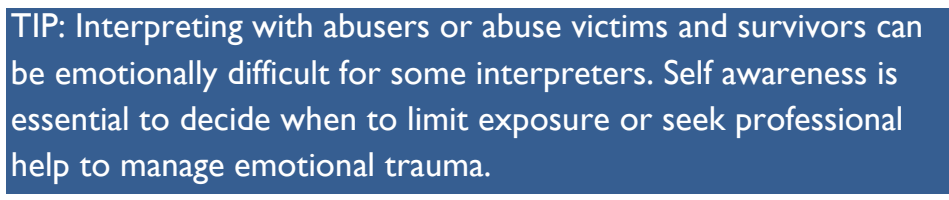

The interpreter may also perceive emotional abuse indirectly from disparaging comments of the business client about deaf people. The business client or other participant may comment about the particular deaf consumer being similar or different in comparison with "typical" deaf people in a way that implies that deaf people are low-worth individuals. These remarks may offend the interpreter who is friendly with many deaf consumers and perhaps a child of deaf parents or a sibling or a life partner of a deaf person. For professional reasons, the interpreter cannot admonish the client for their bigotry, and the interpreter may feel anger, frustration, or even guilt at not defending 
their family or friends. Difficulty processing these feelings and responses to rudeness, disrespect, lying, exploitation, discrimination and oppression may (and should) lead interpreters to counselling. Business clients who resist making payment or argue about team composition for demanding appointments can be perceived as abusive.

As an occupational health concern, it remains difficult to offer evidence-based recommendations about vicarious trauma and emotional injury. More research is needed to predict who will be affected and what form the effects will take. At present, the emphasis must be on healthy coping: awareness of one's own emotional health and making healthy adjustments when professional and other interpersonal relationships are affected, including possible depression (next section). Depending on the circumstances, this may entail being selective about appointments, self-help with peers, or obtaining professional help.

Taking care of oneself is the first line of defence in emotional health. For the self-employed or casual interpreter, economic concerns are often a factor. While the emotional and mental well-being may dictate rest, the worries over economics lead to "presenteeism" or working when a person should rest, particularly when income is linked to presence. Counsellors such as psychotherapists can help the interpreter to resolve unresolved feelings about both the trauma within the appointment (the client's business) and the trauma about the appointment (the business of paid interpreting).

TIP: For the interpreter who is self-employed, a thick skin can go
a long way to business success. Qualified professional counsellors
can help when self-help is not enough.

\section{Depression}

Major depression disorder is fairly common with $8.2 \%$ of Canadians experiencing an episode in the past year (Vasiliadis et al, 2007). Depression may be a response to external situations such as an emotional trauma or disease, or it may occur for no apparent reason due to a chemical imbalance within the body. Professional help should be obtained if someone has more than half of the indicators of major depression consistently for at least a two week period, representing a change of mood from the person's "normal" mood, and interfering with functioning at work, home or socially.

\section{Indicators of Major Depression}

Depressed mood most of the day, nearly every day, as indicated by either subjective report (e.g., feels sad or empty) or observation made by others (e.g., appears tearful).

Markedly diminished interest or pleasure in all, or almost all, activities most of the day, nearly every day

Significant weight gain or weight loss when not dieting (e.g., a change of more than $5 \%$ of body weight in a month), or decrease or increase in appetite nearly every day.

Insomnia or hypersomnia nearly every day

Psychomotor agitation or retardation nearly every day

Fatigue or loss of energy nearly every day

Feelings of worthlessness or excessive or inappropriate guilt nearly every day

Diminished ability to think or concentrate, or indecisiveness, nearly every day

Recurrent thoughts of death (not just fear of dying), recurrent suicidal ideation without a specific plan, or a suicide attempt or a specific plan for committing suicide.

From the Diagnostic and Statistical Manual of the American Psychological Association (DSM-IV)

Professional therapy is called for if the interpreter is experiencing depression or feels unable to help herself. In other cases, where a person is struggling with feelings but mentally healthy and ready to grow, a self-help support group is an effective way for people to meet within a framework of safe mutual confidence, to discuss how they feel and cope with their common situation. Self help is discussed in the next section.

TIP: Signs of depression or more serious mental health concerns

indicate that professional help should be sought. 


\section{Dysfunctional coping}

Some people who are experiencing depression or unmanageable stress fall into dysfunctional coping including drinking and self-medication with prescription and non-prescription drugs.

Alcohol is a problem if you answer yes to two or more of the following questions known as the "CAGE" questionnaire (Ewing, 1984), named for the acronym representing the keywords in four diagnostic questions. Even one yes could indicate a risk of developing a problem in the future.

- Have you ever felt you should Cut down on your drinking?

- Have people Annoyed you by criticizing your drinking?

- Have you ever felt bad or Guilty about your drinking?

- Have you ever had a drink first thing in the morning (as an "Eye opener") to steady your nerves or get rid of a hangover?

According to the College of Family Physicians of Canada (2007) alcoholism is defined as having an extremely strong craving for alcohol, loss of control over drinking, or physical dependence. Alcohol abuse is considered to entail one or more of the following within the past 12-month period.

- Failure to fulfill major work, school, or home responsibilities;

- Drinking in situations that are physically dangerous, such as while driving a car or operating machinery;

- Having recurring alcohol-related legal problems, such as being arrested for driving under the influence of alcohol or for physically hurting someone while drunk; and

- Continued drinking despite having ongoing relationship problems that are caused or worsened by the drinking. Everyone has a great deal to lose by dysfunctional coping through alcohol or other substance abuse. Rather than self-medicating with alcohol or other drugs to decompress after stressful work, interpreters should consider a selfhelp approach, outlined in the next section.

\section{Self help}

When the interpreter is not clinically depressed but wants to improve how she copes with particular kinds of adversity, self help can be a useful tool.

Self help should be differentiated from unstructured peer discussions ranging from the airing of grievances over after-work drinks to giving or receiving advice between friends. Self help is not a complaint session and does not involve one person advising another. Each person helps herself when she is ready, in the way she chooses.

Self help involves getting together with peers in a similar adverse situation, and sharing individual feelings and coping skills in a safe and supportive environment. The primary benefit of self help is that it can validate feelings and reduce the stress that may come from guilt or worry about the feelings. This validation can help people to accept feelings that may be causing worry or guilt, such as being angry or fearful in response to something a client or consumer has said or done. Through self help, the participant can often establish that others have the same feeling and perhaps an effective method of coping that may alleviate stress.

Because participants are peers and not professional clinical therapists, self help is not a substitute for clinical therapy. All participants should be healthy and ready to grow. The format for a self-help meeting is simple. A group of eight to ten people is an ideal size. Larger groups may not allow enough time for all to share. The agenda for the group meeting is listed below.

\section{Self-help group agenda}

Start: is everyone seated, has a name tag if needed, ready to start?

Relaxation: deep breath, shake out, get ready.

Tune-up: become aware of feelings in the moment.

Announcements and highlights that leader or members need to share before proceeding.

Review the rules.

Select a topic. The leader guides the group to use consensus to choose a specific topic for discussion for that session. (Unused topics can be saved for future sessions.) The group should choose a topic of interest to most, but any topic may be more interesting to some than others. If unready to share, any member can 
remain silent on any topic, but each member has the ability to veto a topic that would traumatize her if others were to discuss it in her presence.

Share feelings on topic. Each participant has a turn to speak about the session topic, specifically how she feels about it and copes with it. This helps prevent the session merely deteriorating into grievances. If a participant is not ready to speak when her turn arrives, she can "pass" on her turn and speak after the others.

Compare notes on topic. Once all participants have spoken, each participant has one more turn to make further remarks, typically about how she feels about the feelings and coping skills described by others, reflecting on how she thinks another technique might feel for her, or why she feels one way and others feel differently. This part of the session is not intended to debate one correct way of feeling or coping. No single feeling or coping technique is "correct" but it can be helpful to think aloud about differences, patterns, and the variety the group has expressed.

Wrap up, or choose another topic and repeat.

Socialize if desired.

(Adapted from Woodcock and Aguayo, 2000)

The self-help rules (below) can help a group keep focussed and gain much growth in a short period of time. To prevent the discussion from becoming a debate or advising session, the leader must be prepared to step in and remind the group of the rules.

\section{Self help rules}

I. Honour your feelings. Share only authentic feelings, not necessarily what you think others would expect you to say.

2. Share what you are comfortable sharing. Do not be concerned that others are sharing more.

3. No probing. Others will share what they are comfortable to share, so there is no need to ask them for more information. (If you are not clear what they mean by their words, you can ask them to clarify.)

4. No visitors or observers are permitted. All participants must be peers in the same experience. In an interpreter support group, all must be interpreters, not spouses, clients, consumers, or friends.

5. Everything in the group stays in the group. To share authentically, members must trust that other participants will not repeat their comments outside of the group.

6. No advising or individual problem solving. Each person brings a different experience therefore one person's method of solving a problem is not certain to work for another. Each person helps herself by listening to the experiences of others and making her own choices when and because she is ready to do so.

7. Speak for yourself: use "I" statements. Statements that begin, "when $X$ occurs, you feel $Y$ " suggest that everyone who experiences $X$ will feel $Y$. No one can know for certain what others feel. The self-help rule is to describe only "when $X$ occurs, I feel $Y$ " and let others share their own feelings.

8. Speak for yourself: do not speak for others. If a fellow participant has made a comment and another is unclear about it, let each person explain himself.

9. No cross-talk. Speak in turn. Do not respond to individual comments out of turn, or respond to a response. There is no need to agree, convince others, or reach consensus.

(Adapted from Woodcock and Aguayo, 2000)

Through self help, members usually learn that their feelings are shared by some others, and may learn new alternatives for coping with situations that they might wish to try. Sharing with several peers enables members to compare feelings and coping strategies with peers who are more similar and peers who are more different, and make an intuitive choice of which untried strategies might be more satisfying.

TIP: Structured self help in a group of supportive peers can be beneficial. 


\section{I.5 BIOMECHANICAL HAZARDS}

Biomechanical hazards related to posture are typically reflected in musculoskeletal injuries. These can affect a wide range of body parts and structures, and can occur through a variety of mechanisms. As the AVLIC Resource Guide RSI for Sign Language Interpreters recognized, interpreting imposes several additional biomechanical demands on the shoulders, arms, and hands beyond posture. This section highlights the general postural hazards of interpreting work, including static postures and prolonged standing, and other postural concerns involved in support activities within the overall job of interpreting. A more detailed discussion of the various biomechanical hazards associated with sign production will be covered in detail in a later chapter.

In any context, most postural hazards come from excessive deviation from neutral body posture. Discomfort may also arise from tissue compression or a sustained static posture.

Neutral posture can be envisioned as floating weightless in space or in a swimming pool, with each joint free to find its preferred position. Most joints would not be either rigidly straight or at a $90^{\circ}$ angle. Each joint has a range of motion around its neutral position. It is possible to move to the extremes of the range. In fact, to maintain flexibility, we should stretch through the range of motion as part of our regular exercise program. However, it is undesirable to frequently move a joint to the extremes of its range, particularly with speed or force. Although neutral posture is the ideal, there is no posture that is so perfect that we should maintain it continuously. Posture should therefore be dynamic. For example upright standing is often considered neutral or ideal. However one may still develop discomfort if the upright standing posture is sustained over an extended period of time. The best practise is to vary your posture often, keeping it fluid and dynamic.

Non-neutral postures are the opposite of neutral postures. Where a neutral posture might be envisioned as floating weightless, a non-neutral posture requires addition force from muscles, ligaments, tendons, or external support devices to force the posture outside of the neutral range, moving the joint closer to the end of its range of motion. Non-neutral postures may occur due to poor computer workstation design, where your body must move into non-neutral posture to type or see the display when emailing clients, researching appointment preparation, and invoicing, for example. Non-neutral hand positions might be involved with the use of handheld electronics. While performing an interpreting appointment, non-neutral arm postures may be combined with prolonged standing or sitting depending on the nature of the appointment.

Static posture is a position that is maintained continuously for a period of time. Prolonged static posture is always a concern, even more so when non-neutral. Holding one's head to the side to view a computer display screen or hold a telephone receiver, holding elbows up and out while signing and even sitting upright without a backrest are postures that are often held statically. Intermittent body movement is caused by muscle movement which helps promote blood flow to muscles, and therefore prolonged static postures reduce any muscle movements. A reduction in muscle movement can lead to a reduction of blood flow in the area, reducing nutrient supply and waste product removal from the muscle, which can be experienced as discomfort and fatigue. Prolonged static posture should be avoided.

Tissue compression refers to pressure on a body part where it bears weight in contact with a rigid structure. This can also reduce blood flow and cause numbness or pain. Common tissue compression sites are feet when standing, buttocks when sitting on hard seats, thighs or knees pressed into the underside of a desk or the back of the seat in front, and forearms resting on a ridge at the edge of a desk.

\section{Postural hazard examples during interpreting, other than sign production}

Sitting for prolonged periods is not uncommon in many interpreting situations. However, many chairs in meeting facilities and classrooms have not been designed for postural comfort. For the purpose of interpretation, you should make an effort to find a chair that can be adjusted to accommodate your height, and most importantly contains a back support. It may be difficult to sign freely while also making use of the backrest of the chair, but sitting without a backrest creates static slumped postures in the back. At minimum, while not signing, the interpreter should get as much support as possible from the backrest. Adjustable arm rests may also be an asset if 
they can be rotated out of the way during interpreting, then rotated back during periods of rest to help support the forearm and hand.

TIP: If the appointment is seated, select the most appropriate
chair that will allow you adequate space and support for
interpreting and, equally as important, that will provide the
necessary body support during periods of rest.

Tissue compression in the buttocks can be relieved by selecting a cushioned seat where possible, and alternating sitting and standing. If the compression tends to be uncomfortable or distracting, the interpreter may bring a cushion for seated appointments. Compressive stresses, discomfort and fatigue during prolonged bouts of sitting can be reduced by using a "dynamic sitting posture" (McGill 2002). In the example postures shown (Figure 4) dynamic sitting requires you to adopt a new posture every 20-30 minutes. By continually varying your posture, you are distributing the work of supporting your body among various tissues, allowing each tissue to rest as you cycle through a variety of postures throughout the workday. It is important however to note that many of the postures illustrated can become quite harmful if they are adopted alone for prolonged periods of time. The process of changing posture regularly is the key principle for maintaining comfort, not the characteristics of a single posture.

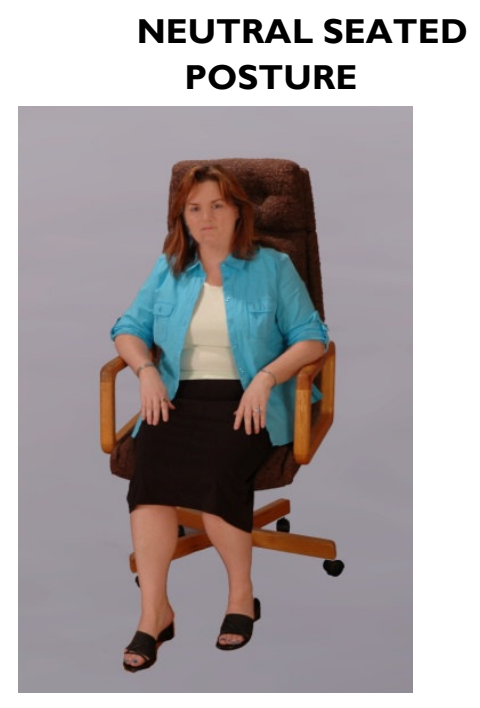

Figure 4. Dynamic sitting posture examples

LEANING BACK
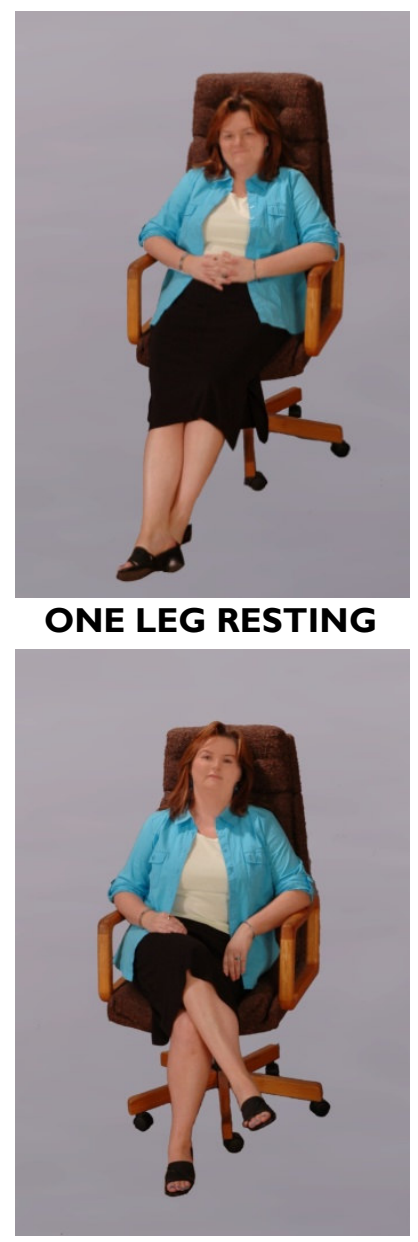

CROSS-LEGGED
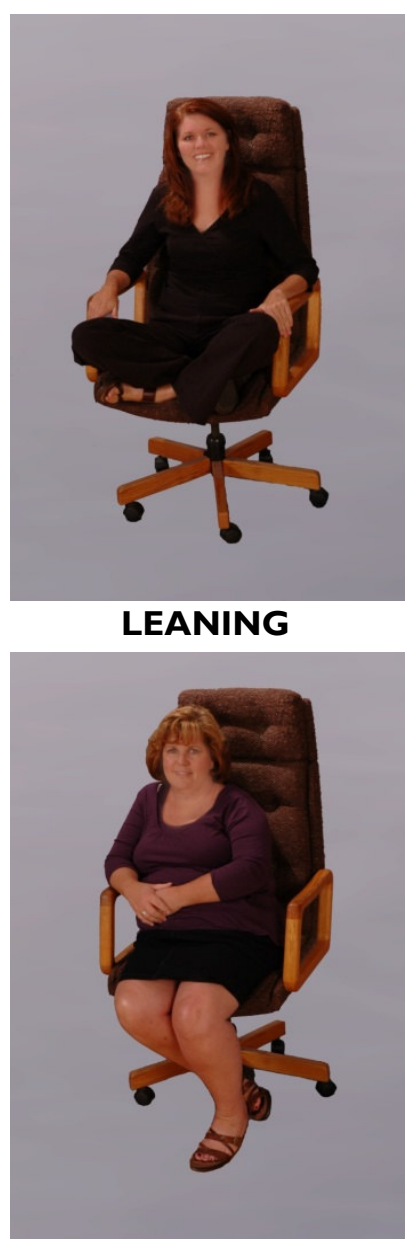
Prolonged standing can impose static postures to hold the body in the unnatural upright standing position and also produce tissue compression in the feet, particularly on hard-surface flooring. Flat shoes with cushioning and arch support may relieve foot tissue compression, although the static posture and weight bearing can still be uncomfortable for back, knees, and hips. Similar to prolonged sitting, dynamic posture can be used to minimize pain and discomfort. Casual leaning on a support during periods of rest, or swaying to and fro can both help to reduce the static loading on any one specific tissue. The interpreter must be careful to balance between personal comfort and professionalism, as they inconspicuously move through a range of postures, while minimizing any distraction to the client as a result of the movement. Alternating between sitting and standing may also help.

TIP: Avoid tissue compression and static postures by varying work
positions. When working in a team of interpreters, standing to
interpret can optimize postural variety by rotating through a
series of seated posture during non-interpreting times.

\section{Postural hazard examples in affiliated tasks}

Many interpreters spend time during working hours or in their personal time working on laptop or desktop computers, using handheld personal digital assistants (PDA), pagers and telephones. When such work is of brief duration, the configuration of the workspace has less impact than for those who work on computers all day long, but interpreters should not neglect it entirely.

The goal in configuring an office workstation is to promote neutral posture as much as possible. In neutral seated posture, the person has the upper arms relaxed at the sides, forearms horizontal or sloping down toward the hands, and wrists neutral with hands in line with forearms, and the line of sight to the monitor straight forward and slightly below the height of the eyes. Reference materials that are frequently used while working on the computer should be placed as close as possible to the monitor, at a similar height and distance from the eyes. Objects that must be handled frequently should be placed where they can be reached within the sweep of the forearm, with elbows relaxed at the sides. Objects that are handled occasionally should be placed where they can be reached with a sweep of the arm, but without leaning the upper body. The key to placement of these materials and objects is how frequently they are used. Keeping infrequently used items out of the immediate area provides room to work, and keeping frequently used items close reduces reaching and static posture.

The "sit-up-straight" posture with elbows, knees, and hips at 90 degrees is not necessarily the ideal posture. Recent research has shown that a hip angle wider than 90 degrees (knees more than 90 degrees below horizontal) promotes a more neutral spine alignment. For some, an unconventional workstation-such as a recliner chair with a laptop computer on a lap table-can provide a neutral posture better than stereotypes of "correct" workstations.

Various types of computer keyboards are available that can accomplish a straighter wrist alignment. Individual users must evaluate to determine whether these are an improvement. They may be of more value to those who touch-type than the "hunt and peck" typist. Likewise wrist rests are beneficial to some people and uncomfortable to others. In order to have the forearms in a neutral position relative to an often non-adjustable desk height, the chair seat height should be adjusted. In a home workstation, investment in an easily adjustable chair is often worthwhile, as kitchen table chairs are poor substitutes and will result in uncomfortable posture for most users. Use of a laptop computer on a fixed desk will result in a lower monitor position but the display can be tilted to achieve an angle perpendicular to the line of sight. If the image is too far away, rather than lean forward, the user should adjust the image size (using zoom controls or screen resolution). Alternatively a docking station and second monitor can be used. With a docking station, a separate keyboard and mouse can be added. A variety of products are available to encourage computer workstation adjustability. The choice of product however; depends on your needs for adjustability, and the amount of time you spend in your home/work office.

Interpreters who use bifocal lenses may find themselves lifting the chin to see the screen through the focal segment allocated to reading. This creates static work and often discomfort in the neck. With the prevalence of computer use, this is a common postural hazard for many bifocal users. Optometrists and opticians are well 
familiar with this need and can provide either separate reading glasses or specially configured bifocals for computer work. With appropriate monitor position, these can help to keep the head in a more neutral position.

TIP: Strive for neutral posture when using a computer
workstation. Evaluate the posture while using the workstation,
not the workstation on its own.

Personal digital assistants (PDAs) and pagers and mobile phone keypads can require repetitive hand movements and require tight grips that can aggravate painful hands and wrists. Some cases of overuse syndromes are being linked to continuous use of these devices. Many of the muscles required for interpreting are also required to operate PDAs, therefore interpreters who have symptoms of pain or discomfort should limit PDA use to comfortable frequency and duration.

Although interpreting is not a "material handling" occupation like warehouse work, many interpreters do carry personal items including identification and money, an agenda and readings for the day's appointments, and a water bottle. In many cases, the total weight of this "daily luggage" can be considerable. Interpreters bringing a change of clothes or travelling to an appointment overnight will also need to carry a backpack or baggage. Bags and other weight should be carried symmetrically or over both shoulders or carried on alternate sides. Wheeled bags are also becoming popular to reduce the load on arms and shoulders.

TIP: Avoid carrying heavy bags. If carrying cannot be avoided,
support the weight with a backpack where straps can be hung
over both shoulders to help support the weight. Ideally, carry
heavy materials in a wheeled bag

\section{I.6 VOICE STRAIN}

The potential for voice strain should not be overlooked. The need to voice to "keep the floor" may prevent the interpreter from resting his voice while thinking through the interpretation. This in turn can add to the muscle tension, making vocal cord strain possible. Vocal cord strain has been noted as an occupational health concern of professions that voice continuously or who must project their voices, and is not a trivial issue. This hazard depends on the degree of exposure. The amount of voicing from signed to spoken language varies from appointment to appointment, thus each interpreter's exposure varies according to the type of appointments he performs. How the interpreter uses his voice is another component. At any sign of vocal discomfort, the interpreter should consider consulting a voice coach. Voice coaches train singers, actors, public speakers and others on how to optimize voice projection and physical wear on the vocal cords. An interpreter could request a referral from family physician or speech pathologist. This type of injury is an under-researched issue for signed-language interpreters and more data would be needed to identify how prevalent it is and specific risk factors in the interpreting job.

TIP: Interpreters can develop skills to project their voice without strain, and may learn how to effectively use a microphone. 


\subsection{OCCUPATIONAL HEALTH PROGRAM: A UNIFIED APPROACH TO ELIMINATING, CONTROLLING, AND MANAGING HAZARDS IN THE WORKPLACE}

Occupational health and safety programs may be formal or informal. While many health and safety program guides emphasize the importance of a health and safety policy, from the perspective of the exposed worker, the performance of the essential elements is more important than formalization by policy. If a policy exists, it is a resource that the individual worker may use to advocate for fulfilment of the policy. If performance is effective, the absence of a policy is itself of little concern to the worker. The general goal of the occupational health and safety program is to minimize exposures to the variety of workplace hazards described.

The optimal hierarchy of occupational health and safety is (I) eliminate the hazard at the source, (2) intercept or block the hazard before it reaches a vulnerable person, and (3) protect the person's body from the impact of the hazard. Hazard controls include "engineering controls" and "administrative controls". Engineering controls are physical devices, apparatus and modifications to reduce hazards. Administrative controls are procedure changes such as altering the methods of handling hazards or scheduling that reduces exposure.

TIP: The preferred method of protecting health and safety is to
eliminate any hazard at its source. When hazards remain, harm
can be reduced by limiting the amount of exposure or
intercepting hazards before a person is injured.

\subsection{INSTITUTIONAL EMPLOYERS}

In most workplaces where Management controls the environment, source control and barriers can be provided. If the interpreter works for a single employer in one workplace such as a school, this option is available. Even when the interpreter goes to the workplace of others, the "general duty" under provincial health and safety legislation will impose an obligation to "take every precaution reasonable in the circumstances for the protection of a worker" (as phrased in Ontario legislation). This obligation may require the employer to provide training that will equip the employee to work in unsupervised environments, such as enhanced hazard recognition skills, or emergency response skills, or appropriate personal protective equipment. It may also require the employer to establish policies and intervene on the interpreter's behalf when hazards are present in offsite workplaces. This would apply to an agency employing and dispatching interpreters to offsite appointments.

Most Canadian workplaces of 20 people or more will have a health and safety committee either voluntarily or as required by law. The committees usually include both supervisory personnel and workers. Committees are responsible to make recommendations to Management on health and safety matters. The establishment of a health and safety committee does not relieve Management of responsibility of providing competent supervision that is capable of identifying and controlling hazards. All employees must know how to report hazards and injuries. The worker's first channel of communication in most cases should be to report a hazard to her supervisor. This will be adequate for resolving many hazards and concerns of which the supervisor was simply unaware. An interpreter working for a single employer should bring unresolved health and safety concerns to her health and safety representative. Most health and safety legislation obliges the employer to ensure that the names of representatives are posted for the information of employees. The committee can escalate unresolved issues, and also bring attention to issues that affect the company as a whole that may not be apparent without the company-wide view.

TIP: Employee interpreters should report hazards to supervisor,
and escalate unresolved concerns to the workplace's health and
safety committee.

Health and safety legislation protects employees from reprisals arising from reporting unsafe work or accidents. For an effective program, the employer must ensure, and the health and safety committee should verify, that 
employees actually do feel comfortable reporting hazards and injuries and reports are not discouraged or suppressed.

Participation is a valuable element of effective health and safety programs. In addition to providing further information and perspectives, participation benefits morale because people are empowered to understand and take control of hazards in their work environment.

\subsubsection{SELF-EMPLOYED INTERPRETERS}

TIP: Health and safety considerations applicable to self-employed
interpreters are often relevant to the interpreter who is deployed
by an agency or institution.

Interpreters who are self-employed must negotiate their terms of service with each business client. Rarely will it be possible to eliminate hazards at the source or introduce barriers other than the controls the business client already has implemented. The remaining prevention mechanism, therefore, is administrative controls (limits on exposure).

The self-employed interpreter needs to know how and where these protections are needed and to inform the business client of health and safety concerns and requirements. The mechanism for that exchange of information is in the purchasing/contracting transaction.

Practising due diligence, many companies are now implementing "contractor safety policies" for contractors they hire. The most obvious motivation for a contractor safety program is to protect the company's own employees from hazards arising from the contractor's work, tools, and materials. Equally important is to ensure that contractors' personnel are not exposed to the company's hazardous materials and processes without the means to protect themselves. There have been serious cases in Canada where contractors were unaware of hazardous materials and sustained serious and even fatal injury or disease. Well-developed safety programs now have policies specific to contractors working on their premises. In cases where contractors will be working regularly or for a sustained duration in the workplace, the company often provides a contractor's orientation that includes information about safety and security. Interpreters should make use of contractor safety programs to ensure that they are aware of hazards in the areas where they will work.

TIP: Make use of contractor-safety programs when working in
workplaces that have them.

Conventionally, contractor safety policy is applied to contractors such as construction and repair service workers, but there is no reason that it should not apply to interpreters. Although the interpreter's work is not likely to harm others, workplace hazard exposures could present a risk to the interpreter.

Interpreters could include in their terms of service a "Health and Safety Policy" clause stating that the client business agrees to notify the interpreter of any health and safety hazards in any areas to which the interpreter will be exposed, to provide Personal Protective Equipment (PPE) or advance notice of PPE requirements, to provide access to Material Safety Data Sheets (MSDSs) when required and on request by the interpreter. The health and safety policy of the interpreter's contract could also refer to the biomechanical exposure of interpreting and the limits the interpreter wishes to impose (see Chapter 5). An example Health and Safety Policy is included in Appendix 2.

TIP: Include health and safety expectations prominently in the interpreting service agreement.

\subsubsection{REPORTING AND SURVEILLANCE}

Another element of health and safety programs is reporting and surveillance. One method of reporting and surveillance is through workplace injury and disease claims to the provincial workers' compensation insurer. Many 
workers in Canada are not covered by these provincial plans, however. These "non-covered" workers include many self-employed people. Relying on workers' compensation statistics to track interpreter injury is thus futile.

All interpreters with symptoms of a workplace injury or disease should ensure that their clinician (family doctor, chiropractor, or other) is aware of the nature of their work and the exposures to specific work environments and activities.

Workers' Compensation benefits cover lost wages and medical expenses for a work-related injury. To obtain benefits, the injured person must meet three criteria. First, the worker must be covered by a workers' compensation policy. Second, the worker must have a diagnosed injury or disease. Third, the diagnosis must establish that the cause of the injury or disease is work-related.

While diseases often have latency, in some cases 20 years or more, injuries that are reported after some passage of time can readily be challenged as potentially non-work-related. Even if there is no apparent injury or need to claim lost wages, prompt reporting of an exposure (slip, fall, splashed by a chemical) is valuable because it establishes that the exposure occurred in the particular workplace on a particular date. Injuries sometimes become more severe after time, even after exposure has ended. With musculoskeletal injuries, it is sometimes difficult to establish the work-relatedness, particularly if they are reported after the passage of time.

TIP: Workers' compensation benefits are only paid to employees
of covered businesses, for diagnosed injuries or diseases judged to
be work-related.

Injuries arising from exposure inherent in a certain job often become associated with the job and establishing work-relatedness is no longer so burdensome. Once the link has been acknowledged by precedent, the worker may need to do little more than prove the diagnosis and exposure to the work. Musculoskeletal injury of the upper extremities and sign language interpreting is at the point of being an acknowledged link, recognized by some but not yet universally.

Extending and formalizing the reporting of injuries to AVLIC would be valuable. Because of the inconsistency of workers' compensation coverage among Canadian interpreters and the lack of aggregation of injury data under common employers, AVLIC is virtually the only platform to collect information on the occupational health and safety experiences of Canadian signed-language interpreters. This would be powerful information but to be valid, this initiative would require a high rate of participation by working interpreters. 


\section{INJURIES ASSOCIATED WITH SIGN LANGUAGE INTERPRETING}

Musculoskeletal injuries have long been recognized as an occupational hazard of sign language interpreting (e.g., Heller et al. 1985; Stedt, 1992). DeCaro et al (1992) reported that $45 \%$ of the interpreters at Rochester Institute of Technology (RIT) were either absent or on reduced workloads due to pain in one academic year. Common diagnoses included tendonitis and nerve entrapment (e.g. Carpal Tunnel Syndrome). Sweeney et al (1994) noted a $92 \%$ annual prevalence ${ }^{*}$ of self-reported symptoms for at least one body region (32\% moderate or severe intensity), and through clinical examination, $13 \%$ of interpreters were found to have symptoms meeting the case definition requirement for an upper extremity disorder. Smith et al (2000) reported prevalence among sign language communicators (including interpreters) of self-reported medically diagnosed carpal tunnel syndrome five times the general working-age population, with $45 \%$ of the interpreters reporting pain severe enough to limit ability to work. Biomechanical studies have verified a musculoskeletal injury risk involved in the repetitive movement of sign production (Shealy et al, 1991; Feuerstein \& Fitzgerald, 1992).

A survey of AVLIC members was completed in 2006, with 314 working interpreters responding. The point prevalence of pain in each site (reported pain at the moment of completing the survey) is shown on Figure 5. Pain was reported most often on the neck and right shoulder, but multiple pain locations were reported. Interpreters rated pain severity during interpreting work (one hour solo or all-day teamed) as significantly more painful than the level felt during completion of the survey.

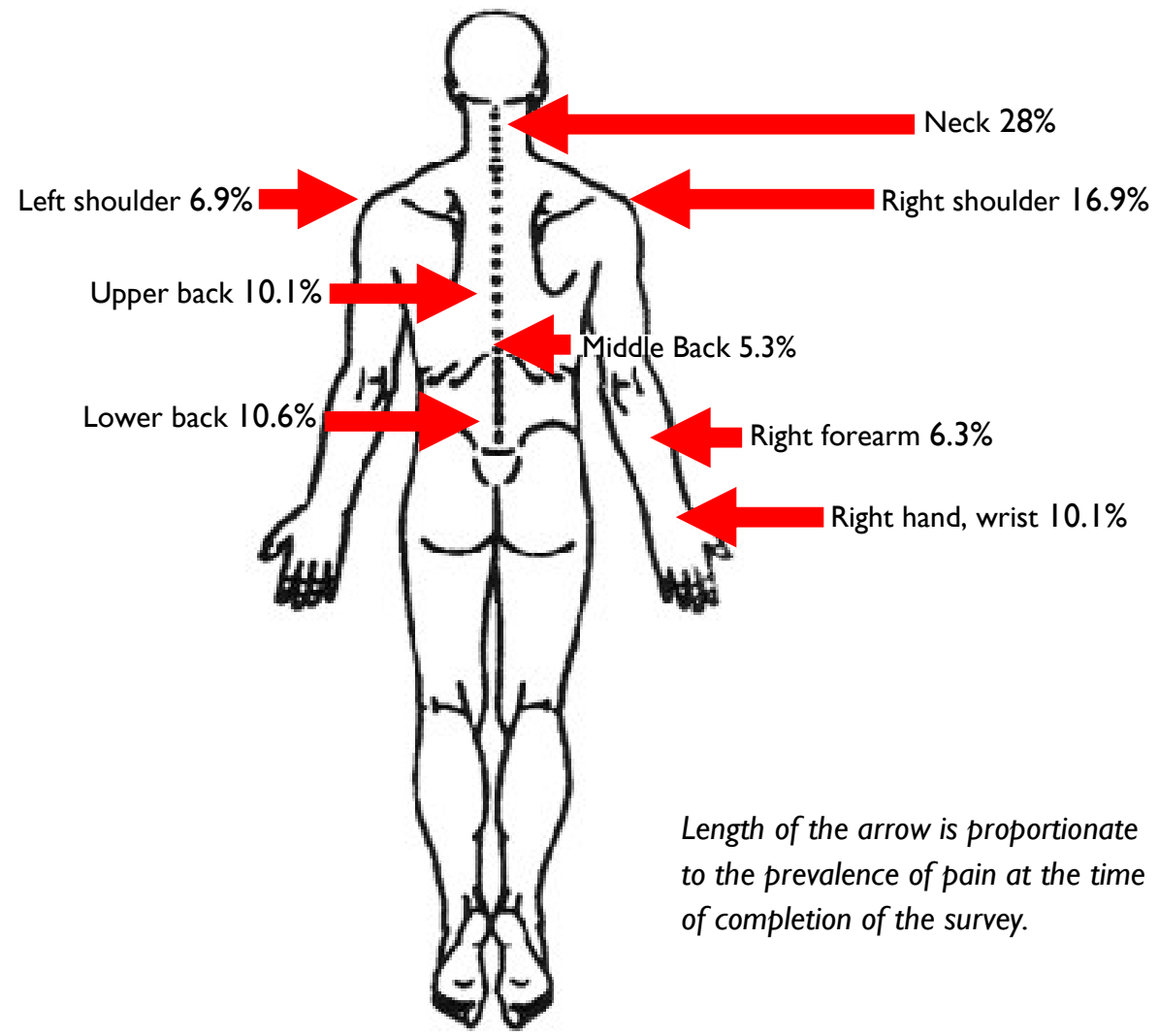

Figure 5. Prevalence of pain at eight sites among Canadian interpreters

* Prevalence refers to the proportion of respondents with the symptom. Annual prevalence refers to the proportion of respondents who have had the symptom in the past year. Lifetime prevalence refers to those who have ever had the symptom. Point prevalence refers to those who have the symptom at the time of responding. It can be difficult to interpret an article or report of the timeframe of the prevalence is not stated. 
Many AVLIC members reported seeking medical treatment in the last 12 months due to pain or discomfort, and receiving a medical diagnosis of one or more musculoskeletal disorders. Tendonitis, carpal tunnel syndrome and arthritis were the most commonly reported medically diagnosed injuries in this survey. The prevalence of these musculoskeletal injuries among sign language interpreters increases with age and, as shown in Figure 6, is much greater than the prevalence in the general Canadian population (adapted from Tjepkema, 2003).

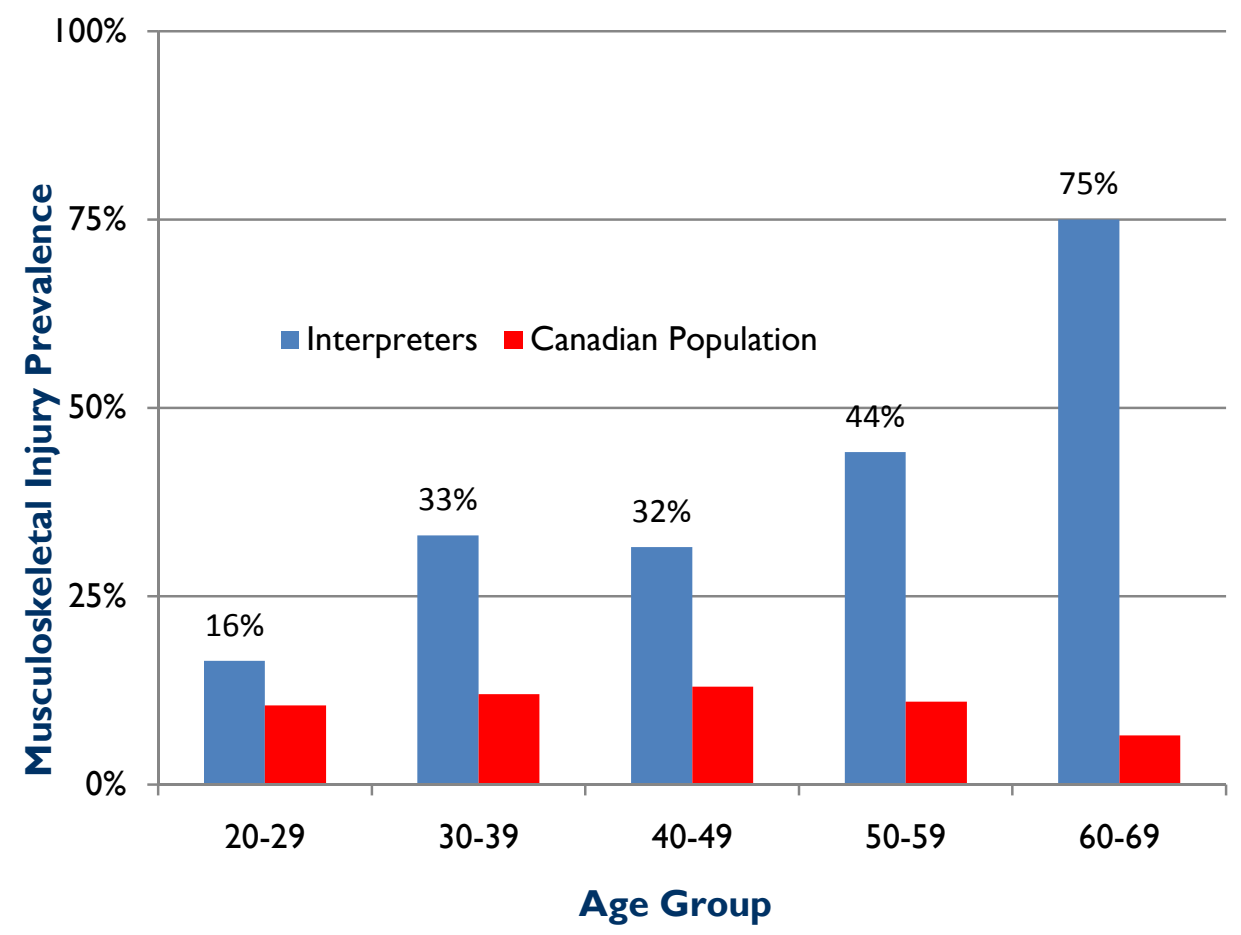

Figure 6. Prevalence of musculoskeletal injury by age group, compared with the general Canadian population

The key to injury prevention is to determine what factors increase and protect against the occurrence of injury. Preventive strategies can be designed to leverage that knowledge. At present, unfortunately, neither the research literature nor the AVLIC survey clearly have linked specific aspects of interpreting with specific injury types. Reported pain was so common among AVLIC respondents that no sub-group had more pain than others, regardless of total working hours, employment format (salaried or self-employed) or length of experience. Obviously, better knowledge about interpreter injury prevention requires better data.

TIP: Reporting your injuries to AVLIC / your provincial workers
compensation board, could become one of the best resources to
help reduce the risk of injury in interpreting.

\section{I ANATOMICAL SITES AND THEIR DAMAGE}

The nature of most injuries observed within the interpreting community were of a cumulative nature rather than a single event injuries, such as the sprained ankle, bruise, or a broken bone resulting from a trip, slip, or fall. Prevention of this type of injury can focus on preventing the causative event, and treatment can be immediate. With cumulative injury, in comparison, the actual initiation of injury may not be perceptible, and the injury does not manifest into pain, discomfort and dysfunction until much later in the process.

A brief anatomy primer is provided to help explain the anatomical features that can become damaged in the cumulative injuries reported by many AVLIC members. Figure 7 is an example of a generic articulating synovial joint in the body, similar to an elbow, knee, or finger joint. 


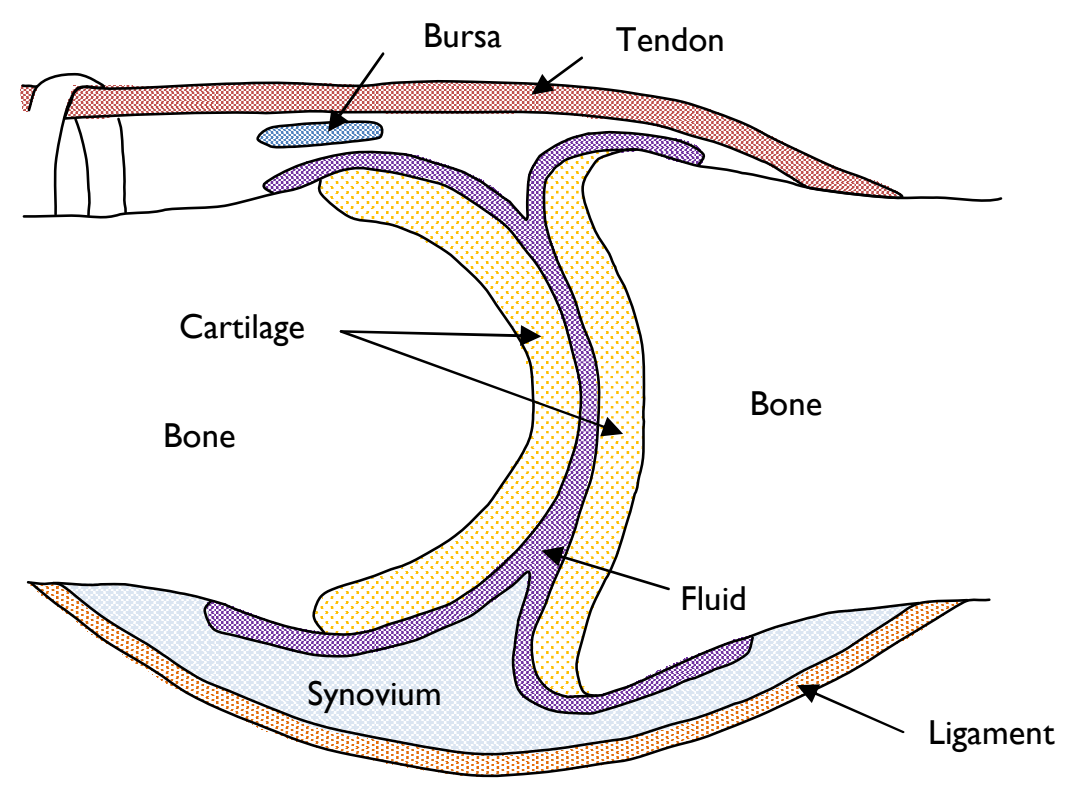

Figure 7. Generic body joint

Each of the listed components plays a key role in movement, and each is therefore susceptible to injury. The most prominent injury locations for upper-extremity disorders are tendons, ligaments, and the synovium. Prolonged sustained postures, in contrast, tend to affect the cartilage, fluid, and sometimes the ligaments.

\section{I.I THE JOINT}

A joint is the point where two bones meet. The body has many different types of joints. While the shoulder joint enables the arm to be moved in a circle around the joint, this is not possible at the elbow or knuckle joint, which can only bend or straighten. The shape of the bones themselves in conjunction with the combination of muscles, ligaments, and tendons, determines the way the particular joint can bend and the range of motion for the joint.

\section{I.2 THE SYNOVIUM}

The synovium is a thin layer of tissue surrounding a joint, or surrounding a tendon or ligament that must slide when stretched, within a confined space such as the carpal tunnel. Synovial fluid inside the synovium helps lubricate the joint or structure to encourage smooth motion, similar to oil lubricating an engine.

The synovium is also susceptible to friction type injuries. Repetitive friction of tendons and various other tissues can cause the synovial tissue to break down, resulting in fibrous tissue formation over the synovium, increasing the friction and causing a cycle of breakdown (Figure 8 - A carpal tunnel example). Friction can also be increased by contracting muscles with greater force, for example, gripping a handle tightly. The more rapid and forcible the contraction, the greater the cumulative stress and friction (Ugbolue et al. 2005, Goldstein et al. 1987).

\section{I.3 THE TENDONS}

Tendons are bands attached to muscles at one end and bone at the other. Similar to strings on a puppet, tendons harness the force produced in muscles, causing bones to move. As a muscle contracts and stretches, the force is transmitted through the tendon to the bone, pulling on the bone and causing it to pivot at the joint.

Many injuries reported by interpreters involve swelling and inflammation of tendons, or tendonitis. It is possible to harm a tendon with sudden excessive force, but this is not the usual method of injury. Instead, the force that harms the tendon is much less than the maximum single force the body can withstand. The minor tissue 
damage may be imperceptible, and is referred to as "microtrauma". Microtrauma heals with rest. However if additional microtrauma occurs before healing is achieved, the trauma will be compounded.

Over time, independent of rest, the friction produced as the tendon slides over the various other tissues causes the lubricating synovial tissues to break down. The resulting stress and friction produces inflammation within the working tendons, leading to tissue degeneration and swelling. Tissue damage may not be felt as pain until a substantial amount of damage has already occurred (Barbe \& Barr 2004). A vicious cycle of progressive damage is established (Figure 8).

The muscle insertion point, or spot where the tendon attaches to the bone, is often a site of pain in overuse injuries. With extended use such as repeated, forceful movements, tissue inflammation and swelling also occurs at the muscle insertion points along the forearm and upper arm, causing pain and discomfort. Examples of this type of injury include lateral or medial epicondylitis (tennis elbow).

\section{I.4 THE NERVES OF THE HAND AND ARM}

Nerves are the electrical system of the body, carrying sensory cues to the brain about the shape, texture, and temperature of things we touch and the position of our body parts. Nerves also carry instructions back from the brain to the muscles to initiate postural changes. When the nerves are pinched, they may fail to complete their functions of carrying signals back and forth to the brain.

Nerve entrapments occur when the space through which the nerve travels is reduced by swelling, inflammation or increases in fibrous material of other tissues in the area. This is particularly problematic in the carpal tunnel, where the median nerve travels to the hand through a small space (the carpal tunnel) also occupied by all the tendons of the hand. When these tendons are overworked, they may become inflamed, or the synovium may break down. With the resulting swelling, the space in the carpal tunnel is reduced. The nerve is then pinched, reducing its ability to transmit signals to muscles, or sensations back to the brain.

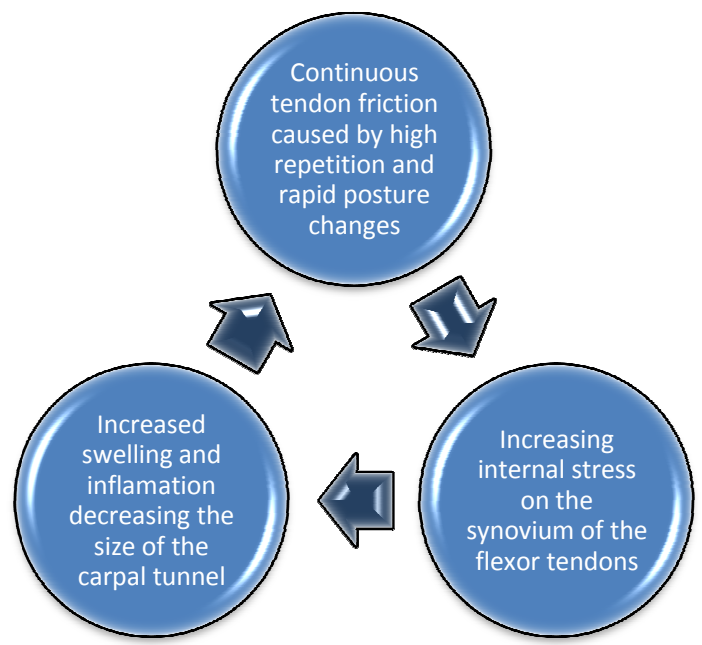

Figure 8. Vicious cycle of progressive injury resulting from high repetition, long duration, and rapid postural changes. A carpal tunnel example.

\section{I.5 THE LIGAMENTS}

Ligaments provide additional support to joints by connecting one bone to another. Ligaments cannot be contracted like muscles. As they are stretched, they become tighter. This provides increasing force to prevent a joint from slipping out of place or rotating more than normal. A ligament can be thought of as an elastic band, helping to prevent two bones from separating or sliding on one another. Ligaments themselves can be injured. For instance, a sprained ankle occurs when the ankle is rotated beyond its tolerance, stretching a series of ligaments beyond their capability and damaging the ligaments. 


\section{I.6 THE CARTILAGE}

The end of the bone is wrapped in a layer of cartilage, which acts as a helmet or shock absorber for the joint. As force is applied on one bone, the cartilage absorbs some of it, reducing the amount of direct force transmitted to the adjacent bone at the joint.

Over time, cartilage tissue can break down due to wear and tear, reducing its ability to cushion forces transferred from bone to bone. Cartilage does not recover over time like most other tissues. If the cartilage is subject to high loading consistently day after day, it will break down with no chance of recovery.

\section{I.7 THE BURSA}

A bursa is a fluid filled sac usually between bone and tendon. It cushions between the sliding tendon and the underlying bone. If the bursa becomes inflamed, the frictionless sliding performance deteriorates. Continued movement of the site can increase the irritation, increasing the swelling, further interfering with the frictionreduction performance. This inflammation of the bursa is bursitis.

\subsection{REFERRED PAIN}

The injured person and sometimes even their clinicians are often confused by the resulting pains because the site of pain or other symptoms is not necessarily the damage site. This is known as referred pain. When a nerve is pinched, the pain could be felt at another point along that nerve, not only in the site where the pinching occurs. Self-diagnosis or diagnosis by a clinician with insufficient experience with musculoskeletal injury could result in ineffective or misguided therapies. For example, a nerve entrapment in the red-shaded area in Figure 9 could be felt as pain or loss of sensation in the yellow-shaded area. For this reason, we recommend evaluation by a health professional knowledgeable about the complexities of musculoskeletal injury, including referred pain syndrome.

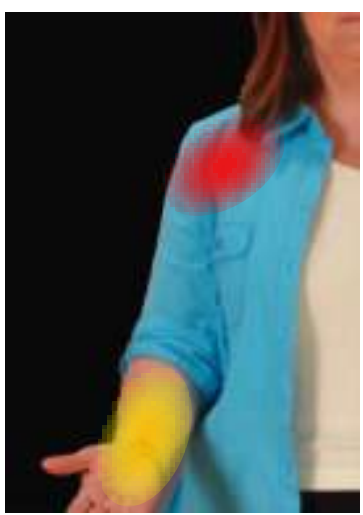

Figure 9. Referred pain.

TIP: Pain over a specific site in the body may not necessarily be
reflective of an injury to that site. Proper diagnosis by a medical
professional is the best way tease out specific injury sites that
might cause pain to be referred to other areas of the body.

\subsection{SYMPTOMS}

To place these injury types into the context of symptoms, some common symptoms of musculoskeletal injuries observed in sign language interpreting are illustrated in Figure 10. The figure illustrates potential locations of pain, tingling, tenderness and numbness. Take note that these are examples only and are not indicative of all injury cases or examples of each musculoskeletal injury experienced by interpreters, nor are they meant for the purpose of self-diagnosis. Always use caution when any of these or other symptoms begin to arise and seek a medical professional when necessary. 


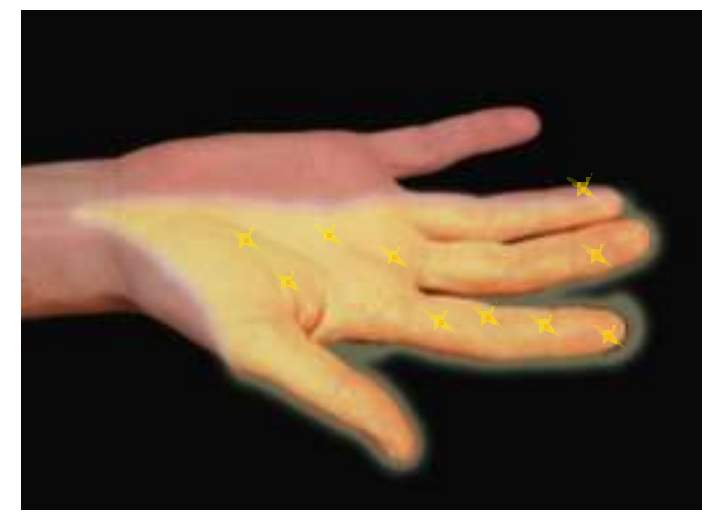

Pain and swelling in individual finger joints

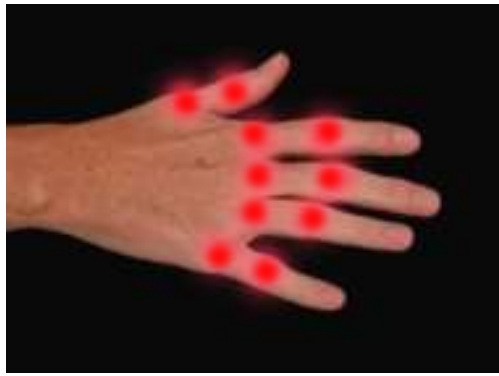

Inflammation at the joints may cause pain and swelling (red areas) possibly indicative of arthritic disorders.

\section{Tingling and loss of sensation}

Tingling and pain sensations in the fingers (yellow area) may be indicative of nerve entrapment disorders such as Carpal Tunnel Syndrome. Symptoms may be worse at night.

\section{Non-specific muscle pain over} any muscle in the body

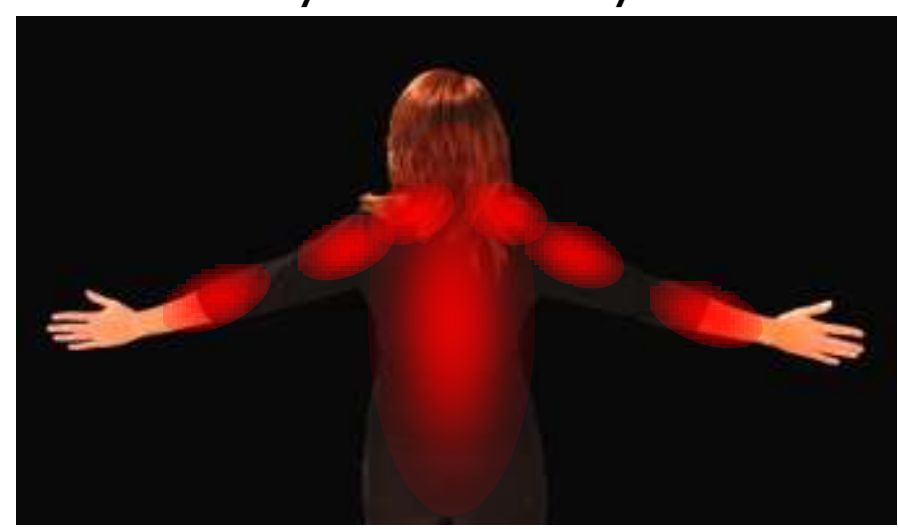

Muscle pain (red shaded regions) may result from fatigue to overwork and insufficient rest time for recovery.

\section{Pain and tenderness at the joint and radiating down the limb}
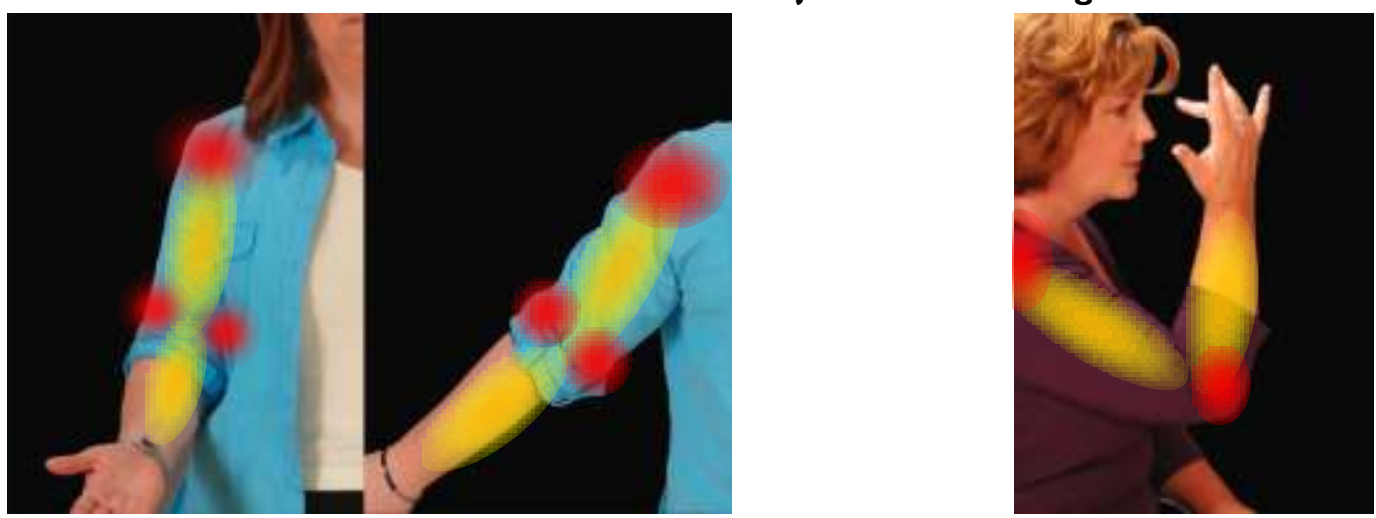

Pain at the joint (red area) potentially with pain radiating down the limb (yellow area) may be indicative of a tendon-inflammation related disorder such as tendonitis or bursitis.

Figure 10. Sites of damage and symptoms

\section{4 “REPETITIVE STRAIN INJURIES"}

These types of injuries are commonly referred to as repetitive strain injury (RSI). While the same injury, for instance, nerve entrapment in the wrist, could also result from single acute injury event such as a fall onto the hands, a repetitive strain case is one that occurs as a result of repetitive motion with insufficient rest and recovery. As such, these symptoms do not invariably equate to "repetitive strain injuries". RSI refers to not only the type of 
injury but also how the injury was acquired. Making a diagnosis of RSI will require information indicating a history of exposure to specific types of repetitive movement combined with inadequate rest and recovery for the affected tissues.

While acute injury has a clear onset event, RSI does not. The damage is cumulative and may be unnoticed until quite serious discomfort is experienced. From an extensive review of the evidence on RSI, Ranney (2003) postulated three progressive stages of RSI.

Stage I RSI - Pain and discomfort exist only when an individual is at the workplace.

Stage 2 RSI - Pain and discomfort continue up to two hours after the completion of work.

Stage $3 \mathrm{RSI}$ - Pain and discomfort still present the following day.

Many interpreters reported having some discomfort at the time of filling out the 2006 survey of AVLIC members. Those findings suggest that some interpreters may be living in stages 2-3 right now. Some fatigue and discomfort with movement is expected, but when symptoms begin to persist throughout the workday (Stage I), into the evening or after work (Stage 2) or right into the next work day (Stage 3), there is a much greater cause for concern. The earlier in these stages you can intervene and influence positive change to reduce any of the general risk factors, the more effective you are likely to be reducing the pain and discomfort.

One small benefit of cumulative occupational injury onset is that the worker has the opportunity to manage exposure before full-blown disorders develop. Effective management of musculoskeletal hazards can make the difference between being an effective and profitable worker or a chronic injury case.

TIP: Early recognition of injury and appropriate diagnosis does not
have to mean lost time and lost wages if it is caught early and
appropriate work changes are adopted to stop the injury from
escalating.

The remaining chapters of this Guide provide information on the risk, prevention, and management of serious musculoskeletal injury. Structured around a multi-factorial model of interpreting injury causation, this Guide reports multiple complementary general strategies to manage, reduce, and prevent injury. Because there is currently little scientific evidence specific to sign language interpreting, the advice in the following chapters reflects broad scientific information linking musculoskeletal injuries to causal factors and interventions. 


\section{LANGUAGE INTERPRETERS: MODEL OF INTERPRETER INJURY}

It is generally accepted that musculoskeletal injury can result from exposure to repetitive motion under certain conditions on a cumulative basis. The key elements of these repetitive or cumulative musculoskeletal injuries are frequency of the repeated movement, the joint acceleration (the "force" of the movement), the joint angle and the duration of the exposure period. Throughout the chapter they will be referred to as the sign production elements. All of the sign production elements (duration of the exposure period, movement frequency, acceleration, and angle) contribute to the physical wear on the interpreter's body.

In addition to the sign production elements, there are situation elements. The situation determines who will be speaking, for how long and at what pace, which affect two of the key characteristics of sign production: movement frequency and duration.

There are also individual elements that contribute to physical susceptibility to injury, and to the degree of effect of injury on the individual interpreter. In relation to susceptibility, the interpreter's physical characteristics such as anatomy and signing style can contribute to injury. Sign style affects the joint acceleration and angle in sign production. Joint angle is also influenced by individual anatomy, with smaller joints sometimes being capable of greater deviation (degree of bending). Signing style can also influence movement frequency. Linguistic choices made by the interpreter can make use of more signs, or fewer, for a given spoken content.

The interpreter's subject matter knowledge relevant to the interpreted situation, combined with the situation itself, influences the psychosocial characteristics of the interpreted event. This influences the interpreter's state of mind, and could affect his physical response in the form of muscle tension.

Individual movements of sign production rarely exceed tissue tolerance. Instead, the tissues become fatigued and can begin to develop injury at the cellular level as discussed in the previous chapter, which may decrease the tissue tolerance of a given structure. Absolute tissue tolerance can vary greatly between tissues and from person to person.

Individual characteristics (such as pregnancy or medication, previous surgeries or injuries) may influence personal physiology and increase the likelihood of swelling or inflammation. The rest and relaxation choices of the interpreter will determine whether the microtrauma is able to heal or will accumulate. Subjective discomfort and fatigue should influence this choice. When microtrauma has not healed, the capacity for further microtrauma is increased. As the cumulative microtrauma accumulates or even exceeds the tissue tolerance, fatigue and discomfort become pain and other symptoms and even loss of function, such as movement or strength reduction can occur. For a given amount of pain and other symptoms, there will be individual differences in how well it will be tolerated. For a given degree of damage, individual perceptions of health, personal supports, preferences, needs and goals will contribute to the resulting decision by the interpreter whether the damage interferes with activity: whether the pain is limiting.

The multivariate develop of injury is illustrated in a model of injury (Figure II). Each individual components of this model will be discussed in more detail in this chapter. 


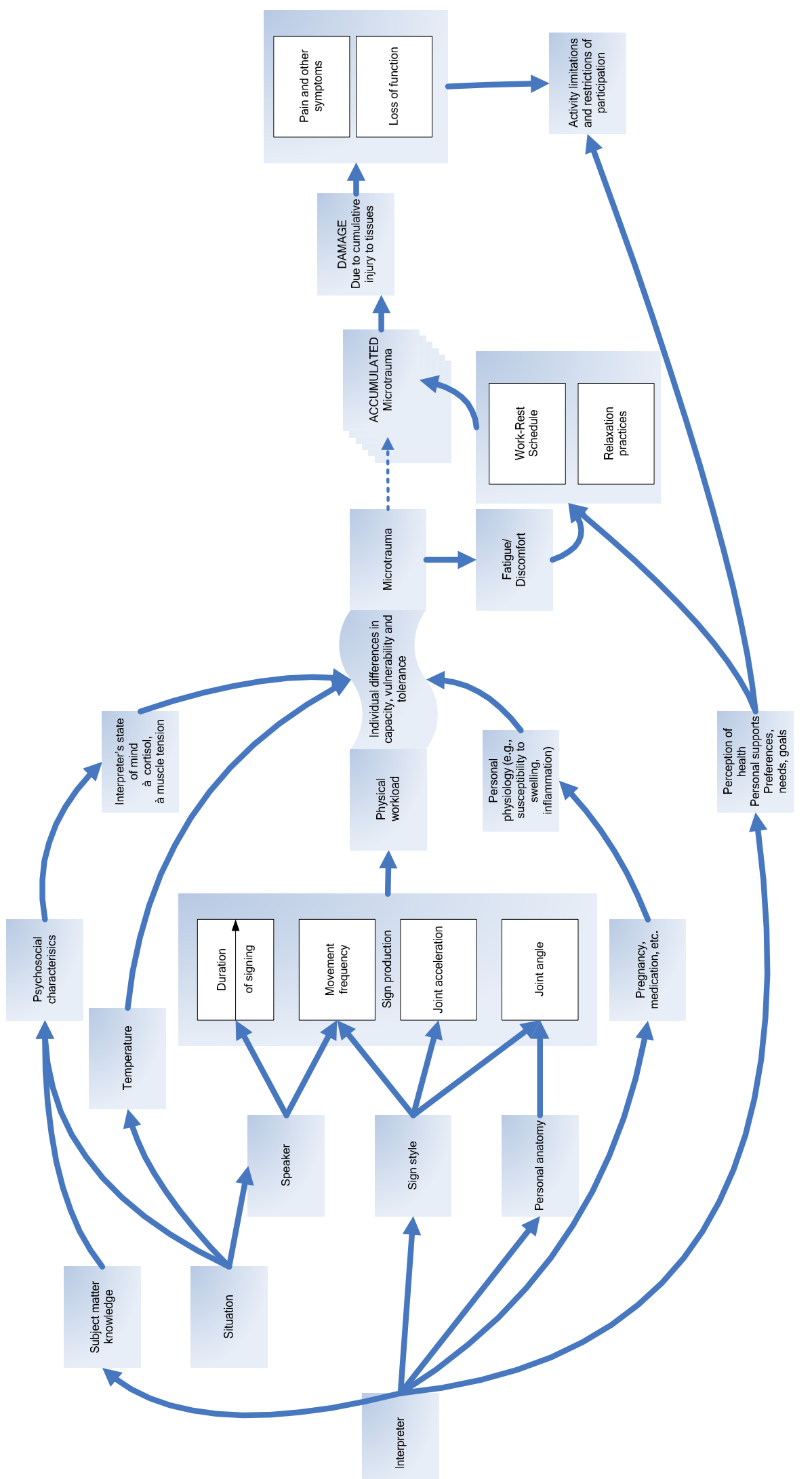

Figure II. Model of interpreter injury 


\section{I SIGN PRODUCTION AND SIGNING STYLE}

Increased movements of the hand and wrist lead to increased prevalence of injury (Marras \& Schoenmarklin 1993). This section will examine common elements of musculoskeletal injury risk-movement frequency, joint angle, and force of movement - in relation to sign production. These three factors are important because of the mechanisms of developing this type of injury. Many injury types result from friction between various tissues. Friction can be modified in a number of ways including frequency, joint angle, and force. Sign production and style has a large effect on the musculoskeletal system by controlling the range, rate, and drive of each muscle contraction. Therefore the signing style of the interpreter can directly affect the risk of developing a musculoskeletal disorder.

\section{I.I MOVEMENT FREQUENCY}

Movement frequency is directly related to how much the speaker talks in a period of time, but also affected by the interpreter's style and choices.

TIP: At an appropriate time, ask that the speaker control his pace
to ensure your safety. A quick speaker not only increases your
chances of missing information, and your cognitive workload and
perceived stress, but also increases your movement frequency and
risk of developing an injury.

The movement required to interpret a particular statement also varies with the choice of signs used in the interpretation. As shown in Figure 12, the most economy of movement for message-equivalent delivery of signs is achieved with ASL. Message-equivalent interpretation can also be accomplished with English-coded signing and considerable fingerspelling, at the expense of much more physical movement. ASL is considered to be the highest calibre of service unless the deaf consumer has expressed a preference for more English delivery. ASL is also preferred for its reduced physical motion and risk factors. However, because English-coded signing involves less cognitive processing before beginning the physical movements, it places less demand on working memory than ASL interpretation. Across a variety of tasks (not just with interpreting), task demands that exceed working memory limitations often lead to conscious or unconscious strategic shifts that typically favour speed over accuracy. In the case of interpreting, "speed" is keeping pace with the speaker, while "accuracy" is the interpreter's preferred retention of the linguistic character of ASL. If the interpreter cannot keep up and tries to avoid shifting to English coding, the message-equivalence will be lost (toward the bottom left corner of Figure 12). Some will lose both message-equivalence and ASL characteristics (bottom right corner). Although every interpreter will have a cognitive "speed limit" or speaker pace that is simply too fast, interpreters with the highest linguistic efficiency and greatest working memory capacity will be most able to avoid this strategic shift as speech rate increases. These interpreters not only provide the preferred quality of service but will benefit from reduced exposure to the risk factors for overuse and repetitive strain based injuries resulting from the extra movements involved in Englishcoded signing.

TIP: Experience and training develop the interpreter's working
memory capacity and her linguistic knowledge of sign language.
Interpreters should continuously work on both increasing their
working memory as well as their ASL and English language
competencies.

The concept of movement frequency includes overall movement and movement of specific joints. Balancing the distribution of movement among joints, using the whole forearm rather than isolating all movement in the hand, and using both hands, can help reduce the movement rate of specific joints. However, this is a strategy for healthy and balanced sign production, not a method to manage pain. If there is pain, the interpreter must address the pain. 


\begin{tabular}{|c|c|c|c|}
\hline \multirow[b]{2}{*}{ 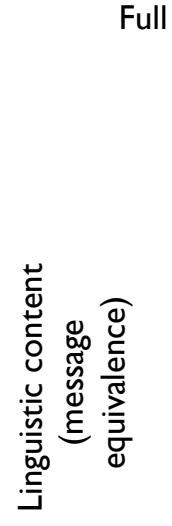 } & ASL & $\begin{array}{c}\text { Orally } \\
\text { supported } \\
\text { conceptually } \\
\text { accurate } \\
\text { English }\end{array}$ & $\begin{array}{l}\text { English coding } \\
\text { with } \\
\text { considerable } \\
\text { fingerspelling }\end{array}$ \\
\hline & $\begin{array}{c}\text { ASL } \\
\text { summarization }\end{array}$ & $\begin{array}{l}\text { KMore time } \\
\text { Time needed } \\
\text { For cognitive } \\
\text { processing } \\
\text { Less timeע }\end{array}$ & $\begin{array}{l}\text { English coding } \\
\quad \text { with } \\
\text { fingerspelling }\end{array}$ \\
\hline Incomplete & $\begin{array}{l}\text { ASL "Swiss } \\
\text { cheese" }\end{array}$ & $\begin{array}{c}\text { Fragmented } \\
\text { English } \\
\text { summarization }\end{array}$ & $\begin{array}{l}\text { English/ } \\
\text { fingerspelling } \\
\text { conceptual } \\
\text { omissions }\end{array}$ \\
\hline & Minimum & & Maximum \\
\hline & & Physical work & \\
\hline
\end{tabular}

Figure 12. Proposed model of trade-off between message equivalence and physical work in relation to time needed.

\section{I.2 JOINT ANGLE}

Biomechanical risk is reduced by promoting neutral joint angles and avoiding the extremes of any joint's range of motion. As joints move through a range of motion, the tissues translate over each other, creating friction. Friction may be increased at extremes of the range of motion, as tendons are no longer working at their optimal position. Ligaments may also be jeopardized if the rapid forceful movements are made towards the end of the range of motion. Interpreters who have smaller joints may be able to achieve a greater range of motion. Women typically have smaller joints than men, and many if not most English-ASL interpreters are women.

Joint angle is directly related to carpal tunnel syndrome. Pressures within the carpal tunnel are increased as one moves away from neutral wrist postures (Schuind 2002, Smith et al. 1977, Keir et al. 1997). In turn, this increases friction leading to microtrauma. Although many signs entail extreme postures, it is often possible to use a more optimal posture. Figure 13 show the initiation and completion of the sign PUSH. The top photos show the sign using a neutral wrist posture and the second row of photos show the sign produced with an extremely deviated wrist posture.

To avoid extremes of motion, the ideal limits for hand movement is the boundary of an area $25 \mathrm{~cm} \times 25 \mathrm{~cm}$ around the hands when elbows are relaxed at the sides. Studying interpreters working at the National Technical Institute for the Deaf at the Rochester Institute of Technology (NTID/RIT), Feuerstein and Fitzgerald (1992) found that those with musculoskeletal pain produced signs outside of the defined $25 \mathrm{~cm} \times 25 \mathrm{~cm}$ box significantly more than those without pain symptoms. One possible explanation is that when a larger envelope is used, it requires more joint acceleration to return to the neutral point or move on to the next sign to keep up with the pace of incoming speech. In ASL, the signing envelope is a larger area, as shown with a red box in Figure 14. Signs such as PAH, BOSS and AUSTRALIA are at the outer boundaries of the space. Signs that do not require using extreme locations should be produced in a smaller scale rather than using the entire area of the space. 

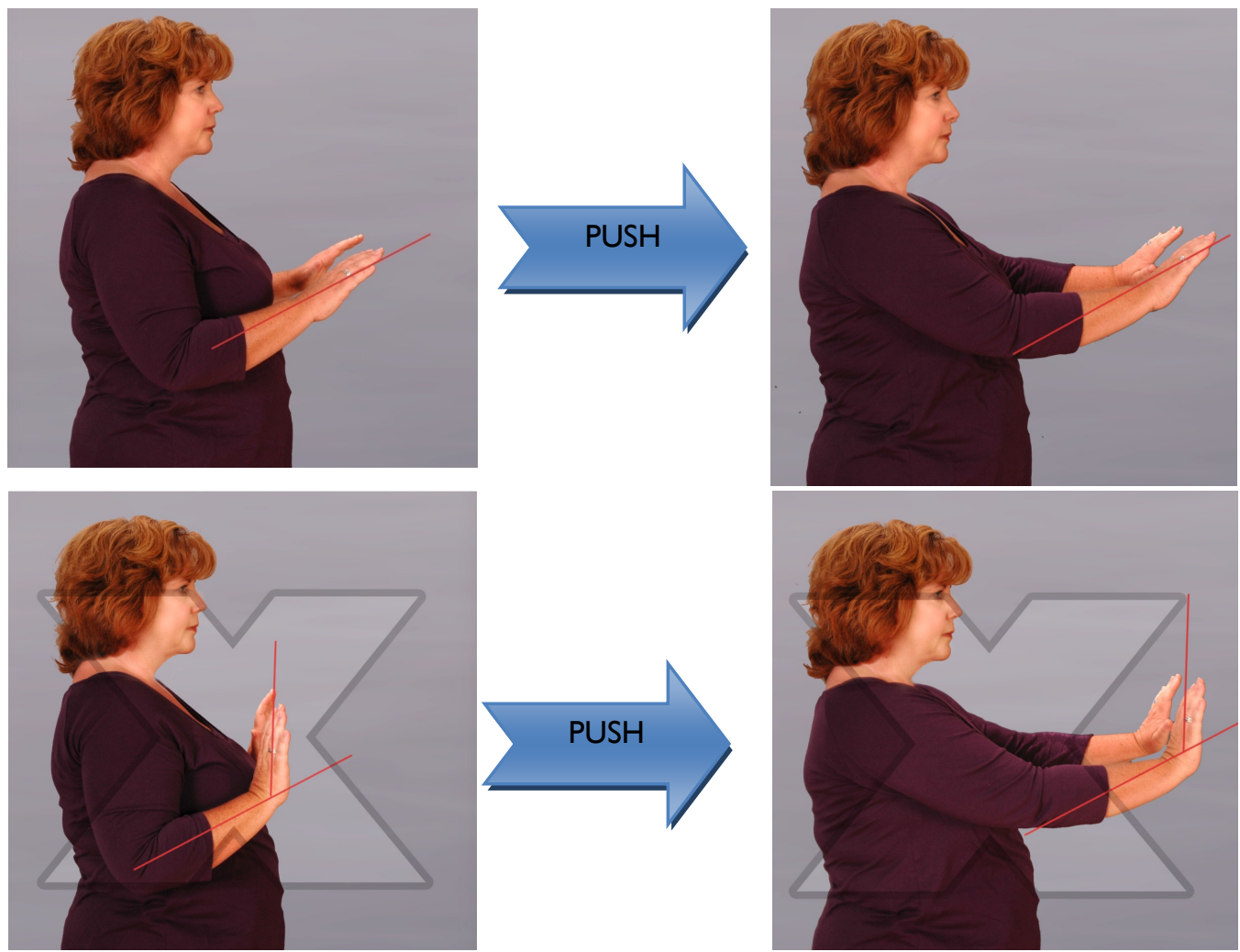

Figure 13. Initiation and completion positions of sign PUSH showing neutral wrist posture (top) and an undesirable deviated wrist posture (bottom).

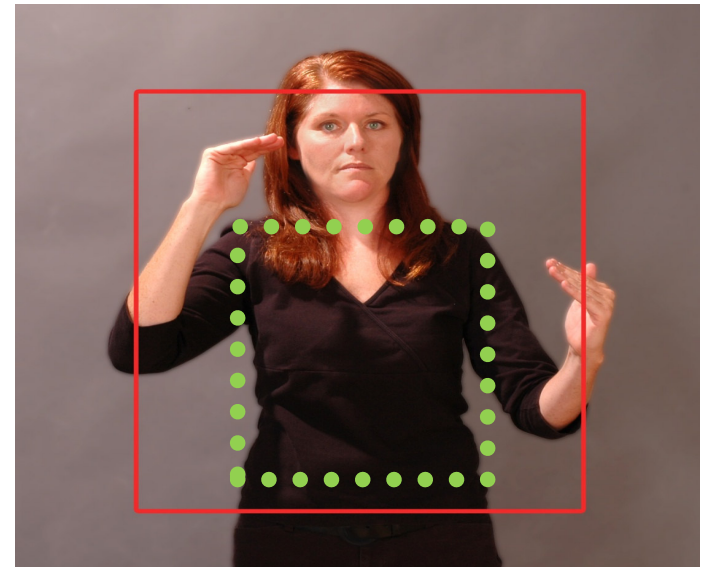

Figure 14. Keep signs within $25 \mathrm{~cm}$ area around neutral hand position

(green dots) rather than the full conversational ASL signing space.

Avoid holding extreme and non-neutral postures when not part of a specific sign. The most obvious unnecessary non-neutral posture in interpreting would be a static posture with the elbows out from the sides (non-neutral upper arm). Non-involved parts of the arms should be kept in a neutral and non-twisted position. In the case of fingerspelling, the hand should be kept in line with the forearm. Some interpreters, particularly novices, notice that this results in the palm facing diagonally across the body rather than toward the audience, and as a result may attempt to rotate their forearm to make the palm "face the audience". It should be reassuring to notice that Deaf 
people do not do this. It is not needed for clarity and results in additional wrist strain. Avoid this practice. Keep wrists in line with the forearm.

The interpreter's ability to achieve a neutral posture can also be limited by other factors that affect posture such as genetic spinal curvatures or previous injuries. Fatigue due to poor fitness level, nutrition, or lack of sleep can be expressed in poor posture. Effects of anxiety-raised or rounded shoulders-alter posture as well.

TIP: Strive for good posture through adequate rest and optimal
fitness.

Favour neutral postures during "microbreaks" while interpreting, rather than non-neutral postures that are not as restful. When the speaker is pausing and while the interpreter is processing a spoken message, shoulder, elbow and wrist should be brought close to a neutral position by resting elbows at the sides, with hands can be placed in the lap or gently clasped supporting each other.

TIP: The simplest method to reduce joint loading during micro-
breaks is to simply let the arms hang down beside the body, or
rest on your lap if you are in a seated position.

Figure 15 depicts several neutral wrist and arm postures (preferred) and postures that adopt highly flexed or extended wrist postures (avoid). These are examples, rather than a comprehensive postural catalogue or recommended and prohibited postures. Keep in mind that minor postural nuances can play a major role the development of tissue injury. Rest in neutral postures. Likewise, while resting the arms, avoid compression stress at the point of contact, such as resting the forearm on the edge of a desk. Tissue compression can restrict circulation to the hands.

Resting elbows on an armrest of a chair is a useful position for microbreaks, but avoid leaning on the armrests
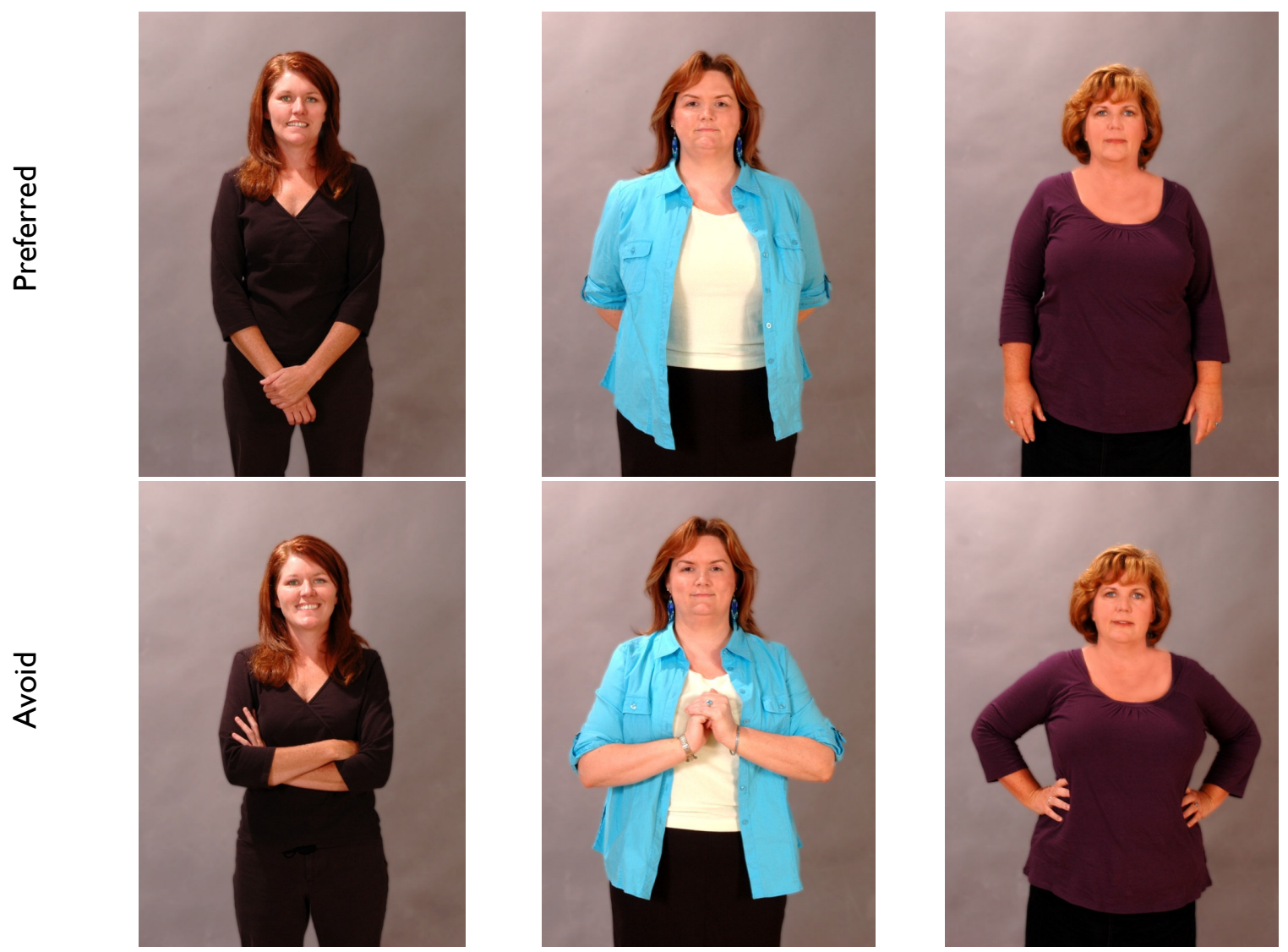

Figure 15. Neutral and non-neutral resting positions 
while interpreting. Allowing the elbows to move freely rather than fixing them on the armrest allows the sign to be expressed using both elbow and wrist movement rather than concentrating all required movement in the wrist.

TIP: Make use of opportunities to rest during brief breaks while
interpreting, but avoid reducing the freedom of movement of
larger parts such as the elbows while interpreting as this can
concentrate all movement in the wrists and fingers.

\section{I.3 "FORCE": JOINT ACCELERATION}

Interpreting is unique among musculoskeletal injury-prone occupations in that no force is being applied to an object. The interpreter is moving his own body parts but no external application of force is involved.

Musculoskeletal injury prevention recommendations in most occupations refer to reducing external forces, such as heavy lifting. For signed-language interpreting, the attention is on internal forces created by moving the hand and arm at high accelerations.

TIP: Avoid signing with rapid acceleration, particularly at extremes of the range of motion and when changing direction of movement.

Some force is seen in contacts from hand to hand (Figure 16). Conventional injury prevention guidelines advise against striking objects with the hand because doing so causes brief compression stress on the point of contact in the hand, and sends shock waves through the local circulatory system. Signs that require hand-to-hand impacts (STOP, IMPACT, APPROVE, RIGHT/CORRECT) should be produced with gentle impacts. The interpreter needs to find a balance. Pulling back before the impact transfers the strain to another structure that resists the momentum of the movement.
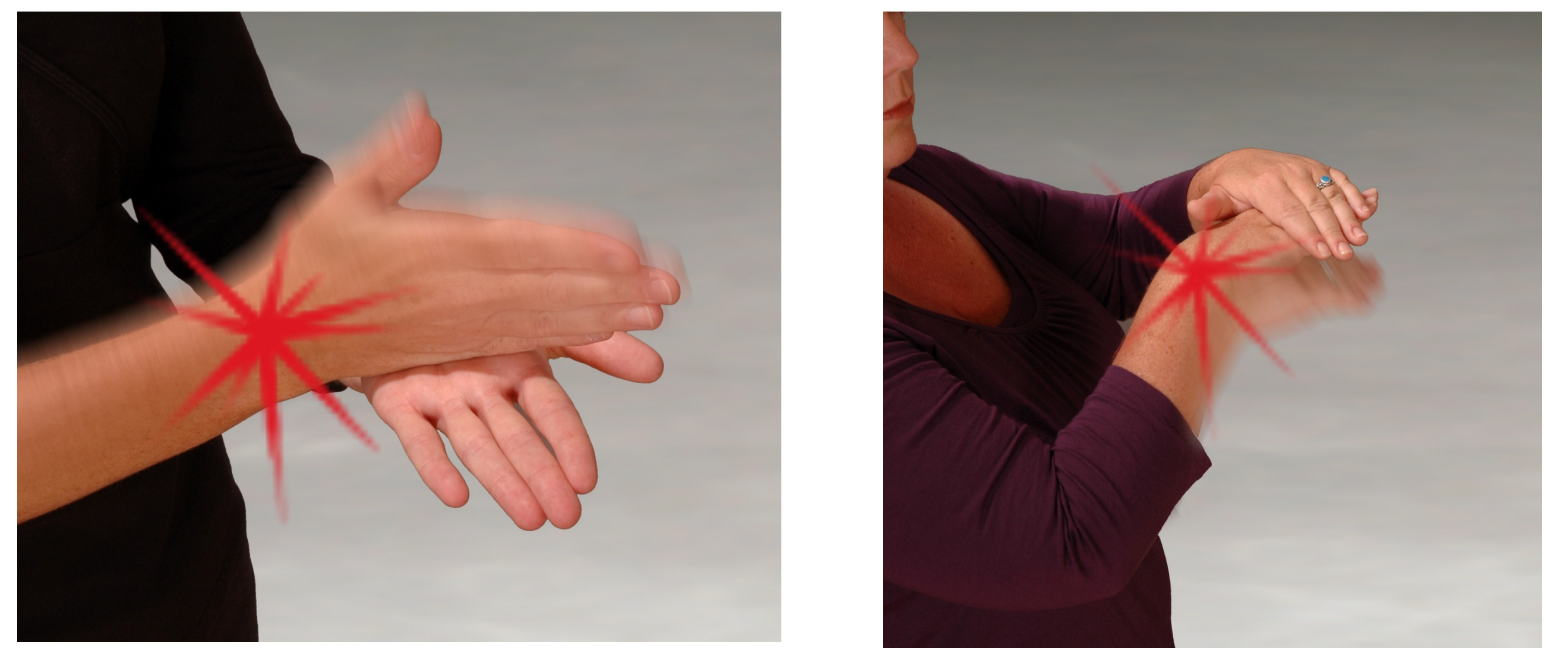

Figure 16. Examples of signs using hand-to-hand impacts

Grammatical facial expressions should be comfortable to avoid straining facial muscles as well, but there are no occupational health concerns if no discomfort is felt and the expression feels natural. 


\subsection{SITUATION FACTORS}

The main biomechanical hazard of interpreting is producing signs, and sign production is inherent to the activity and cannot be eliminated. Some needless risk of injury can be reduced by modifying signing technique but there is a close link between signs and sign production and some situational factors. Additional modification and attention to situational factors can greatly improve risk reduction. These additional risk reduction efforts must address elements of the situation. The situation factors are covered in this section.

\subsection{SUBJECT MATTER KNOWLEDGE}

As illustrated in Figure I I, cognitive demands associated with a job can have a direct impact on how and when upper extremity symptoms are manifested (Huang et al. 2002). To correctly and efficiently interpret the material requires adequate subject matter knowledge. The interpreter who understands the subject matter will be more efficient and effective in their cognitive work because the content and linguistic knowledge will already be organized in the interpreter's knowledge base. Interpreters who work regularly in the same environment develop subject matter knowledge that they bring to subsequent appointments. Interpreters who are familiar with the subject matter will feel less stress, therefore decreasing the risk of developing a musculoskeletal injury. Other interpreters consider that preparation before the appointment (for instance, through research and reading), which rewards them the same way.

There have been suggestions that interpreters should have at least an undergraduate degree other than interpreting, in order to be comfortable with advanced subject matter. Others suggest an interpreting education should involve liberal studies. What is clear is that sign language fluency and linguistic ability to interpret between spoken and signed languages in real time are not the only competencies required in interpreting.

Deaf people sometimes remark that the difference in interpreter expertise is seen in the interpreter's apparent skill in understanding the spoken message to be interpreted rather than ASL fluency. This difference is not necessarily specific to advanced technical concept knowledge. What often makes the difference is worldly maturity. With experience, the interpreter has not just acquired skills in interpretation but is also older and has been exposed to more information about the world in general. Conceptual content makes more sense when one knows more about the context.

TIP: An interpreter who is well versed in the subject matter can
process more effectively and economize movement.

With the increase of self-employment and contract work in the world at large, individual responsibility for professional development has come to the forefront in almost every line of work. In all sorts of occupations, the employer/client expects the professional to be work-ready, not just willing to be trained. Interpreters are no exception and are obligated through the AVLIC Code of Ethics and Guidelines for Professional Conduct. Another strategy for enhancing subject matter knowledge is specialization. Interpreters who cannot comprehend economics, for example, should decline and defer to a colleague those appointments that involve economics.

The purpose of this section is not to take a position on how much subject matter knowledge is required or to set entry level criteria. Rather, the point is that the less subject matter knowledge the interpreter has, the more cognitive work is involved in interpreting, and the more stressful the interpretation will be. In turn, this not only degrades the quality of the interpretation but it also increases the risk of injury.

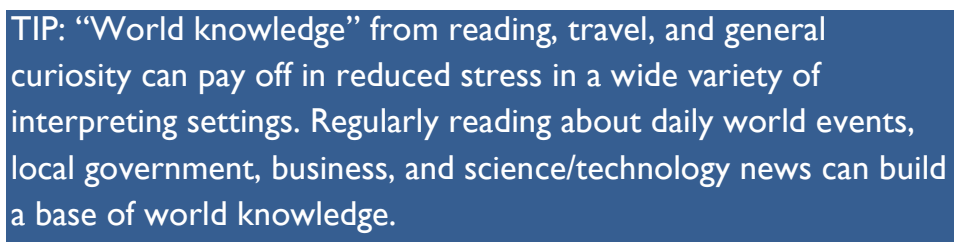




\subsubsection{PSYCHOSOCIAL ELEMENTS OF THE EVENT}

Interpreters bring personal experiences to every appointment. As a result, the psychosocial elements of the interpreting experience are a combination of the interpreter's reaction to the subject matter, the participants involved, and the nature of the appointment.

Trust and comfort between interpreters in a team can also benefit the psychosocial experience. A novice interpreter may feel more comfortable working with a veteran interpreter who can give valuable feedback. Interpreters who have worked well together in the past will know each other's strengths and know what type of support is needed. Conversely, there are some interpreters who prefer not to work together. The logistics of creating a team vary according to the employment situation of the interpreters and no one knows who works well together better than the interpreters themselves. Therefore self-employed interpreters should arrange their own teams whenever practical, rather than leaving it to the client's meeting planner to book interpreters at random.

TIP: Promote psychosocial comfort through teams built by the
interpreters, rather than random pairings arranged by agencies
and meeting planners.

The psychosocial nature of the appointment can be improved by familiarity with the style of interpreting that suits the situation. Having interpreted in the situation before, knowing the consumers reasonably well, and having had positive feedback in this type of situation in the past can all relieve concerns about performance that could weigh on the mind through the appointment. The interpreter can gain a sense of control over the situation by negotiating event details and confirming working conditions in advance.

Some interpreters may feel intimidated by people in positions of power, particular subject matter, or even certain consumers. Although they may be capable of interpreting the content being discussed in the situation, they feel uncomfortable. There does not need to be a rational basis for the intimidation for it to have an effect. Different people have different approaches in dealing with their discomfort. While some prefer to take on new challenges, others prefer to work where they have an acceptable comfort level. If there is enough work to keep busy, the latter is an efficient solution. Discussing the subject matter or interpreting preferences with the deaf consumers may help to demystify the situation. If the issue is content expertise or how to convey a concept in sign language, bringing the deaf consumers into the interpreting team can be helpful.

TIP: Check in with the consumer to ensure the interpretation is
understood. This not only improves quality but can increase
confidence.

Interpreting excellence usually makes the best use of feedback, but some interpreters may take critiques as a personal affront. There are people who criticize with the intent to insult, but, in most cases, even feedback that notes a deficiency reflects respect for the interpreter's professionalism and commitment to growth. Most deaf consumers and interpreter colleagues are providing feedback to share their knowledge with the interpreter. They are demonstrating a belief that with this knowledge the interpreter can be even more effective. The psychosocial stress of feedback can be alleviated by cultivating this positive outlook rather than dwelling on the negative.

The psychosocial experience will be different in a progressive and accessible organization that is deaf-aware than in a deaf-oblivious organization. If the organization is well-acquainted with deaf people through their personnel or consumer base, the interpreter's role will be readily understood. Conversely, in a deaf-oblivious organization, the interpreter may experience pressures and be exposed to prejudices. To mitigate the stress, the interpreter can provide consultation and education regarding the interpreting service prior to commencing the work

TIP: Open communication with the business client and particularly
with the deaf consumer can help alleviate the interpreter's stress
about appropriate interpretation.




\subsubsection{INTERPRETER'S STATE OF MIND: EMOTIONAL LABOUR}

Emotional labour refers to work that requires the person to display a particular outward demeanour, possibly to the extent that he must refrain from displaying authentic emotions. Interpreting clearly constitutes emotional labour, as the AVLIC Code of Ethics and Guidelines for Professional Conduct precludes superimposing the interpreter's views and values on the substance of the interpreted event. Emotional labour can be benign and even rewarding, as in the case of theatrical performers. However, in some cases it can be troubling.

Some appointments raise moral issues for certain interpreters, for example birth control counselling or divorce negotiations. Some interpreting environments may retrieve unpleasant or traumatic personal experiences that have affected the interpreter or her family or friends, for example substance abuse rehabilitation programs or rape crisis centres. The AVLIC Code of Ethics and Guidelines for Professional Conduct precludes inserting personal opinion into the interpretation, but does not oblige the interpreter to have no opinion, or to accept a request for service that causes moral conflict or retrieves traumatic memories. If the substance of the appointment conflicts with the interpreter's values or will entail personal trauma, it is advisable to decline the request as it may be healthier to do so. Some of the trauma of these challenging appointments will be alleviated by accepting that these feelings may occur and it is valid to experience them. A healthy practice is to find an effective outlet such as a support group, counselling or therapy.

Another stressful type of appointment is when the deaf person is in jeopardy or has much at stake. The interpreter is conscious that he plays an important part in the deaf person having a fair trial, receiving an accurate diagnosis of physical or mental conditions, getting a chance at a job, or earning a good mark on a presentation. Ethically, the interpreter must accept only those requests that are within her skill level. It is particularly important that the interpreter decline the request that exceeds her skills, particularly if the consequences could be grave. The business client will not understand that the interpreter was struggling to cope or indeed has missed critical content. The deaf consumers may not have been aware of what was missed. Having accepted the appointment, even the capable interpreter will quite appropriately be conscious of striving to be at her very best in these grave situations. From the perspective of skills, the situation can be invigorating. Psychologically referred to as arousal, potentially serious consequences increase the capacity of the attentional resource, sometimes actually improving performance. At the same time, the physical responses to stress should be respected. Being aware of the stress in the moment, taking care to breathe, relax, and pause when pace permits. After the situation, debrief and acknowledge the stress with self-care.

\section{TIP: Acknowledge the stress of difficult situations when} interpreting disagreeable content.

Situations of oppression or abuse are also emotionally demanding. The interpreter may detect voice intonations that reveal condescension or oppressive intent. The interpreter may know from worldly knowledge that the discussion with the deaf person is not the normal course of discussion for similar events. For instance, a job interviewer may not ask the deaf person a complete set of questions, may ask questions that the interpreter knows are not asked to others, or indeed ask questions that are in violation of the deaf person's human rights. Aside from conveying any observable or audible condescension or oppressive intent through the interpretation, the interpreter should not take responsibility for objecting or protecting the deaf person from this treatment. The need to refrain from correcting injustice may cause unexpected emotional conflicts for the interpreter. To effectively interpret, the interpreter must empathize with the speaker, but in doing so the interpreter uncomfortably becomes the conduit of abuse, obliged to lie, oppress, discriminate, and demonstrate rudeness, prevented by the AVLIC Code of Ethics and Guidelines for Professional Conduct from repairing the damaged situation.

The opposite situation may also be true. The interpreter with prior knowledge of a particular deaf person's situation may feel complicit in the exploitation of a program or demand for unjustified consideration. The AVLIC Code of Ethics and Guidelines for Professional Conduct limits the interpreter to reflecting the deaf person's signed statements using speech and intonation. It is not the interpreter's responsibility to reveal the deaf person's 
misrepresentation. Again, the interpreter is obliged to be the conduit of deceit and abuse, unable to right the wrong.

Emotional abuse and violence is an occupational health hazard in its own right (as was described in Section 3.I.4) but the stress of these situations can also affect the physical performance of interpreting work. Additionally, the demand on attention and working memory content distracts interpreters from awareness of pain and injury. Research has shown that mental stress can cause muscular activation even in the absence of physical exposure, increasing the risk of developing pain and discomfort (Lundberg et al. 2002). For this reason, it is very important to deal with mental stresses through debriefing, counselling, yoga, or various other methods the interpreter finds effective for relieving stress. With sufficient time between appointments, some interpreters may be able to enjoy pleasant music, scenery, or a purposeful walk to and from the car. Others unfortunately will have stress with traffic and parking.

TIP: Follow stressful appointments with stress-relief and self-care practices to reduce emotional distress.

\subsubsection{PHYSICAL EFFECTS OF NON-PHYSICAL WORK: INTERPRETING FROM SIGN LANGUAGE TO SPOKEN LANGUAGE}

Another element of the psychosocial characteristics of the situation is interpreting from sign language to spoken language. If the deaf consumer expresses himself through a spoken language, or if the event is a public lecture without much chance for audience feedback, there may be no call for interpreting from ASL to English. Conversely, if a deaf person consumer is using ASL to make a presentation, interview for a job, or testify in court, then interpreting from ASL to English will be an important part of the appointment. Ethical and proficient interpreters are conscious of the importance of choosing an appropriate level of discourse so that the message reflects an appropriate formality and coherence. If a deaf person is speaking to an audience of professionals, equivalent professional vocabulary and sentence structure in English are called for. In a student peer study group, the interpretation should be of an informal register in the spoken language matching the group's vernacular. If a deaf person is to be diagnosed for mental health symptoms, the spoken interpretation must retain the character of the person's utterances, including intonation.

Although the spoken language may be the interpreter's first language, this native fluency did not include all of the various registers and dialects in that language. People must be alert for new registers and dialects as they encounter them, and be observant of the differences between locker room and law firm, or regional dialect, or disordered thought processes.

The task is not simply retrieving words corresponding to signs, but rendering the message faithfully with all of the form, tone and deeper meaning. The cognitive workload is thus high, although the physical work is largely invisible. However, as with interpretation from English to ASL, muscle tension can increase in response to perceived stress. Tense shoulders may carry over into the signed interpreting. Confidence in signed-to-spoken language interpretation will reduce the stress experienced.

Ongoing professional development plans are as appropriate in the first language as they are in the languages learned later in life.

TIP: To reduce physical stress caused by insecurity and negative feedback, interpreters should continue to develop competency in

the spoken language even if it is the interpreter's first language.

\subsubsection{SPEAKER'S PACE}

The faster the speaker speaks, the more information per unit of time is to be interpreted. The human information processing system describes two alternate strategies for high pace situations. One is to sign very quickly and output the incoming information as quickly as possible. The other is to compile and digest information in working memory and output it in more conventional ASL using more economical movements. Interpreters practice to 
develop fluency in ASL to be able to do the latter. It is not feasible if the working memory "pipeline" is inadequate to hold all the incoming information long enough to do the compilation and linguistic analysis to produce an interpretation. In that case, it will not only result in poor interpretation, but also stress.

Feuerstein and Fitzgerald (1992) suggested a pacing/accuracy trade-off. Although it may result in reduced accuracy, "micro breaks" during interpreting seemed to reduce the risk of injury development.

Further research has examined the relationship between speed of wrist deviations (Marras \& Schoenmarklin, 1993) and interpreting pace (Hagberg et al. 1987) on injury development. Each showed that those having faster wrist movements or those interpreting faster were more susceptible to injury. Research specific to carpal tunnel syndrome and tendonitis suggest that these disorders may be a result of increased friction in muscle tendons which can be caused both by increasing the speed of movements, and the degree of deviation from a neutral posture (Tanzer 1959, Goldstein et al. 1987, Armstong et al. 1987, Remple \& Diao 2004).

The evidence for pace of interpreting as an injury risk is strong when related specifically to the rate and magnitude of wrist movements required to interpret quickly. To ensure their own safety in various interpreting roles, interpreters must adopt strategies to control pace.

Speakers may not realize that interpretation involves grammatical restructuring and is not a straight sign-forword substitution. If they need to moderate their pace, the interpreter may need to make them aware that pausing between sentences or every few sentences is more helpful than pausing between words.

TIP: Ask speakers to moderate their pace or pause, and to speak
one at a time.

Keeping speakers in order can be a difficult objective. More often than not, the deaf consumer has no particular power to control other participants, nor are the other participants particularly responsive to intervention by the interpreter. However participants are responsive to the authority of the party that arranged or hosts the event, and its representative, such as the meeting chairperson. The most efficient method to keep order is to leverage the chairperson's authority over other participants.

In an event such as a meeting, a good chairperson will moderate the speakers for everyone's benefit. Interruption of the discussion by the interpreter is rarely the best resolution to fast paced delivery of information. Forcing the speaker to consciously slow down may derail their train of thought, and the interpreter's interruptions to slow down rapid speakers may even draw resentment to the deaf person. Rather than interrupting during the event, the interpreter and chairperson could agree in advance on a method to signal when a speaker is speaking too quickly or multiple participants are speaking simultaneously. The chairperson may then mediate when the interpreter alerts the chairperson.

These pre-event discussions can be useful orientation for any colleagues not familiar with communication access, and to reinforce the principles that the interpretation is for all participants, not "for" the deaf participants, and that the host is responsible for making the event accessible, while the interpreter is responsible for making the event bilingual.

TIP: Interruptions and stress can be minimized by teamwork with the meeting chairperson prior to and during an event.

\subsubsection{INTERPRETING DURATION}

Recovery from fatigue build-up and microtrauma requires adequate and regular rest. The amount of rest required and the amount of interpreting that can be done before rest is required will vary. It is difficult to make a universal prescription of an appropriate ratio. Research has shown a strong trend that the risk of developing a variety of musculoskeletal injuries is increased by more repetitive movements and greater exposure to forceful situations (Armstrong et al. 1987, Soslowsky et al. 2002, Sharma \& Maffulli 2005). However the scientific evidence does not support any specific prescription for a healthy duration of interpreting exposure. Unfortunately, it is also difficult for the individual interpreter to judge, until early signs of injury are apparent. For many interpreting events, the deaf consumer and business client simply want interpretation to happen for a certain period of time. Neither has 
any particular interest in how many interpreters it takes to accomplish that, other than the economic advantage of one interpreter compared with two.

Most established policies for the maximum duration of solo interpreting currently call for maximum solo appointment duration of I $1 / 2$ hours (NTID Standard Practice paper 1997). AVLIC has advocated the I 1 $/ 2$ hour maximum solo bout since 1993. Unfortunately, these limitations are based on "best practices". Organizations have implemented a $1 \frac{1}{2}$ hour guideline in multi-component interventions that appeared to be generally successful in reducing injury-related absence (Feuerstein et al. 2000, Delisle et al. 2004), providing some empirical support for a $\mathrm{I} 1 / 2$ hour guideline. However, there is no clear evidence that I hour would not be better or that $13 / 4$ hours would not be equally good. There is also lack of explicit definition of what constitutes $I \frac{1}{2}$ hour "interpreting". An appointment that is $75 \%$ stand-by time could easily be an all-day solo appointment as long as the individual bouts were not of excessive duration. Johnson and Feuerstein (2005) further reported that a rotation of interpreters every 20-30 minutes was beneficial in reducing or preventing symptoms. Experimental findings suggested that neither discomfort nor error differed significantly in work-rest intervals of different lengths ranging from 20 to 60 minutes, but noted individual differences in work styles and recommended more frequent short breaks if possible (von Grinsven 2005). Ongoing research is being conducted to collect empirical evidence to determine the allowable duration of single bouts, daily dose, and weekly dose allowances.

Aside from the variation in work pace and cognitive demands from appointment to appointment, one major reason why work-to-rest ratios are scarce in the scientific literature is due to the human variability. One interpreter may be able to work more than another interpreter for any number of reasons ranging from previous injury to age to genetics. General theory and evidence about musculoskeletal injury is summarized in Table 2.

Table 2. Factors increasing and decreasing Work-Rest durations

\begin{tabular}{|c|c|c|c|}
\hline \multicolumn{2}{|c|}{$\begin{array}{l}\text { Length of } \\
\text { time exposed before rest } \\
\text { is needed }\end{array}$} & \multicolumn{2}{|c|}{$\begin{array}{l}\text { Length of } \\
\text { rest required } \\
\text { between exposures }\end{array}$} \\
\hline Increased by & Decreased by & Increased by & Decreased by \\
\hline $\begin{array}{l}\text { Neutral posture } \\
\text { Less joint acceleration } \\
\text { Psychosocial comfort of } \\
\text { the situation } \\
\text { Physical relaxation of } \\
\text { muscles }\end{array}$ & $\begin{array}{l}\text { Non-neutral posture } \\
\text { More joint acceleration } \\
\text { More sign production } \\
\text { outside optimal zone } \\
\text { Psychosocial stress in the } \\
\text { situation or in general } \\
\text { Muscle tension } \\
\text { Fine bone structure/ small } \\
\text { joints } \\
\text { Hormonal or other causes } \\
\text { of swelling } \\
\text { Deconditioning due to } \\
\text { recent work absence }\end{array}$ & $\begin{array}{l}\text { Longer exposure since } \\
\text { previous rest } \\
\text { Symptoms and signs of } \\
\text { injury } \\
\text { Muscle tension (related to } \\
\text { stress or overwork) }\end{array}$ & $\begin{array}{l}\text { Shorter exposure since } \\
\text { previous rest } \\
\text { Good nutrition } \\
\text { Appropriate stress } \\
\text { management }\end{array}$ \\
\hline
\end{tabular}

Many interpreters have been successful at advocating for a team approach for events greater than $1 \mathrm{l} / 2$ hours. Some interpreters have more liberal personal policies and others are more selective about working conditions. All interpreters should be aware that the policies of one interpreter affect another. A hazard in all self-employment is the temptation to earn more income by working longer hours. Self-employed interpreters may have strong economic incentives to accept an appointment of excessive solo length or beyond a healthy week's workload. However, without solidarity, best-practices policies are difficult for an individual interpreter to defend. Continued success requires unity among interpreters such that individuals will not undermine the I $1 / 2$ hour guideline. If interpreters consistently limit solo work to appointment durations that can safely be managed, business clients will become accustomed to using a two-interpreter team for longer appointments. 
Until evidence-based recommendations are available, solidarity among interpreters is critical. Proactive approaches to reducing injury begin with the negotiation of safe working conditions. Do not undermine others who choose to turn down work that does not allow the interpreting tasks to be completed in a safe and relatively risk free environment.

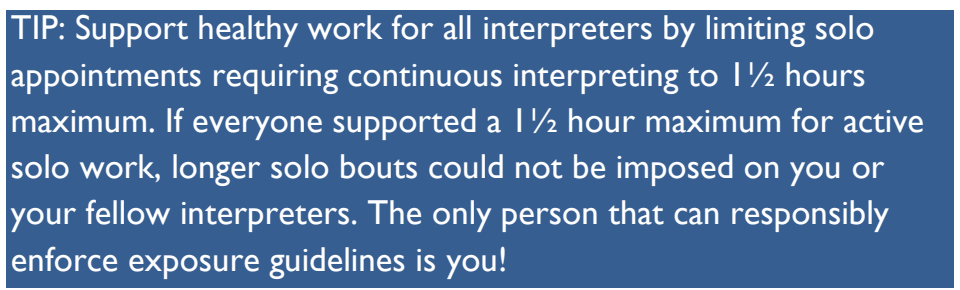

Results from the recent AVLIC survey indicate that those working in full time positions perform solo interpreting 7 hours more per week, on average, than do self-employed interpreters. Full time employed interpreters also reported working a maximum solo bout of $2^{3 / 4}$ hours in the previous normal work week compared to selfemployed interpreters, who worked solo bouts of I hour and 52 minutes. Both exceed the AVLIC recommendation of I $1 / 2$ hour maximum solo duration. Demographic results from the survey showed that full time interpreters tended to be younger, while self-employed interpreters were older. These results have suggested a hypothesis that younger workers may be overworked (due to employers' assignment policy, personal financial need, or social responsibility), leading to early injury onset. When experienced interpreters transition to selfemployment, they may not be able to reduce exposure enough to recover from injuries they have already sustained through overwork earlier in their career.

Solo work for longer appointments could be acceptable if the interpreting is only intermittent. "Rest" time is not just the time that is spent away from the interpreting work-site or unpaid time. Rest includes all non-signing time of reasonable length, including stand-by time such as portions of a class where the teacher is not speaking and deaf students are working independently or with each other without interpretation, or segments of business functions when no interpreted discussion or conversation is taking place. Demanding teamed interpreting for appointments that include substantial inherent rest creates an impression that teamed interpreting is a preference, not a need. The more the interpreter knows about the appointment, the easier it will be to determine and defend an appropriate team composition.

The reverse situation is also true: unpaid periods are not necessarily rest. Occupational health rules of thumb traditionally presume that rest is a period free from exposure to the hazard. Principles used to determine acceptable hazard exposures, such as material handling workloads, or noise exposure are based on 8 hour days, not extended or double shifts. In most cases, this assumption is good. Smelter workers rarely go home to a smelter-temperature home, and foundry workers rarely go home to a 90 decibel home. However in recent decades, the economic environment has led many workers to take second jobs which sometimes involve the same hazards as the first. Workers who perform manual material handling in one job may also lift heavy objects in another. This extra exposure to similar physical demands may interfere with the necessary recovery. Interpreters who have deaf partners or volunteer extensively in the deaf community will be signing outside of the paid work environment and should be particularly careful to rest when experiencing pain. Driving a vehicle mirrors the posture used while interpreting into sign language. Interpreters and students of interpreter education programs should be careful to monitor their part-time employment, computer use, and driving exposure as well as interpreting time. While fatigue from the interpreter's unpaid recreational or overtime work might make teaming desirable in even substantially stand-by appointments, the interpreter should not be surprised if business clients are uninterested in paying for this as many will perceive being fit and ready to work as the employee or contractor's responsibility.

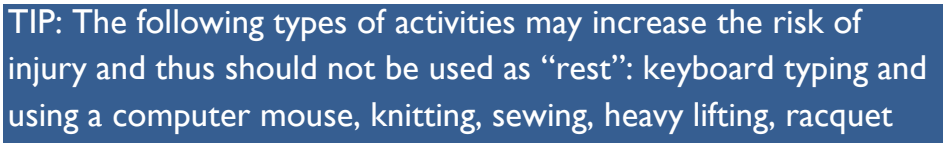


Although research does not support a specific and uniform evidence-based guideline for work-to-rest ratios, each interpreter ultimately can choose a work-to-rest schedule that suits her own feelings and tolerances to work. A ratio is a good choice when it is physically as well as cognitively and emotionally satisfactory. The difficulty arises when an interpreter already has symptoms of pain and fatigue but takes on more work due to financial or social reasons.

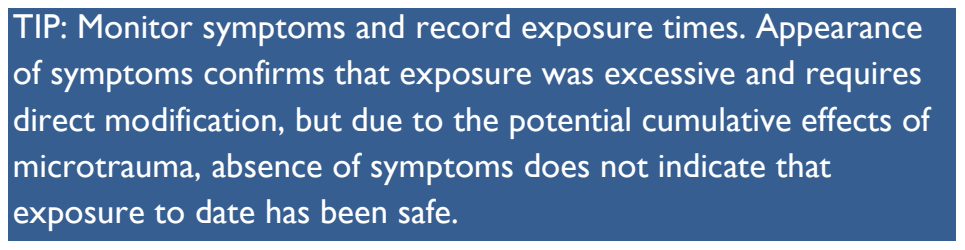

In appointments with two or more interpreters, the duration of each interpreter's turn is negotiated within the team. Turns are typically in the range of 15 to 20 minutes per turn but much variation is seen from team to team and situation to situation. The rhythm of the appointment may suggest a turn-taking schedule. For example, at an event with a series of 20 -minute presentations, it is practical to alternate when the speakers change, to allow the resting interpreter to physically and cognitively relax for an entire presentation. The turns should be long enough to relieve fatigue for the resting interpreter but short enough to avoid excessive fatigue for the working interpreter and to keep the resting interpreter mentally tuned in. Alternating or taking breaks at planned intervals is preferred to working until feeling discomfort or fatigue, as microtrauma may initially be imperceptible. Once fatigue is felt, the recovery requirement is greater.

The $50 \%$ duty cycle is common, and in a "standard work week" of 35-40 hours would equate to 17-20 hours of interpreting per week. However, no information is given on why this value has been chosen. One possible explanation is that it is more convenient to administer than, say a $2 / 3$ or $3 / 4$ duty cycle. One may also speculate an evolutionary basis, in that signed languages evolved to facilitate communication among deaf people, optimizing physical and cognitive components of communication in the visual-spatial channel. In a balanced conversation between equals, the input from each of the communicators is $50 \%$, thus a $50 \%$ "duty cycle" of physical interpreting is plausible. Whether this means that interpreting can be $50 \%$ of any total exposure time is unknown.

TIP: Negotiate multiple breaks/frequent breaks or working in a
team of interpreters when agreeing to terms and conditions of
service provision.

In general, the same total amount of rest time is more restorative when interspersed with shorter work periods than when combined as a single rest after an extended work bout. As a result, the healthy maximum for weekly work hours for an interpreter who works only in teams might be longer than the maximum for an interpreter who works alone and takes longer breaks between appointments. Unfortunately, no empirical evidence is available on either side of this question. Research is still needed to establish specific guidelines but where events are minimally complex, of short durations, and have interpreting teams, rest should be at least $50 \%$ of the length of the event, e.g., 30 minutes' rest after one hour. A greater ratio of rest to completed work should be used after an event that was highly complex, of long duration, or required continuous interpretation. In these more demanding cases, the rest should be at least as long as the event, or possibly longer.

TIP: More frequent short rest is better than infrequent long rest.

\subsubsection{TEMPERATURE}

Some appointments both outdoors and indoors take place in cold environments. When the body is cold, blood circulation to the extremities (hands, feet) is decreased. This results in reduced oxygen to the muscles and build- 
up of waste products. Research has suggested the cold temperatures decrease neuromuscular hand function (dexterity, precision gripping general control of fine finger movements etc.) and while the hand is trying to overcome these deficits by moving more blood into the hand it is at a greater risk of developing injury (Guerts et al. 2005). Temperatures are specific to different tissues and are related to internal body temperatures which tend to be approximately $37.5^{\circ} \mathrm{C}$. Environmental temperatures affect tissue temperatures at varying rates depending on the proximity of the tissue to the skin's surface. For example, some touch receptors are located within the skin layers, making them very susceptible to environmental changes in temperature. Therefore, choosing a position away from drafts may prevent being unnecessarily chilled by air conditioning. Similarly in outdoor interpreting, prepare the event to locate the interpreting position out of the wind. Choose gloves that are warm but not snug. Snug gloves may resist movement, adding a force to be overcome to produce the required signs. Superficial warming strategies such as rubbing hands to create friction warmth may relieve cold-related discomfort, but will not produce the deeper warming to warm the muscles to work. Interpreters with poor circulation should consult a health care professional for advice, or avoid outdoor and cold work.

\subsection{INDIVIDUAL FACTORS}

In addition to the physical workload, both personal physiology and the interpreter's state of mind will affect the physical damage that occurs. These individual differences not only in exposure but in capacity, vulnerability and tolerance for the physical work can vary the onset of symptoms from just a few years to many years, or indeed allow the interpreter to remain free of injury throughout her career.

\subsection{INDIVIDUAL PHYSIOLOGY AND BEHAVIOUR}

Pregnancy and other hormonal changes have been identified in relation to some of the factors above. Balanced hormones and minimal reliance on medications, balanced nutrition, adequate sleep, and good general fitness levels can collectively encourage a healthier body less prone to injury. Factors such as smoking and increased body fat can have a direct influence on your health and perceived pain (Burdorf et al. 1997, Billington et al. 2000, Richardson and Jamieson 2004 ). By maintaining a proper diet, exercising regularly, and limiting your intake of coffee and other caffeinated or artificially sweetened products you will decrease your risk of developing a musculoskeletal soft tissue injury. The Prevention chapter (chapter 7) includes more information about health promotion.

The individual's personal situation can also determine how restorative his rest will be. Interpreters need to ensure that their personal time activities do not inadvertently aggravate the same structures that need rest. Interpreters who do extensive computer work, play musical instruments, engage in certain hobbies, or work on other jobs that use the same body parts are not resting the affected areas just by refraining from signing. An interpreters who does more than incidental driving should ensure that her vehicle seat is supportive and properly adjusted and that she is comfortable while driving.

TIP: Ensure that leisure time is genuinely restorative by avoiding
pastimes that involve joint deviations, repetitive work and
uncomfortable postures.

Many interpreters make extensive use of computers for accessing travel directions, emailing deaf consumers and business clients to obtain appointment preparation material, and communicating with other interpreters. Keyboard use has been recognized as an occupational exposure that increases risk of hand-arm injury. For those who are already at risk or experiencing injuries, some people recommend the use of voice-recognition devices to facilitate text input without typing. However, mistranslations are common and must always be corrected, to avoid training the software to continue to translate incorrectly. This may require more repetition than keyboard entry would require, and if perceived as frustrating, it could contribute to muscle tension rather than the desired relaxation and relief from physical work. Even commercial promoters of voice recognition (e.g., Barksdale, 200I) acknowledge that shifting an inherently excessive workload from hands to voice can cause its own problems and may require 
periods of non-use of the voice. Since the interpreter must retain the use of the voice, this remedy may be only moderately useful.

TIP: If the workload itself is too heavy, transferring it from one
part (hands) to another (voice) may simply relocate the overuse
problem.

\subsubsection{PHYSICAL TENSION}

The interpreting situation has a complex psychosocial character. Psychosocial conditions have become a recognized contributing factor to musculoskeletal injuries. In studies in other industries, workplaces with strict deadlines and less individual control over the work pace have more symptoms than workplaces where workers had some control. Though interpreters may not have control over the physical environments they work in, they do have some control over their working conditions.

The psychological stress the interpreter experiences also has possible physical effects. Muscle tension increases when people are psychologically stressed as the body prepares to escape the perceived danger. During this "fight or flight" response, the body produces cortisol, because it provides things needed for immediate survival, including a burst of energy, heightened memory functions and reduced pain sensitivity. Muscle tension also increases, to enable escape. Although the interpreter is unlikely to run away from the psychosocially stressful situation, this tension felt in the shoulders and arms is an unintended-if not unconscious-response to stress in a very primitive way. Tense muscles may be more susceptible to damage than relaxed muscles, and may require more rest to recover from microtraumas. Practicing relaxation between stressful appointments or bouts of interpreting may help reduce tension and cortisol thereby avoiding the adverse effects of their accumulation.

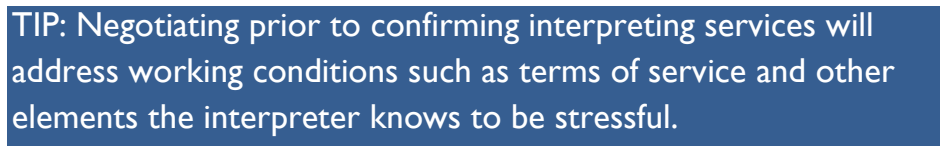

\subsubsection{FITNESS}

Overweight and obesity have been increasing among Canadian adults on the whole, with 34\% overweight and I4\% obese according to the best data available to Health Canada in their Canadian Guidelines for Body Weight Classification in Adults (2003). The general health effects of being overweight have been extensively publicized and will not be further discussed here. However it is important to identify the link between being overweight and musculoskeletal injury risk. A recent review of literature indicated that those with diabetes or weight related factors had an increased risk of developing shoulder pain (Viikari-Juntura et al., 2008). This suggests that interpreters can reduce injury risk to some degree by maintaining a healthy body weight.

In the 2005 survey of AVLIC members, well over half of responding interpreters reported a weight greater than recommended for their height. Body mass index (BMI) is calculated from weight and height: one's weight in kilograms divided by the square of one's height in metres. Overall, $31 \%$ had a BMI between 25 and $30 \mathrm{~kg} / \mathrm{m}^{2}$, identifying them as overweight based on published guidelines (Health Canada, 2003). A further $24 \%$ had BMI >30 $\mathrm{kg} / \mathrm{m}^{2}$, identified as obese. While the number of male responses from the AVLIC survey is too few to compare statistically, $29 \%$ of female interpreters reported weights classified as overweight and $25 \%$ as obese, compared with 25\% overweight and 14\% obese for Canadian women aged 18-74 (Health Canada, 2003).

Sign language interpreting is not an occupation that imposes a high metabolic demand, so interpreters will need to cultivate an active healthy life outside of work.

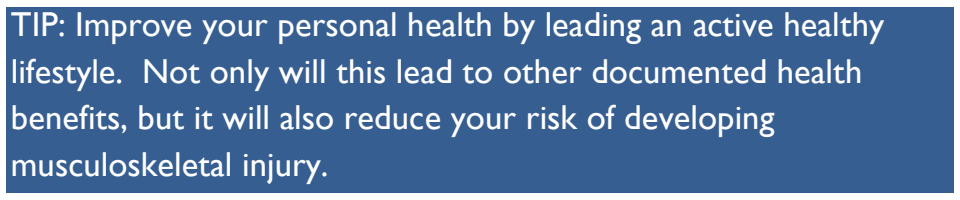


6 TREATMENT AND REHABILITATION OF MUSCULOSKELETAL INJURIES OF SIGN LANGUAGE PRODUCTION

\section{I INJURY AND DISABILITY}

\section{I.I THEORETICAL FRAMEWORK OF HEALTH AND DISABILITY}

The boundary between health and disability is more than vague; it is non-existent. Health and disability are seen to be points on a continuum rather than opposite sides of a coin. In its International Classification of Functioning and Disability (ICF), the World Health Organization (WHO) portrays functional impairments, activity limitations, and participation restrictions arising from the combination of attributes of a whole person. WHO does not even use "disability" as a characteristic of the individual in the current ICF system. Instead, the concepts of "activity" and "participation" are used.

"Functional Impairment" is the anatomical level of the classification. In "impairment", an anatomical structure is absent or non-functional. To use an example familiar to all interpreters, deaf people have absent or non-functional auditory apparatus. This may be due to missing or damaged structures in the ear, breakdown of the cochlea or auditory nerves, or a failure of central processing of sound in the brain.

"Activity Limitation" is the constraint on what the person can do as a result of the functional impairment. An inability to hear interferes with spoken communication and may limit the activities of the deaf person, without interpreters or assistive technology. If an activity is not desirable or necessary for the person, then there is no real activity limitation. For example, a deaf person may wish to paint portraits, not sing opera. In this case, it is the artistic ability, not the inability to hear, that would limit activity.

"Participation Restriction" refers to participation in society, and results from a combination of activity limitations and environmental barriers. For example, if no interpreters are provided, a deaf person may not be able to participate in the School Council where her children go to school and thus she has a participation restriction in parental involvement, although she may have full participation in other areas such as education, work, health, and civic participation other than the School Council.

One effect of the WHO classification is to discourage the perception that "disability" is a characteristic of the person, but that it is rather the combination of the person and the activity. The classification also makes it clear that everyone has some activity limitations, not just those conventionally considered "disabled". The person with the greatest limitation in a particular interpreting situation is not necessarily the deaf person.

However, the WHO classification also expands the scope of "disability" to anyone whose activities are limited by a functional impairment. In the case of musculoskeletal injury, the affected body parts may have limited range of motion that interferes with some desired or necessary activity, such as interpreting. Pain may also create a functional impairment by deterring certain actions. Pain may be absent at rest but occur when signing, or pain at rest may cause the interpreter to refrain from signing.

Unlike impairments of hearing or vision, or limited range of motion, however, pain is subjective. The interpreter must decide whether pain prevents producing signs. The experience of pain is very subjective. For a given degree of physical damage, some people have a higher pain tolerance than others. There is also some evidence that fear of pain can be worse than the pain itself (Ploghaus et al 1999).

Because the experience of pain is subjective, the individual interpreter must determine whether pain exists or whether interpreting work aggravates pain, in conjunction with health professionals. The opinion of the client or consumer or another interpreter has no bearing on whether the interpreter has an injury.

"Musculoskeletal Injuries" comprise numerous individual diagnoses. It would be irresponsible for this Guide to suggest that interpreters diagnose themselves. Obtaining an accurate diagnosis requires consultation with a qualified clinician or therapist. For some people, this is a physician and allied health professionals referred by physicians. Others favour complementary practices, from chiropractic to homeopathy, naturopathy, acupuncture and other complementary practices. Values and beliefs will influence these choices. In view of the complexity, a 
practitioner with experience seeing musculoskeletal injury cases will be better able to determine whether the condition is a musculoskeletal injury syndrome or whether it is a different condition with a superficial resemblance.

\subsubsection{SIGNS AND SYMPTOMS OF INJURY}

Despite the literature linking musculoskeletal injury to interpreting, all soreness of hands and arms is not a workrelated musculoskeletal injury syndrome. The initial soreness of starting a new job or sport is often merely the process of conditioning. The same might occur after an extended vacation or time spent doing different work. When conditioning is lost, it must be regained. An acute injury to the same body parts, such as breaking a fall by landing on the hands, could be aggravated by work exposure to repetitive motion of the arms. A diagnosis of work-related musculoskeletal injury is more likely when symptoms consistently persist or become worse with work exposure and are relieved with rest.

Symptoms are perceptions of the person that cannot be verified by another person. There are numerous symptoms commonly associated with musculoskeletal injuries as discussed in a previous chapter. Interpreters should monitor for these symptoms and take note of the presence of any symptoms that occur after exposure to work and improve at rest. If the symptoms improve but do not entirely disappear with overnight rest, the interpreter should consult a professional.

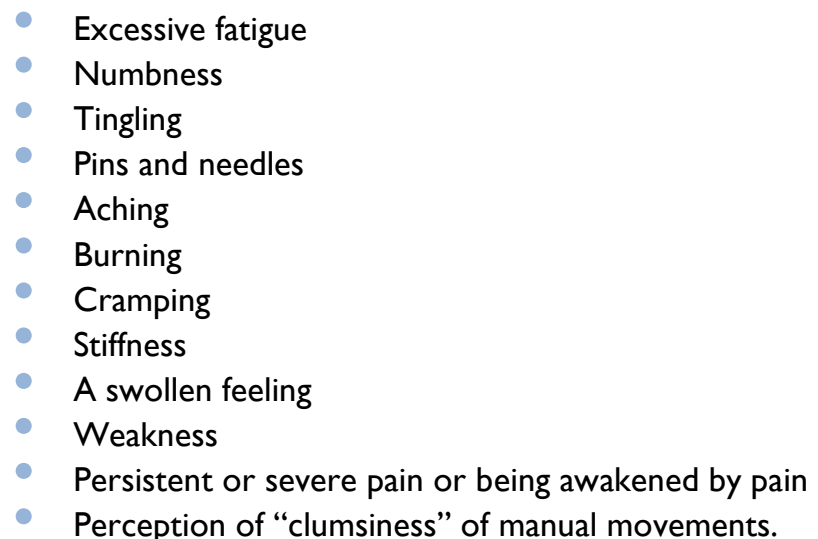

In addition to considering the interpreter's reported symptoms, the professional will examine signs of injury. Signs are clinically apparent indicators of injury. A clinician may note some of the following signs found in musculoskeletal injuries. To identify these signs, the clinician may make use of $x$-rays, electromyography (EMG) and nerve conduction tests as well as asking the patient to make particular movements or positions.

- Discolouration

- Swelling or lumps and bumps

- Abnormal temperature

- Reduced range of motion

- Reduced grip strength

- Reduced sensory perception

- Movements causing pain

- Internal inflammation, depending on the suspected disorder

Many of the signs and symptoms are quite common and on their own could be unremarkable. However, an interpreter should seek clinical evaluation if experiencing a pattern of worsening with signing and improving with rest, and appearance of signs and symptoms in a cluster, particularly the common ones below (Messner \& Bankers 1995).

- Numbness and tingling in the fingers

- Localized pain over a muscle when pressure is applied to it

- Decreased pinch grip strength

- Pain with particular movements (raising the arm, rotation of the forearm etc.) 


\section{I.3 MONITORING AND EVALUATING SYMPTOMS}

The Disability of the Arm Shoulder and Hand (DASH) screening tool (Hudak et al. 1996) may be used to quantify the degree of disability of arm, shoulder or hands. The questionnaire based tool was developed by the Institute of Work and Health. It has been extensively used in studies that track improvement or deterioration over time. Using a series of questions related to your ability to perform normal tasks, a score out of 100 is generated, which can be related to your degree of disability. For example a score of 25 is the lowest possible score and you are considered to have no impairments. A score of 90 however would suggest that you are greatly disabled and should seek medical assistance immediately. As the score increases, your degree of disability increases. Conversely, if your score decreases your disability level is less, meaning you have improved. The DASH is a simple tool to regularly monitor your improvements or declines by testing yourself weekly or monthly. A copy of the DASH survey with instructions is included in the appendix for your own assessment of hand, arm and shoulder disability

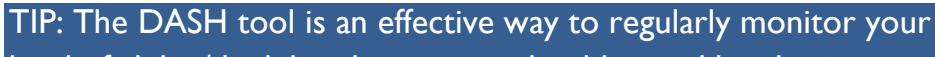

level of ability/disability due to arm, shoulder, and hand pain.

As described in earlier sections, the microtrauma mechanism of musculoskeletal injury onset is one of escalation from a mild and transient pain or discomfort to one that is pervasive and which may even require medical or surgical intervention. Therefore, if you feel any pain and discomfort, you need to take action. If you have pain or discomfort only while working, it is important that you adjust your schedule to ensure adequate rest and recovery, and continue to be proactive in reducing any risk factors identified using this Guide. If your pain or discomfort lingers for two hours after completing the work, you should seek medical advice, and closely monitor symptoms as well as continuing to adjust your schedule, improve your rest and recovery regimen, and implement other strategies in this Guide. If your pain or discomfort can still be felt the next day, under the direction of a medical professional you should consider taking time off, until the pain and symptoms can be reduced.

\subsection{IDENTIFYING AS HAVING A DISABLING INJURY}

The presence of tissue dysfunction does not mean an interpreter will consider herself injured or disabled. Criteria for diagnosis were discussed in a previous section. This section considers identity issues in determining the interpreter's self-identification as injured. Some people can have identical exposure but because of different anatomy and cognitive capacity, one may have no symptoms while another could be in pain. In addition, the differences in tolerance for discomfort will influence self-perception of symptoms.

The attitudes and values of influential support networks and colleagues will influence whether a person will feel encouraged to seek help for symptoms or discouraged from seeking help. A symptomatic interpreter will inherently be trading off her professional goal to be an active and in-demand interpreter, or the community's interpretation needs, against her own comfort and health. She may reframe her "health" as "comfort" and her "need" as "preference". She may in fact believe her symptoms are typical of the experience of other interpreters, and presume since they are continuing to work, that she simply needs more determination to overcome them.

Acquired disability entails a process of identity change. The process involves several stages. The model used in this Guide describes the stages of confusion, comparison, concession, recognition, activism, depression, and synthesis.

TIP: Discuss resolution of psychosocial stress factors as well as
physical symptoms with your clinician.

Confusion is characterised by an emerging awareness of the symptoms as independent phenomena and possibly as a change from former experience. The interpreter may become conscious of pain that did not suddenly appear but was not previously noticed. This stage is sometimes retrospectively called "denial". The interpreter may consider that she has worked for years or decades, therefore work does not seem to explain emergence of new symptoms. New interpreters might associate musculoskeletal injury with long exposure, and not associate this explanation with their pain. The interpreter may have experienced similar symptoms in connection with specific injuries. The non-specific nature of musculoskeletal pain makes it easy to find another explanation. The Institute of 
Work and Health has noted that the chronic stage of most musculoskeletal disorders is usually considered to begin at about 12 weeks post-onset (Hogg-Johnston et al, 1999). Delays in recognition of symptoms can interfere with optimal management of the case. It is not the goal of this Guide to convince interpreters that they are injured when they feel fine. However in the early stages, symptomatic interpreters may not associate their symptoms with the pattern of work-related injury, and this prevents the timely adoption of a coordinated plan to remedy and mitigate the condition.

Comparison is the stage when the symptoms and experiences are compared with others, some of whom have identified themselves with a particular condition. Discussion among interpreters, professional development workshops, and documents such as this Guide can make comparison easier.

Concession is the stage when the person acknowledges the technical similarity of the symptoms with the condition, but may not be ready to identify as a "person with the condition". This stage may be characterized by "bargaining" behaviour. In this stage, the person acknowledges the symptoms and the need to manage them, but imagines that people with the condition have some additional characteristic that he does not have, therefore feels free to use remedies and management strategies selectively. The interpreter may rationalize accepting an excessive appointment by planning not to work the following day. He may find remedies that relieve symptoms and allow him to work because he now has no pain. He regards the symptoms as temporary aberrations. Until the condition deteriorates, there may be no cue prompting progression to the next stage, recognition.

Recognition is the stage when the person has recognized that she has the condition. The interpreter may begin to use terms describing the condition as a whole in self-description rather than describing symptoms individually. The recognition stage may be a temporary transition on the identity change. Progressing on to the next stage is more likely if there is reinforcement of the feeling that musculoskeletal injury can be managed. The interpreter will be more likely to feel comfortable moving forward if there are resources to support people with musculoskeletal injuries and general acceptance of the necessary accommodation strategies. The interpreter will be more likely to move back to concession if other people belittle their concerns and describe musculoskeletal complaints as subjective and a failure of effort, or if they provide sympathetic feedback, special attention, or other rewards for suffering exceptionally. The Institute for Work and Health referred to iatrogenic risks due to "overinvestigation, over-treatment and inadvertent encouragement of a sick role" during the early stages of musculoskeletal injury (Hogg-Johnston et al, 1999).

Activism is the next stage. In activism, the experience of the condition, and the awareness that it affects others, inspires the person to advocate for better diagnosis, better accommodation, better treatment, more respect, consideration, and the like. The activist may feel anger at those who deny their own injuries or the injury experience of others. The activist may be angry at not having been adequately trained or warned. The activist may also be angry at herself for not having taken enough effort to educate or protect herself. The activism can be beneficial in the sense of empowerment, but one risk is that the condition may "spread" to consume the focus of the person's identity in this stage, playing a disproportionate role in life as a whole (Wright, 1960).

Depression is a stage when the person perceives the activism as being ineffective at changing the circumstances around the condition. Loss of income and opportunities to interact with colleagues are legitimate reasons for depression and compound the depression feeling. Those who blame the depression only on the loss of income or activity will fail to appreciate, however, the depression that comes from the disappointment at not being able to control the circumstances that led to the situation.

Synthesis is the stage when the person accepts that the condition is present, circumstances will never fully be perfected, has a set of strategies that allow her to cope, and that there is more to life than fighting against or for the condition.

Transitions through the stages of identity change do not invariably occur in one direction or at a steady pace, nor do all people reach the synthesis stage. The representation of the stages as a sequence does not imply that a later stage is "better" than an earlier stage, although there are more prospects of finding solutions at later stages than earlier ones. However, some people find their personal comfort level at another stage and do not need to 
continue to another stage, or may spend years in a stage before finding that they are ready to move to a new stage.

Optimal management of these injuries at the individual level and across the profession requires a delicate balance between unwisely trying to work through pain, and becoming engulfed in the identity of the condition. Due to the nature of musculoskeletal injury and the risk factors of interpreting work, the interpreter must be careful that effective treatments do not negate self-identification as a person with musculoskeletal injury. Although free of pain, the interpreter who has been symptomatic must always be vigilant of exposure to risk factors to avoid recurrence of pain and potentially worsening of damage.

Successful coping with health challenges has been linked to how meaningful it is to the person to manage her challenge, how comprehensible the challenges are within the explanatory frameworks available to the person, and how manageable the challenge is perceived to be within the resources available (Antonovsky, 1987). Participating in a support group of other interpreters with injuries can validate the injury experience and enhance a sense of belonging to a community. Giving up on coping is less likely if it would extinguish this valued community membership. Belonging to a group can also enhance comprehensibility, since the injured interpreter will not feel singled out by adversity when surrounded by others with the shared experience. Peer support can help management psychosocial elements of the condition and return to work challenges, as well as provide referrals to trusted and empathetic professionals.

\subsection{TREATMENT AND REHABILITATION}

Musculoskeletal injuries are a complex category of many different injuries, affecting a variety of body sites and structures and mechanisms of injury. Because the damage is all inside the body, it can be difficult even for health professionals to diagnose. Therefore this Guide strongly recommends that interpreters do not attempt to diagnose and treat themselves. Rehabilitation from musculoskeletal injury depends on the nature of injury, and is best planned with professional advice from a qualified clinician experienced in work-related musculoskeletal injury. Accordingly this Guide does not recommend a particular rehabilitation program. Rehabilitation can include treatments such as massage, chiropractic, and physical therapy, use of splints to immobilize the joint, surgery, acupuncture, injections, and use of vitamins, anti-inflammatory and analgesic medications. Complementary therapies include relaxation techniques, biofeedback, imagery and meditation.

Individual interpreters may make different choices in the same situation when experiencing a certain type of restricted range of motion or degree of pain. The interpreter's first concern will likely be to recover and be able to return to work as soon as possible.

TIP: Discuss psychosocial stress factors, physical symptoms, and
non-work related health conditions of muscles, tendons and
ligaments with your clinician.

\subsection{SELF TREATMENT}

Many individuals with wrist pain self-administer the use of wrist splints. The splint is designed to immobilize the wrist and is meant to be worn at rest, to avoid flexion, extension, and deviation while sleeping, for example. If the splint is worn while working, producing the intended signs would oblige the tendons to overcome the resistance of the splint. Ordinary signing requires the tendons only to move the mass of the hands and arms themselves. Producing signs against the resistance of the split adds the requirement to apply force to an object, adding another risk factor for musculoskeletal injury. The use of splints should be implemented only on the advice of trained medical professionals, and should be used only as a temporary "crutch" until the tissue begins regeneration.

TIP: Use a wrist splint or wrap only at rest unless a clinician
specifically directs you to use it while signing.

Analgesics and anti-inflammatory medications may be recommended. The interpreter should consult with a health care professional about appropriate dosage and duration of these medications, even at over-the-counter doses. 
Many anti-inflammatory medications can have adverse health implications at prolonged use. If an injury is substantial enough to warrant prolonged use of anti-inflammatory medications, proceed to a medical professional to examine alternative remedies. Depending on the actual tissue injury an anti-inflammatory drug may actually mask important symptoms and reduce the body's ability to heal the injury.

Interpreters who are healing from an injury should give due attention to the psychosocial contributors and effects of injury. Like physical overwork, psychologically stressful working conditions must be remedied or any recovery may be temporary.

TIP: Review prevention practices and address any gaps that may

have led to the injury.

\subsubsection{RETURN TO WORK}

Injury healing time is very specific to each individual and each injury type. Table 3 summarizes the expected healing times for use in a compensation framework for various musculoskeletal injuries. If signs and symptoms are treated appropriately and quickly, these times can be greatly decreased. Conversely, some of these injuries may never completely heal.

Upon return to work, if pain is absent, it can be tempting to resume work as normal. If the absence was required to recover or receive treatment of injury, the past injury experience should be enough to convince the interpreter that the past workload is capable of causing injury. Rather than starting at the old workload as a baseline and reducing from that level, the interpreter should start at a small fraction of that workload and gradually increase, carefully monitoring for signs of fatigue and discomfort. If a lengthy absence was due to unrelated reasons such as family leave, long vacation, or working in other occupations, resuming gradually respects the body's need to recondition to full working capacity.

Table 3. Expected healing times.

\begin{tabular}{lr} 
Expected Healing Times & \\
\hline Soft Tissue Injuries & 3 months \\
\hline Soft tissue injuries (muscle, tendon) & 3 months \\
Knee ligament injuries & $3-6$ months \\
Herniated disc - conservative treatment & \\
\hline Fractures & $4-6$ months \\
\hline Complex facial fractures & $3-6$ months \\
Upper limb & $3-6$ months \\
Hand fractures & 12 months \\
Spinal fractures/dislocations & $6-12$ months \\
Femur and hip fractures & $6-9$ months \\
Tibial fractures & $3-6$ months \\
Other lower limb and foot fractures & 6 months \\
Complex and/or complicated fractures & 6 months \\
Fracture dislocations of major joints (including wrist and ankle) & \\
\hline Infections & $4-8$ months \\
\hline Osteomyelitis & $\ldots$......ntinued
\end{tabular}




\section{Expected Healing Times}

Injuries to the Nervous System

Peripheral nerve injuries

Minor head injuries

Brain injuries with persisting neurological deficit

Spinal cord and cauda equina injuries

\section{POST-SURGICAL HEALING TIMES}

Shoulder arthroscopy

Most other shoulder operations

Knee arthroscopy

Knee arthrotomy

Knee ligament repair

Ankle ligament repair

Spinal fusion

Spinal stenosis decompression

Nervous System

Major nerve repair

Minor nerve repair

Carpal tunnel or other nerve release

Flexor tendon repair or tendon transfer

Extensor tendon repair

Tendon release
3-12 months

3 months

I year

I year

3 months

3-6 months

3-6 weeks

3 months

3-6 months

3-6 months

6-12 months

3-12 months

\section{6-12 months}

4-5 months

3 months

3-6 months

3 months

3 months

Adapted from the Workplace Health, Safety and Compensation Commission (WHSCC) of New Brunswick. 


\section{PREVENTION}

The model of interpreting injury (Figure II) and the previous sections have outlined the multiple interrelated mechanisms of injury. Intuitively, reversing the mechanisms is the pathway to prevention.

The research literature on interpreter injury prevention fails to establish a clear link between specific exposures and injury. The well-known injury prevention program at the National Technical Institute for the Deaf at the Rochester Institute of Technology, based on findings from Feuerstein et al. (2000) successfully used a multidimensional intervention. An intervention at Montréal schools reported by Delisle et al. (2004) used biomechanical and psychosocial interventions separately, reaching inconclusive results. Various interventions helped some interpreters, but did not help all.

The recommendations common to planned programs including interventions related to the period of work, interventions related to work management, and interventions related to musculoskeletal injury control and management. These interventions are summarized in Table 4.

Table 4: Successful interventions to help reduce musculoskeletal injuries in sign language interpreters Interventions Related to the Period of Work

Limit daily and weekly hours

Reduce the duration of a single bout of interpreting

Team interpreting with 2 or 3 person interpreting rotations allows bouts of continuous interpreting to be limited to an agreeable length, such as 15-20 minutes, and also helps limit weekly exposure

Create micro-breaks to help slow the pace, reducing the frequency of hand movements

Interventions Related to Work Management
Improve communication between the interpreter and the business client to enhance subject
matter knowledge, and selective matching between interpreters and jobs or appointments
to ensure interpreters are working at their skill level
Improve subject knowledge to reduce the need for finger spelling
Employers, supervisors and interpreters booking personnel have an obligation to be informed
and provide a climate of health in the work environment
Interventions Related to Musculoskeletal Injury Control / Management
Management, treatment and recognition of musculoskeletal injuries must occur in a timely
manner to be most effective
Use workplace stress management techniques, encouraging the use of support networks to
help "debrief"
Provide information to health care providers on the various injuries and the nature of
interpreting work

These prevention guidelines are qualitative, not quantitative. Furthermore, most programs have been implemented and studied in salaried interpreter pools where it is easier to recruit and maintain research participants. However a significant proportion of interpreters work entirely or partially on a self-employment basis where income is proportionate to work exposure. The model of interpreting injury suggests that economic considerations will be a factor in shaping the work organization (exposure) and stress on the interpreter.

It is each interpreter's individual responsibility to be proactive in injury prevention. Situations will arise where an interpreter will be faced with an undesirable interpreting appointment that may be too long, or contain subject matter with which he may not be familiar. He may feel the need to take some days off to rest emotionally or physically but might ignore that need and continue to work because he cannot accommodate the loss of income. In 
making choices between two risks, it is human nature to favour the one that is more concrete and immediate over one that is theoretical and off in the future, even if it is the more serious risk. This can influence the interpreter to make a short-term-gain choice that has long-term consequences. When comparing two costs, it is also human nature to overlook smaller benefits. Although the immediate days off may entail a loss of income, they may also entail some savings on business expenses such as fuel, parking, meals, dry-cleaning, and other costs that are not incurred on non-working days. It is worthwhile to be realistic about pros and cons of safe work limit.

The nature of the necessary rest depends on the nature of the fatigue. In some cases, the stress is pervasive and outright relaxation is essential. In other cases, the fatigue is simply physical. When physical rest is needed but cognitive rest is not, it opens a window for fulfilling professional development activities.

Allowing adequate time for rest must resolve two of the most compelling factors that lead toward overwork against the interpreter's better judgement: economic necessity and an altruistic need to fill unmet accommodation needs in the community. Financial planning advice can help to control budgeting allowing the interpreter to work within healthy workloads, while being financially responsible. The altruistic drive to fill a community need can be addressed by building a professional network that can back up each other's appointments when an activity is likely to be beyond emotional, cognitive, or physical limits.

Scheduling of appointments should take into account the physical, cognitive and emotional work of the individual appointments and the cumulative work of consecutive appointments. For instance fast-paced or lengthy solo interpretation is physically demanding. There is a high cognitive load in terminologically rich situations or appointments where interpreting errors and miscues could have grave consequences for either party.

Interpretation of oppressive or exploitive interactions or discussion of sensitive or tragic experiences imposes a heavy emotional weight. It is often better to rotate work demands among different types of work rather than deliberately scheduling consecutive appointments with the same type of demand, but some demands might be so extreme that a scheduled rest break may be required. Team interpretation can prevent physical overload by building rest into the scheduled appointment time, aid cognitive workload by providing backup for messageequivalent interpretation, and also serve as a debriefing partner to relieve emotional stress.

Table 5 presents a hypothetical work week for a community interpreter, illustrating these principles. This schedule is not intended to be a "recommended ideal" schedule, but rather an example which shows that exposure limits can be incorporated even when teaming is not always available. Where "teaming" is indicated, interpreters will alternate roles every 15-20 minutes. The hypothetical interpreter respected her boundaries and declined an appointment involving troublesome content and appointments that would have been back to back with the appointments she already had booked. She negotiated a teamer for two 90 minute appointments that were too complex or unfamiliar to tackle solo. At the start of the day and after longer breaks, the interpreter does a warmup before interpreting, and when teaming, clarifies team roles and rotation schedule on arrival. She uses time between appointments for travel and for administration, following up on invoices, reviewing preparation materials for upcoming appointments and contacting clients about requested appointments to determine the duration, travel time, complexity, need for teaming and other information. She keeps in contact with regular clients and cultivates follow-up appointments, such as her Tuesday and Friday afternoon solo appointments, where she finds the 90minute appointment quite manageable because she interprets the same events with the same participants on a regular basis. While administration activities are essential components of her professional work, she can control the pace and posture of physical activities such as keyboarding to avoid discomfort or fatigue to the muscle groups used in sign production. Furthermore, by contributing to a sense of control over her situation, they may even alleviate stress. She has a short evening appointment on one day and accepted a half-day teamed appointment on Saturday of this week, but she has kept Sunday for personal and family time. She makes a point to break for lunch each day, and to exercise through the week, realizing that overall fitness and nutrition benefits her hand-arm health. In driving between appointments, and in personal activities such as cooking and child care, she is sensitive of fatigue cues to avoid interfering with recovery from sign production. Every interpreter will apply these principles in a unique way depending on the clients and consumers to be accommodated. When the only calls an interpreter receives are for back-to-back 2-hour solo appointments, it can be tempting to despair of achieving a healthy and 
economically sustainable schedule, but the possibility of developing a cumulative injury is too high to accept backto-back 2-hour solo appointments, even only 20 hours/week. Networking can be of great value for more than peer support, as other interpreters may have excess service requests on an opposite schedule, or be available to fill in when it is necessary to withdraw from a committed appointment to recover from fatigue. The resourceful interpreter with healthy boundaries will place a high priority on achieving a balanced weekly schedule.

Table 5. Example of a safely organized work week of 20.5 hours with "hands in the air"

\begin{tabular}{|c|c|c|c|c|c|c|c|}
\hline TIME & Monday & Tuesday & Wednesday & Thursday & Friday & Saturday & Sunday \\
\hline 7:00 & \multirow{3}{*}{$\begin{array}{l}\text { Wake up and } \\
\text { get ready for } \\
\text { the day }\end{array}$} & \multirow{3}{*}{$\begin{array}{l}\text { Wake up and } \\
\text { get ready for } \\
\text { the day }\end{array}$} & \multirow{3}{*}{$\begin{array}{l}\text { Wake up and } \\
\text { get ready for } \\
\text { the day }\end{array}$} & \multirow{3}{*}{$\begin{array}{l}\text { Wake up and } \\
\text { get ready for } \\
\text { the day }\end{array}$} & \multirow{4}{*}{$\begin{array}{l}\text { Wake up and } \\
\text { get ready for } \\
\text { the day }\end{array}$} & & \\
\hline $7: 30$ & & & & & & & \\
\hline $8: 00$ & & & & & & Wake up & \\
\hline $8: 30$ & \multirow{2}{*}{ Exercise } & \multirow{2}{*}{$\begin{array}{l}\text { Travel, warm- } \\
\text { up, negotiate } \\
\text { team roles }\end{array}$} & \multirow{2}{*}{ Exercise } & \multirow{2}{*}{$\begin{array}{c}\text { Travel - } \\
\text { warm-up upon } \\
\text { arrival }\end{array}$} & & $\begin{array}{l}\text { and get } \\
\text { ready for }\end{array}$ & \\
\hline $9: 00$ & & & & & \multirow{2}{*}{$\begin{array}{l}\text { Travel, warm- } \\
\text { up, negotiate } \\
\text { team roles }\end{array}$} & the day & \\
\hline $9: 30$ & \multirow{2}{*}{$\begin{array}{l}\text { Travel, warm- } \\
\text { up, negotiate } \\
\text { team roles }\end{array}$} & \multirow{6}{*}{$\begin{array}{c}\text { Teamed } \\
\text { interpreting } \\
\text { appointment }\end{array}$} & \multirow{2}{*}{$\begin{array}{c}\text { Travel - warm- } \\
\text { up upon } \\
\text { arrival }\end{array}$} & \multirow{2}{*}{$\begin{array}{c}\text { Solo } \\
\text { interpreting } \\
\text { appointment }\end{array}$} & & \multirow{2}{*}{$\begin{array}{c}\text { Travel, } \\
\text { warm-up, } \\
\text { negotiate } \\
\text { team roles }\end{array}$} & \\
\hline $10: 00$ & & & & & \multirow{6}{*}{$\begin{array}{c}\text { Teamed } \\
\text { interpreting } \\
\text { appointment }\end{array}$} & & \\
\hline $10: 30$ & \multirow{3}{*}{$\begin{array}{c}\text { Complex } \\
\text { interpreting } \\
\text { appointment- } \\
\text { Teamed }\end{array}$} & & \multirow{2}{*}{$\begin{array}{l}\text { Solo } \\
\text { interpreting } \\
\text { appointment }\end{array}$} & Travel & & & \\
\hline II:00 & & & & & & Teamed & \\
\hline $11: 30$ & & & Travel & Aaministration & & appointment & \\
\hline Noon & Travel & & \multirow[b]{2}{*}{ Lunch } & \multirow[b]{2}{*}{ Lunch } & & & \\
\hline $\begin{array}{r}12: 30 \\
\text { PM }\end{array}$ & \multirow{2}{*}{ Lunch } & Travel & & & & Travel & Free time \\
\hline $1: 00$ & & \multirow[b]{2}{*}{ Lunch } & \multirow[b]{2}{*}{ Administration } & \multirow{2}{*}{$\begin{array}{l}\text { Travel, warm- } \\
\text { up, negotiate } \\
\text { team roles }\end{array}$} & \multirow[b]{2}{*}{ Lunch } & \multirow[b]{2}{*}{ Lunch } & \\
\hline $1: 30$ & \multirow{2}{*}{$\begin{array}{l}\text { Travel - warm- } \\
\text { up upon } \\
\text { arrival }\end{array}$} & & & & & & \\
\hline $2: 00$ & & \multirow{2}{*}{$\begin{array}{c}\text { Travel - } \\
\text { warm-up upon } \\
\text { arrival }\end{array}$} & \multirow{2}{*}{$\begin{array}{l}\text { Travel, warm- } \\
\text { up, negotiate } \\
\text { team roles }\end{array}$} & \multirow{5}{*}{$\begin{array}{c}\text { Team } \\
\text { interpreting } \\
\text { appointment }\end{array}$} & \multirow[b]{2}{*}{ Administration } & & \\
\hline $2: 30$ & Solo & & & & & Exercise & \\
\hline $3: 00$ & $\begin{array}{l}\text { Interpreting } \\
\text { appointment }\end{array}$ & & $\begin{array}{c}\text { Complex } \\
\text { interpreting }\end{array}$ & & Travel - & & \\
\hline $3: 30$ & Travel & $\begin{array}{l}\text { Solo } \\
\text { interpreting } \\
\text { appointment }\end{array}$ & $\begin{array}{c}\text { appointment- } \\
\text { Teamed }\end{array}$ & & $\begin{array}{l}\text { warm-up upon } \\
\text { arrival }\end{array}$ & & \\
\hline $4: 00$ & & & Travel & & & Fren time & \\
\hline $4: 30$ & Admınıstration & Travel & & Travel & $\begin{array}{l}\text { Solo } \\
\text { interpreting }\end{array}$ & rree time & \\
\hline $5: 00$ & & & Dinner & & appointment & & \\
\hline $5: 30$ & Dinner & Administration & & Dinner & Travel & & \\
\hline $6: 00$ & & & Travel & Exercise & & & \\
\hline $7: 00$ & & Dinner & $\begin{array}{c}\text { Solo } \\
\text { appointment }\end{array}$ & & Dinner & & \\
\hline $8: 00$ & Free time & & Travel & Free time & & Free time & Free time \\
\hline $\begin{array}{l}9: 00 \\
10: 00\end{array}$ & 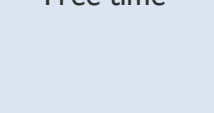 & Free time & Free time & & Free time & & \\
\hline $11: 00$ & Go to bed & Go to bed & Go to bed & Go to bed & Go to bed & Go to bed & Go to bed \\
\hline
\end{tabular}




\section{I CONDITIONING}

Exercise specialists speak of conditioning or "work hardening". Gradually increasing weights and repetitions with each additional workout at the gym strengthens muscles. The principle can apply to physical work in remunerative employment as it does with exercise. Muscles and tendons have a great ability to adapt to new conditions. Conditioning can increase strength and endurance. However, the level of training plays a large role in how effectively training will improve function. A schematic representation of the importance of training level is illustrated in Figure 17.

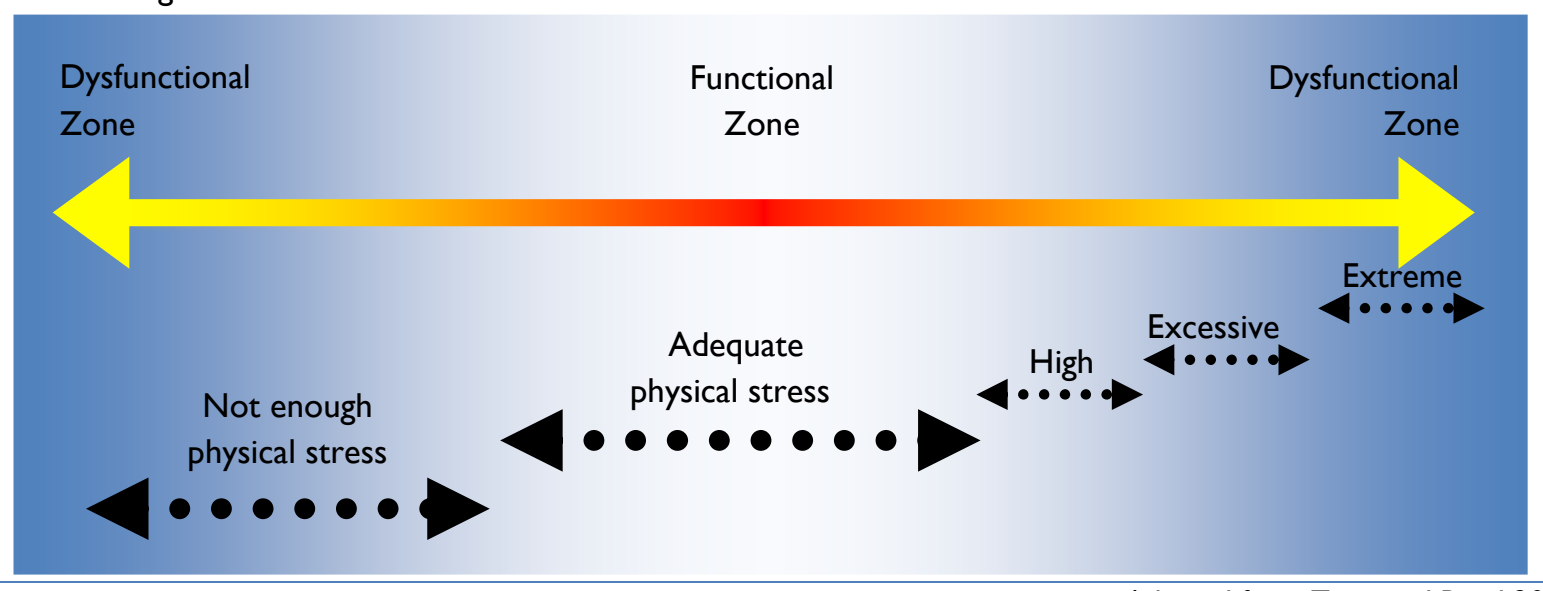

Figure 17. Continuum of physical stress states

Using this continuum-based approach, interpreters could improve style and motion patterns by training the wrist motions commonly used in interpreting. For example, choose a few common signs and practice using those signs with attention to joint postures and range of motion. Try to sign without pushing your wrist motions to their end range, and complete them at a moderate to slow speed. This is somewhat counterintuitive in that the training is at a rate less than what an interpreter would undergo during a normal interpreting session. Full range and full speed movements during training could cause damage and fatigue to build prior to muscle adaptation. Normal interpreting is much too strenuous to allow for proper adaptation and rest, and would often fall with in the High to Extreme categories highlighted in the continuum. Tissue conditioning occurs when the tissue has been challenged at a high enough level to cause tissue rebuilding and regeneration, but not so high that the tissue is breaking down at a faster rate the rebuilding and regeneration can occur.

TIP: An effective conditioning exercise is to use common signs but
with motions and speed that are less extreme than the actual
work activity would require.

Conditioning will not prevent all injury. For instance if a nerve is pinched by swelling of an inflamed tendon, lack of muscle conditioning is not to blame. However, strength and endurance training provides a number of benefits. Conditioning will reduce the risk of developing injuries, and also improve posture, increase stability, build stamina and fatigue resistance and encourage a healthier quality of life. Exercise is associated with an increase in endorphins (Carr et al. 1981; Camacho et al. 1991) which can enhance attention, motivation, and learning retention (Johnson et al. 1992). Strength conditioning should be completed 2-5 times per week. Conditioning exercises should include a series of weight-bearing activities that challenge the various muscles of the body while maintaining proper body postures.

When choosing exercise, it is important to choose activities that will hold your interest. Some people prefer a variety of fun and refreshing activities. Others prefer a steady routine. A wide range of activities can be use for strength training including hiking, weight resistance training (in a gym or at home), Pilates, fitness classes, off road biking, horseback riding, yard work (tree trimming, mowing grass etc.) or any other activity that challenges a 
number of body parts. Pilates, martial arts, yoga, and weight resistance training are particularly beneficial to joint stability and body posture.

Endurance training may be completed separately or concurrently with a strength training bout and should provide you with 30-45 minutes of moderate to vigorous activity. Endurance activities include but are not limited to walking, jogging, cycling, swimming, soccer, basketball, hockey, tennis, squash, fitness classes, martial arts / self defence classes etc.

The main outcomes of any fitness program should be to improve general health and well-being. An improvement in body posture and joint stability should be noticeable during interpreting. Other health benefits should be normal blood pressure, resting heart rate between $60-74$ beats per minute, and a body mass index below $25 \mathrm{~kg} / \mathrm{m}^{2}$. Consult a local fitness center or personal trainer for advice on proper technique and exercises to safely and effectively achieve your fitness goals.

TIP: Every person is suited to different activities by body type and
by temperament. Experiment and find activities for strength
training and endurance training that you enjoy and can complete
regularly. If you don't enjoy an activity, then any benefits you gain
from participation in it may be overshadowed by the increase in
stress and discomfort brought out by having to complete it!

\subsection{WARM-UP}

Warm-up and active stretching prior to interpreting may help enhance flexibility. Warm-up exercise increases blood flow to your muscles. Blood flowing to your muscles brings nourishment and gets rid of waste by-products in the muscle tissue. Improved circulation can help shorten recovery time from muscle injuries.

Increase blood flow to the muscles prior to interpreting by doing a proper warm-up that includes brief movements that give the fingers and arms an opportunity to complete a range of movements and increases muscle temperatures. A brief warm-up also provides adequate time to mentally prepare for the task. A typical warm-up should last 5 to 10 minutes.

A warm-up might include some level of light cardiovascular exercise, followed by some light stretching of the hand and wrist, shoulders and neck. Table 6 and Figure 18 provide an example of a warm up, with stretching examples. Notice how brief and practical such a warm-up can be!

Table 6. Warm up schedule

\begin{tabular}{cc} 
Exercise & Time \\
Brisk walk up/down 3-4 flights of stairs & $2-3$ minutes \\
Wrist circles & 30 seconds \\
Wrist stretches & 15 seconds per stretch \\
Arm circles & 30 seconds \\
Shoulder stretches & 15 seconds per stretch \\
Shoulder rolls & 30 seconds \\
Neck rolls & 30 seconds \\
\hline
\end{tabular}


Figure 18. Warm up stretches

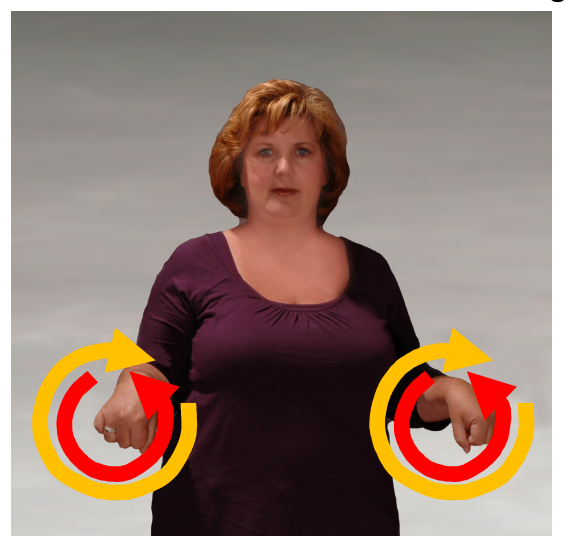

Wrist circles: with upper arms neutral, circle wrists both clockwise and counterclockwise.

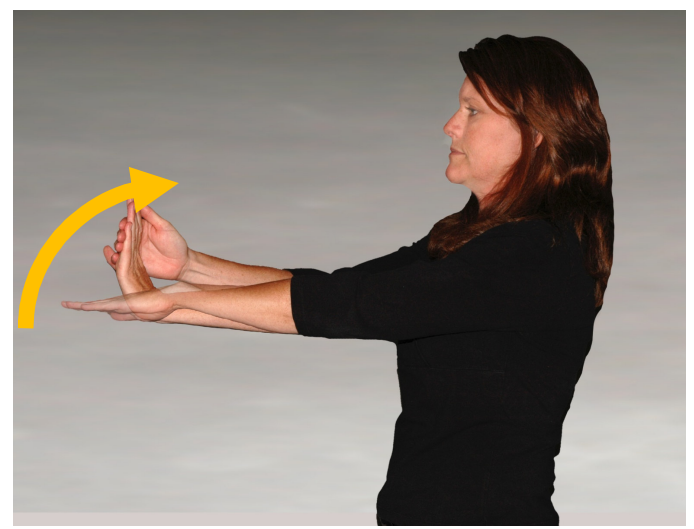

Upward wrist stretch: use free hand to gently stretch hand back from wrist

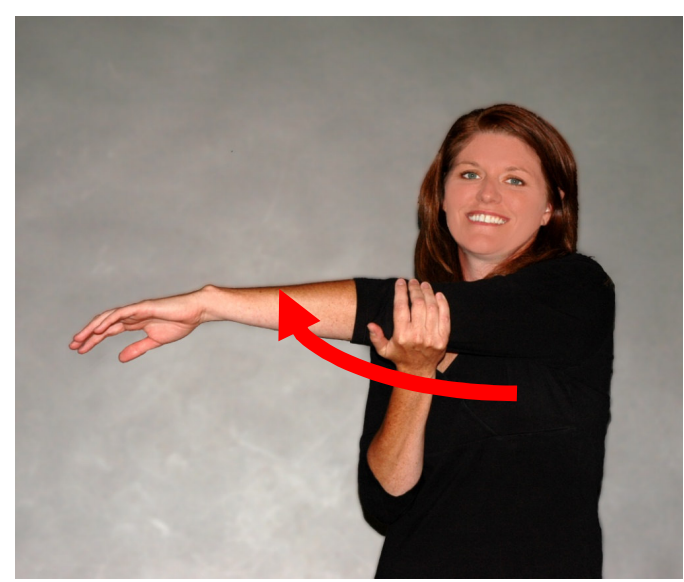

Cross body shoulder stretch: use free hand to pull elbow in and across body

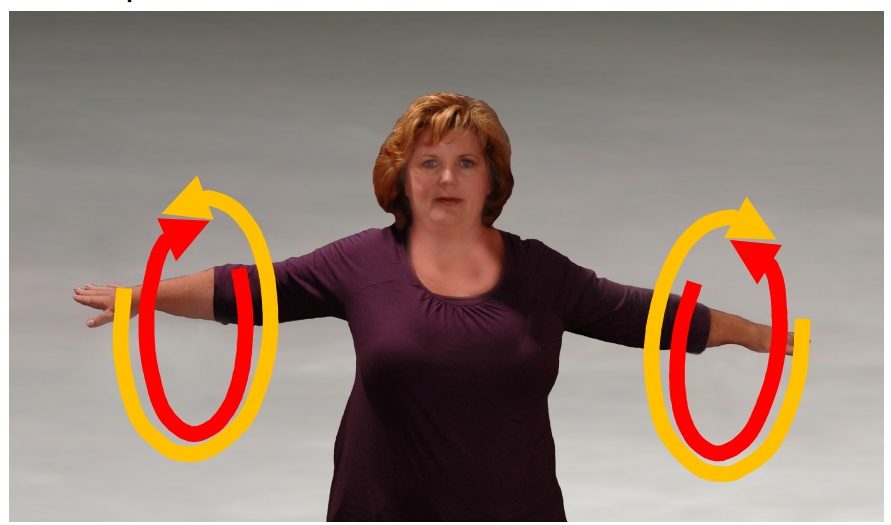

Arm circles: with arms out to sides as shown, circle arms in small circles both forward and backward.

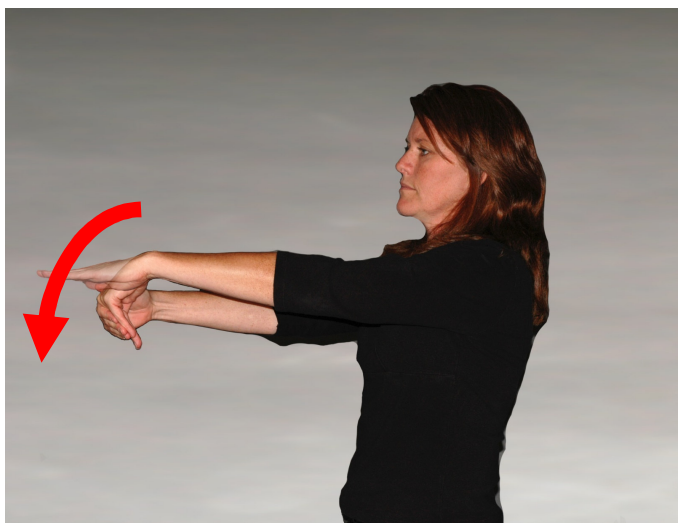

Downward wrist stretch: use free hand to gently stretch hand down toward palm

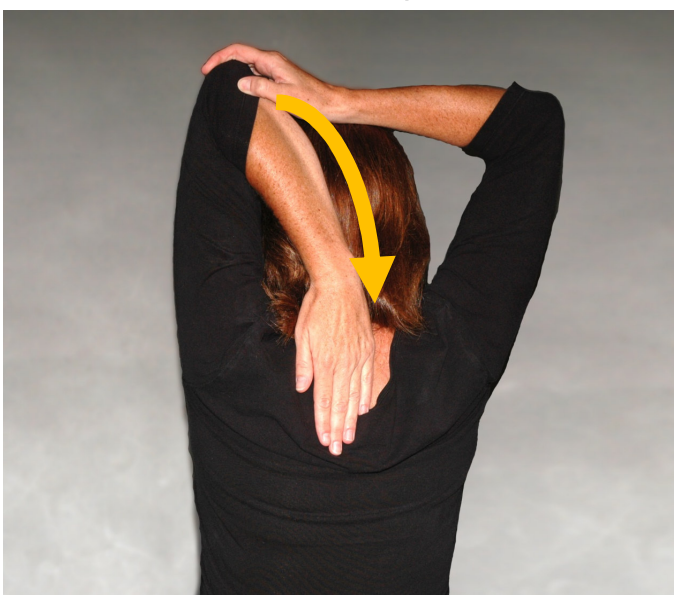

Shoulder stretch overhead: use free hand to pull elbow down, stretching the hand down between the shoulder blades. 


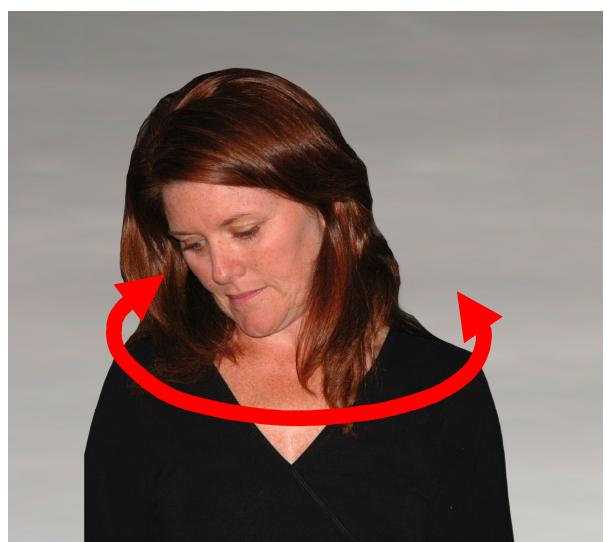

Neck rolls: drop chin to chest and circle head clockwise and counter-clockwise, stretching ears toward shoulders with shoulders relaxed and down, but avoid full-circle head rolls to the back.

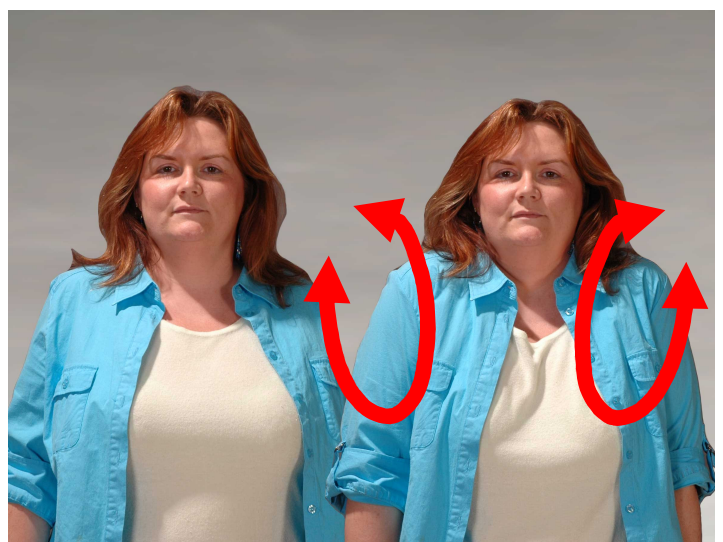

Shoulder rolls: circle shoulders in both directions-forward and backward - stretching as far up, back, down and forward as possible.

\subsection{RELAXATION}

Since the cognitive component of interpreting has such an important effect on the physical response, interpreters who feel stressed should set aside time for relaxation, dealing promptly with emotional reactions to problematic appointments. Everyone reacts to pressures differently and finds different things relaxing. For some it might be a routine of daily aromatherapy soaks, and for others, it may be a week of whitewater rafting once a year.

Relaxation should be sufficient to release physical tensions that may have accumulated. The interpreter should be able to get a good night's sleep, have comfortable range of motion, and be free from a sense of tension.

The interpreter who has a cordial relationship with the Deaf community and other interpreters (or avoids appointments entailing friction) will likely need less remedial relaxation than one who is worried about being criticized.

\subsection{PREPARATION}

The current standard of professionalism entails preparing for appointments to interpret to the best of the interpreter's ability. Preparation includes reviewing available materials for content such as terminology and names, and reflecting on the conceptual structure of the subject matter. Obtaining materials in advance may be effective in reducing the stress of an event. However, business clients are not always able to comply and deaf consumers are not always in favour of aggressive approaches to obtain preparation materials, as they may fear subtle retaliation for the imposition that results.

Having made the best effort reasonable in the circumstances, the interpreter should not dwell on the "more perfect" interpretation that would have been possible if materials had been available or more time allowed. Discussing this with the deaf consumers can alleviate these concerns. Consumers are not adequately served by skipping content or lackadaisical form, but there are cases where the consumer is familiar with the content and can put the interpreter's subject matter concerns at ease if the situation is discussed ahead of time. In other cases such as credit courses or legal matters, the deaf consumers can reinforce with the business, institution, or school that preparation is required, and can ally with the interpreter to have it provided.

Charging separately for preparation is interpreted differently in different contexts. Consultants and lawyers demand and receive fees for all work on the client's file, but usually have elaborate fee schedules, different rates for courtroom appearances, work done in the office, and travel time (only when not performing services billed to other clients, of course) and a high rate for the partner and a low rate for the junior associate. Consultants and lawyers, however, produce a tangible work product that the client retains, while the interpreter's service unfortunately has no lasting tangible "product". In performing arts settings, the need for rehearsal is a familiar and even self-evident, so a contract for interpretation of a performance could perhaps leverage this familiar concept. In 
other settings, while there may be no disagreement about the need for preparation, a client engages a professional in the same way she hires an employee: selecting someone who is prepared to step into the position. When hiring a tradesperson to service an appliance, the homeowner is willing to pay for a functional appliance, not for the time required to review manufacturer's documentation to learn how that model works, no matter how necessary that preparation is to the successful service. The homeowner assumes that the tradesperson's fee includes preparation as a factor in the hourly rate for that category of service. Services entailing much preparation are billed at a higher hourly rate than services entailing negligible preparation. The point of this brief discussion is to encourage interpreters to incorporate preparation into the hourly fee for a particular category of service rather than increasing stress levels arguing with clients about the importance of preparation.

TIP: Preparation can be a tool to reduce stress and even physical workload, not just better accuracy of interpretation.

\subsection{GOOD HEALTH}

Interpreters who are in good general health will be in a better position to manage stresses of all kinds. Good health includes good nutrition, healthy exercise, not smoking, driving safely, and managing occupational hazard exposures. The latter was covered in Chapter 3, but this section provides links to other guidance for good health.

Health Canada has produced Canada's Food Guide (Appendix 3). This guide is the current gold standard for nutrition in Canada. On the Health Canada website www.hc-sc.gc.ca, users may obtain more information about incorporating cultural traditions and customizing the Food Guide to age, sex, and food preferences. Healthy Exercise guidelines and suggestions can be found at the Public Health Agency of Canada - Physical activity website www.phac-aspc.gc.ca/pau-uap/paguide/index.html or visit the website for Canadian Council for Health and Active Living at Work at www.cchalw-ccsvat.ca/. Smoking cessation programs may be located through the local public health unit and found online at www.hc-sc.gc.ca/hl-vs/tobac-tabac/quit-cesser/now-maintenant/index_e.html.

\subsection{VEHICLE MAINTENANCE}

Many interpreters travel between appointments by personal vehicle, and maintaining one's vehicle in good condition and driving safely are essential components of occupational and public health. Many work-related fatalities are due to motor vehicle collisions. Traffic collisions comprise $43 \%$ of occupational fatalities in the U.S., where statistics are compiled on the national level by the Bureau of Labor Statistics, are by far the leading cause of work-related death. Self employed interpreters who drive between appointments should take defensive driving and skid control courses to be better equipped to react to traffic and road conditions. Agencies that send interpreters to appointments by car should provide this training. 


\section{CLOSING REMARKS}

This Guide has been developed to help provide a more detailed understanding of the processes involved in sign language interpreting as they affect the body. The document tips are based on a best evidence approach as presented by the scientific literature at this time. While this Guide has been peer reviewed by members of the academic community, new knowledge is continually evolving. This Guide cannot anticipate all possibilities and concerns. Rather, it attempts to illustrate a variety of principles to help enlighten your understanding of musculoskeletal troubles and the other occupational health and safety concerns that affect interpreting work. The authors' goal is to help provide you with enough sound evidence and tools to help guide your workplace decisions in a manner that will greatly reduce your risk of developing any type of occupationally related dysfunction. 


\section{REFERENCES}

Andersen, J., Kaergaard, A., Frost, P., Frolund Thomsen, J., Bonde, J., Fallentin, N., Vilhelm, B., \& Mikkelsen, S. (2002). Physical, Psychosocial, and individual risk factors for neck/shoulder pain with pressure tenderness in the muscles among workers performing monotonous, repetitive work. Spine, 27, 660-667.

Antonovsky, A. (1987). Unravelling the mystery of health: How people manage stress and stay well. San Francisco: Jossey-Bass Publishers.

Armstrong, T., Buckle, P., Fine, L., Hagberg, M., Jonsson, B., Kilborn, A., Kuorinka, I., Silverstein, B., Sjogaard, G., \& Viikari-Juntura, E. (1993). A conceptual model for work-related neck and upper limb musculoskeletal disorders. Scandinavian Journal of Work and Environmental Health, 19, 73-84.

Armstrong, T., Castelli, W., Evans, G., \& Diaz-Perez, R. (1984). Some histological changes in carpal tunnel contents and their biomechanical implications. Journal of Occupational Medicine, 26, 197-20I.

Armstrong, T., Fine, L., Goldstein, S., Lifshitz, Y., \& Silverstein, B. (1987). Ergonomic consideration in hand and wrist tendinitis. Journal of Hand Surgery, 12A, 830-837.

Arnott, F., Edworthy, S., Bloch, D., McShane, D., Fries, J., Cooper, N., Healey, L., Kaplan, S., Liang, M., Luthra, H., Medsger Jr, T., Mitchell, D., Neustadt, D., Pinals, R., Schaller, J., Sharp, J., Wilder, R., \& Hunder, G. (1988). The american rheumatism association 1987 revised criteria for the classification of rheumatoid arthritis. Arthritis and Rheumatism, 3I, 3I5-323.

Barbe, M. \& Barr, A. (2006). Inflammation and the pathophysiology of work-related musculoskeletal disorders. Brain, Behavior, and Immunity, 20, 423-429.

Barksdale, K. (200I). We have an epidemic on our hands. www.speakingsolutions.com/news/epidemic.asp. Accessed June 2006.

Barr, A., Barbe, M., \& Clark, B. (2004). Work-related musculosketetal disorders of the hand and wrist: Epidemiology, pathophysiology, and sensorimotor changes. Journal of Orthopaedic and Sports Physical Therapy, 34, 610-627.

Billington, C.J., Epstein, L.H., Goodwin, N.J., Hill, J.O., Pi-Sunyer, F.X., Rolls, B.J., Stern, J., Wadden, T.A., Weinsier, R.L., Wilson, G.T., Wing, R.R., Yanovski, S.Z., Hubbard, V.S., Hoofnagle, J.H., Everhart, J. \& Harrison, B. (2000). Overweight, obesity, and health risk. Archives of International Medicine, 160(7), 898-904.

Burdorf, A, \& Sorock, G. (1997). Positive and negative evidence of risk factors for back disorders. Scandinavian Journal of Work and Environmental Health, 23(4), 243-256.

Camacho, T.C., Roberts, R.E., Lazarus, N.B., Kaplan, G.A., Cohen, R.D. (1991). Physical-activity and depression evidence from the Alameda county study. American Journal of Epidemiology, 134(2), 229-23I.

Carr, D.B., Bullen, B.A., Skrinar, G.S., Arnold, M.A., Rosenblatt, M., Beitins, I.Z., Martin, J.B., McArthur, J.W. (I98I). Physical conditioning facilitates the exercise-induced secretion of beta-endorphin and beta-lipotropin in women. New England Journal of Medicine, 305 (10), 560-563.

College of Family Physicians of Canada (2007) Alcohol — what to do if it is a problem for you. http://www.cfpc.ca/English/cfpc/programs/patient education/alcohol/. Accessed December 2007.

Conboy, I. \& Rando, T. (2005). Aging, stem cells and tissue regeneration. Cell Cycle, 4, 407-4I0.

DeCaro, J., Feuerstein, M., \& Hurwitz, A. (1992). Cumulative trauma. Disorders among educational interpreters: Contributing factors and intervention. American Annals of the Deaf, 137, 288-292.

Delisle, A., Durand, M., Imbeau, D., \& Larivière, C. (2007). The effects of two interventions on persistant pain: a multiple single-case study among sign language interpreters. International Journal of Industrial Ergonomics, 37, III-I23. 
Delisle, A., Durand, M., Imbeau, D., Larivière, C. (2004). Suivi de deux interventions visant la prévention des troubles musculo-squelettiques aux membres supérieurs en milieu de travail. IRRST Document R-379.

Delisle, A., Larivière, C., Imbeau, D., \& Durand, M. (2005). Physical exposure of sign language interpreters: baseline measures and reliability analysis. European Journal of Applied Physiology, 94, 448-460.

Ewing, J.A. (1984). 'Detecting Alcoholism: The CAGE Questionaire'. Journal of the American Medical Association 252: 1905-1907.

Feuerstein, M. \& Fitzgerald, T. (1992). Biomechanical factors affecting upper extremity cumulative trauma disorders in sign language interpreters. Journal of Occupational Medicine, 34, 257-264.

Feuerstein, M., Carosella, A., Burrell, L., Marshall, L., \& DeCaro, J. (1997). Occupational upper extremity symptoms in sign language interpreters: Prevalence and correlates of pain, function, and work disability. Journal of Occupational Rehabilitation, 7, 187-205.

Feuerstein, M., Marshall, L., Shaw, W., \& Burrell, L. (2000). Multicomponent intervention for work-related upper extremity disorders. Journal of Occupational Rehabilitation, I0, 7I-83.

Fried, L. \& Guralnik, J. (1997). Disability in older adults: Evidence regarding significance etiology and risk. Journal of the American Geriatric Society, 45, 92-100.

Goldstein, S., Armstrong, T., Chaffin, D., \& Matthews, L. (1987). Analysis of cumulative strain in tendons and tendon sheaths. Journal of Biomechanics, 20, I-6.

Grinsven, A. von (2005). Tijd voor sprekende gebaren: Een onderzoek naar werk/rust schema's bij tolken Gebarentaal. (Time for a clear gesture: An investigation in the work/rest patterns of sign language interpreters.) Amsterdam, The Netherlands: EXPres - Expertisecentre for Rehabilitation, Ergonomics and Sports.

Guerts, CLM., Sleivert, GG., \& Cheung, SS. (2005). Local cold acclimation of the hand impairs thermal responses of the finger without improving hand function. Acta Physiologica Scandinavica, 183(I), I 17-124.

Hagberg, M., Stenburg, B., \& Sundelin, G. (1987). The use of sign language as an aggravating factor in shoulder tendinitis, a case history of a deaf-mute cleaner. Journal of Human Ergology, 16, 173- 178.

Hales, T. \& Bernard, T. (1996). Epidemiology of work-related musculoskeletal disorders. Occupational Disorder Management, 27, 679-709.

Harvey, M.A. (200I). Vicarious emotional trauma of interpreters: a clinical psychologist's perspective. Journal of Interpreting, Millennium Edition. RID Publications.

Health Canada, Canadian Guidelines for Body Weight Classification in Adults (Ottawa: Health Canada, 2003).

Retrieved March 2008 from http://secure.cihi.ca/cihiweb/products/CPHIOverweightandObesityAugust2004_e.pdf.

Heller, B., Stansfield, M., Stark, G., \& Langholtz, D. (1985). Sign language interpreters stress: An exploratory study. Proceedings of the American Deafness and Rehabilitation Association. Little Rock AR: ADARA.

Hirata, H., Tsujii, M., Yoshida, T., Imanaka, K., Morita, A., Okuyama, N., Nagakura, T., Sugimoto, T., Fujisawa, K., \& Uchida, A. (2005). MMP-2 expression is associated with rapidly proliferative arteriosclerosis in the flexor tenosynovium and pain severity in carpal tunnel syndrome. Journal of Pathology, 205, 443-450.

Hochberg, M., McAlindon, T., \& Felson, D. (2000). Osteoarthritis: New insights - Part 2 Treatment approaches. Annals of Internal Medicine, I33, 726-737.

Hogg-Johnson, S., Cole, D., Côté, P., Frank, J.W. (1999) What we know about the timing and site of interventions for soft-tissue injuries of the low back, neck and upper extremity. In the Royal Commission on Workers' Compensation in British Columbia Staff's, For the Common Good: Final Report of the Royal Commission on Workers' Compensation in British Columbia. Government of British Columbia. www.qp.gov.bc.ca/rcwc/research/hogg-johnson-interventions.pdf. Accessed June 2006. 
Huang, G., Feuerstein, M., \& Sauter, S. (2002). Occupational stress in work related upper extremity disorders: Concepts and models. American Journal of Industrial Medicine, 4I, 298-3I 4.

Hudak, PL., Amadio, PC., Bombardier, C., Boland, A., Fischer, T., Flatow, EL., Gartsman, GM., Louis, DS., Axelrod, T., Buchbinder, R., Hawker, g., Hotchkiss, R., Katz, J., Bedard, T., Lederman, R., Louis, D., McCormick, C., O’Driscoll, S., Richards, D., Richards, R., \& Simmons, B. (1996). Development of an upper extremity outcome measure: The DASH (Disabilities of the arm, shoulder, and hand). American Journal of Industrial Medicine, 29(6), 602-608.

Jinrok, O., Zhao, C., Amadio, P., An, K., Zobitz, M., \& Wold, L. (2004). Vascular pathologic changes in the flexor tenosynovium (subsynovial connective tissue) in idiopathic carpal tunnel syndrome. Journal of Orthopaedic Research, 22, 1310-1315.

Johnson, E.O., Kamilaris, T.C., Chrousos, G.P., Gold, P.W. Mechanisms of stress - A dynamic overview of hormonal and behavioural homeostasis. Neuroscience and Biobehavioural Reviews, I6 (2), II5-130 1992.

Johnson, W. \& Feuerstein, M. (2005). An interpreter's interpretation: Sign language interpreters' views of musculoskeletal disorders. Journal of Occupational Rehabilitation, I5, 40 I-4I5.

Keir, P. \& Wells, R. (1999). Changes in geometry of the finger flexor tendons in the carpal tunnel with wrist postures and tendon load: an MRI study on normal wrists. Clinical Biomechanics, 14, 645.

Keir, P., Bach, J., Hudes, M., \& Rempel, D. (2007). Guidelines for wrist posture based on carpal tunnel thresholds. Human Factors, 49, 88-99.

Keir, P., Wells, R., Ranney, D., \& Lavery, W. (1997). The effects of tendon load and posture on carpal tunnel pressure. The Journal of Hand Surgery, 22A, 628-634.

Kroemer, K. (1992). Avoiding cumulative trauma disorders in shops and offices. American Industrial Hygene Association Journal, 53, 596-604.

Luchetti, R., Schoenhuber, R., \& Nathan, P. (1998). Correlations of segmental carpal tunnel pressures with changes in hand and wrist positions in patients with carpal tunnel syndrome and controls. Journal of Hand Surgery, 23B, 598-602.

Lundberg, U., Forsman, M., Zachau, G., Eklöf, M., Palmer, G., Melin, B., \& Kadefors, R. (2002). Effects of experimentally induced mental and physical stress on motor unit recruitment in the trapezius muscle. Work and Stress, 16, 166-178.

Marras, W. \& Schoenmarklin, R. (1993). Wrist motions in industry. Ergonomics, 36, 34I-35I.

McGill, S. (2002). Low Back Disorders. (Ist ed.) Windsor Ontario: Human Kinetics.

Messer, R. \& Bankers, R. (1995). Evaluating and treating common upper extremity nerve compression and tendonitis syndromes ... without becoming cumulatively traumatized. Nurse Practitioner Forum, 6, I52-166.

Moore, A., Wells, R., \& Ranney, D. (1991). Quantifying exposure in occupational manual tasks with a cumulative trauma disorder. Ergonomics, 34, I433-1453.

National Institute for Occupational Safety and Health (NIOSH). (1997). Elements of Ergonomic Programs. A

Primer Based on Evaluations of Musculoskeletal Disorders. DHHS (NIOSH) Publication No. 97-I 17. http://www.cdc.gov/niosh/pdfs/97-I 17.pdf. Accessed June 2006.

NTID Professional Standards Committee (1997). Standard practice paper: Cumulative motion injury. The Registry of Interpreters for the Deaf.

Pearlman, L.A. \& Saakvitne, K.W. (1995). Trauma and the therapist: counter transference and vicarious traumatisation in psychotherapy with incest survivors. New York: W.W. Norton and Co.

Phalen, G. \& Kendrick, J. (1957). Compression neuropathy of the median nerve in the carpal tunnel. Journal of the American Medical Association, 164, 524-530. 
Ploghaus, A., Tracey, I., Gati, J.S., Clare, S., Menon, R.S., Matthews, P.M., \& Rawlins, J.N.P. (1999) Dissociating pain from its anticipation in the human brain. Science, 284, 1979-1981.

Podhorodecki, A. \& Spielholz, N. (1993). Electromyographic study of overuse syndromes in sign language interpreters. Archives of Physical Medicine and Rehabilitation, 74, 26I-262.

Ranney, D. (1993). Work related chronic injuries of the forearm and hand: their specific diagnosis and management. Ergonomics, 36, 87I-880.

Ranney, D., Wells, R., \& Moore, A. (1995). Upper limb musculoskeletal disorders in highly repetitive industries: precise anatomical findings. Ergonomics, 38, $1408-1423$.

Rempel, D. \& Diao, E. (2004). Entrapment neuropathies: pathophysiology and pathogenesis. Journal of Electromyography and Kinesiology, I4, 7 I-75.

Rempel, D., Bach, J., Gordon, L., \& So, Y. (1998). Effects of forearm pronation/supination on carpal tunnel pressure. The Journal of Hand Surgery, 23A, 38-42.

Richardson, J. \& Jamieson, S. (2004). Cigarette smoking and the ulnar mononeuropathy at the elbow. American Journal of Physical and Medical Rehabilitation, 83(9), 730-734.

Salston, M. and Figley, C. (2003). Secondary traumatic stress effects of working with survivors of criminal victimization. Journal of Traumatic Stress, 16(2), 167-174.

Schechtman, H. \& Bader, D. (2002). Fatigue damage in human tendons. Journal of Biomechanics, 35, 347-353.

Scheuerle, J., Guilford, A., \& Habal, M. (2000). Work-related cumulative trauma disorders and interpreters for the deaf. Applied Occupational and Environmental Hygiene, 15, 429-434.

Schuind, F., Ventura, M., \& Pasteels, J. (1990). Idiopathic carpal tunnel syndrome: Histologic study of flexor tendon synovium. Journal of Hand Surgery, I5A, 497-503.

Schuind, F. (2002). Canal pressures before, during, and after endoscopic release for idiopathic carpal tunnel syndrome. The Journal of Hand Surgery, 27A, 1019-1025.

Sharma, P. \& Maffulli, N. (2005). Tendon injury and tendinopathy: healing and repair. Journal of Bone and Joint Surgery, 87, 187-202.

Shealy, J., Feuerstein, M., \& Latko, W. (1991). Biomechanical analysis of upper extremity risk in sign language interpreting. Journal of Occupational Rehabilitation, I, 217-225.

Sheon, R.P. (1997). Repetitive strain injury I. An overview of the problem and the patients. Postgraduate Medicine, 102, 53-68.

Smith, E., Sonstegard, D., \& Anderson Jr, W. (1977). Carpal tunnel syndrome: Contribution of flexor tendons. Archives of Physical Medicine and Rehabilitation, 58, 379-385.

Smith, S., Kress, T., \& Hart, W. (2000). Hand/wrist disorders among sign language communicators. American Annals of the Deaf, 145, 22-25.

Soslowsky, L., Thomopoulos, S., Esmail, A., Flanagan, C., lannotti, J., Williamson, D., \& Carpenter, J. (2002). Rotator cuff tendinosis in an animal model: Role of extrinsic and overuse factors. Annals of Biomedical Engineering, 30, 1057-1063.

Stedt, J. (1992). Interpreter's wrist: Repetitive stress injury and carpal tunnel syndrome in sign language interpreters. American Annals of the Deaf, 137, 40-43.

Sweeney, M., Peterson, M., \& O'Neill, V. (1994). NIOSH Health hazard evaluation report: Ohio chapter, Registry of Interpreters for the Deaf (Rep. No. HETA-92-0268-2477).

Tallia, A.F., Cardone DA. (2003). Diagnostic and Therapeutic Injection of the Wrist and Hand Region. American Family Physician; 67(4), 745-750. http://www.aafp.org/afp/200302 I5/745.html. Accessed June 2006.

Tanzer, R. (1959). The carpal tunnel syndrome. The Journal of Bone and Joint Surgery, 4I A, 626-634. 
Teefey, S., Hasan, A., Middleton, W., Patel, M., Wright, R., \& Yamaguchi, K. (2000). Ultrasonography of the rotator cuff: A comparison of ultrasonographic and arthroscopic findings in 100 consecutive cases. The Journal of Bone and Joint Surgery, 82-A, 498-504.

Tjepkema,M. (2003). Repetitive Strain Injury. Statistics Canada Health Reports, I4(4), I I-30.

Topp, K. \& Boyd, B. (2006). Structure and Biomechanics of Peripheral Nerves: Nerve Responses to Physical Stresses and Implications for Physical Therapist Practice. Physical Therapy, 86, 92-109.

Ugbolue, C., Hsu, W., Goitz, R., \& Li, Z. (2005). Tendon and nerve displacement at the wrist during finger movements. Clinical Biomechanics, 20, 50-56.

Vasiliadis, H-M., Lesage, A., Adair, C., Wang, P.S., Kessler, R.C. (2007). Do Canada and the United States differ in prevalence of depression and utilization of services? Psychiatric Services, 58, 63-7I.

Viikari-Juntura, E., Shiri, R., Soloviea, S., Karpinpinen, J., Leino-Arjas, P., Varonen, H., Kalso, E., \& Ukkola, O. (2008). Risk factors of atherosclerosis and shoulder pain - Is there an association? A systematic review. European Journal of Pain, 12, 412-426.

Weiss, N., Gordon, L., Bloom, T., So, Y., \& Rempel, D. (1995). Position of the wrist associated with the lowest carpal tunnel pressure: Implications for splint design. The Journal of Bone and Joint Surgery, 77-A, 1695-1699.

Williams, R. \& Westmorland, M. (1994). Occupational cumulative trauma disorders of the upper extremity. The American Journal of Occupational Therapy, 48, 4 II-420.

Woodcock, K. \& Aguayo, M. (2000). Deafened people: Adjustment and support. Toronto: University of Toronto Press.

Workplace Health, Safety, and Compensation Commission of New Brunswick. (2005). Expected Healing Times. [internet]. Available at: http://www.whscc.nb.ca/revhea7b_e.asp [accessed March 12 2008]

Wright, B.A. (1960). Physical disability: a psychosocial approach. New York: Harper and Row.

Wright, T., Glowczewskie, F., Cowin, D., \& Wheeler, D. (2005). Radial nerve excursion and strain at the elbow and wrist associated with upper extremity motion. The Journal of Hand Surgery, 30A, 990-996. 
IO APPENDIX I. QUICK DASH TO ASSESS DISORDERS OF THE ARM AND SHOULDER

\section{THE \\ QuickDASH}

OUTCOME MEASURE

\section{INSTRUCTIONS}

This questionnaire asks about your symptoms as well as your ability to perform certain activities.

Please answer every question, based on your condition in the last week. by circling the appkopriate number. If you did not have the ppportunity to perform an activity in the past veek, please make your best estimate of which response wround be the most accurate.

It doesn't matter which hand or arm you use to perform the activity; please answer based on your ability regardless of how you perform the task.

QuickDASH (c) 2006 Institute for Work and Health Reprinted with permission for educational and noncommercial use only. See conditions of use and download copies on http://www.dash.iwh.on.ca/conditions.htm. Discuss your ratings with your health care professional. 


\section{QuickDASH}

Please rate your ability to do the following activities in the last week by circling the number below the appropriate response.

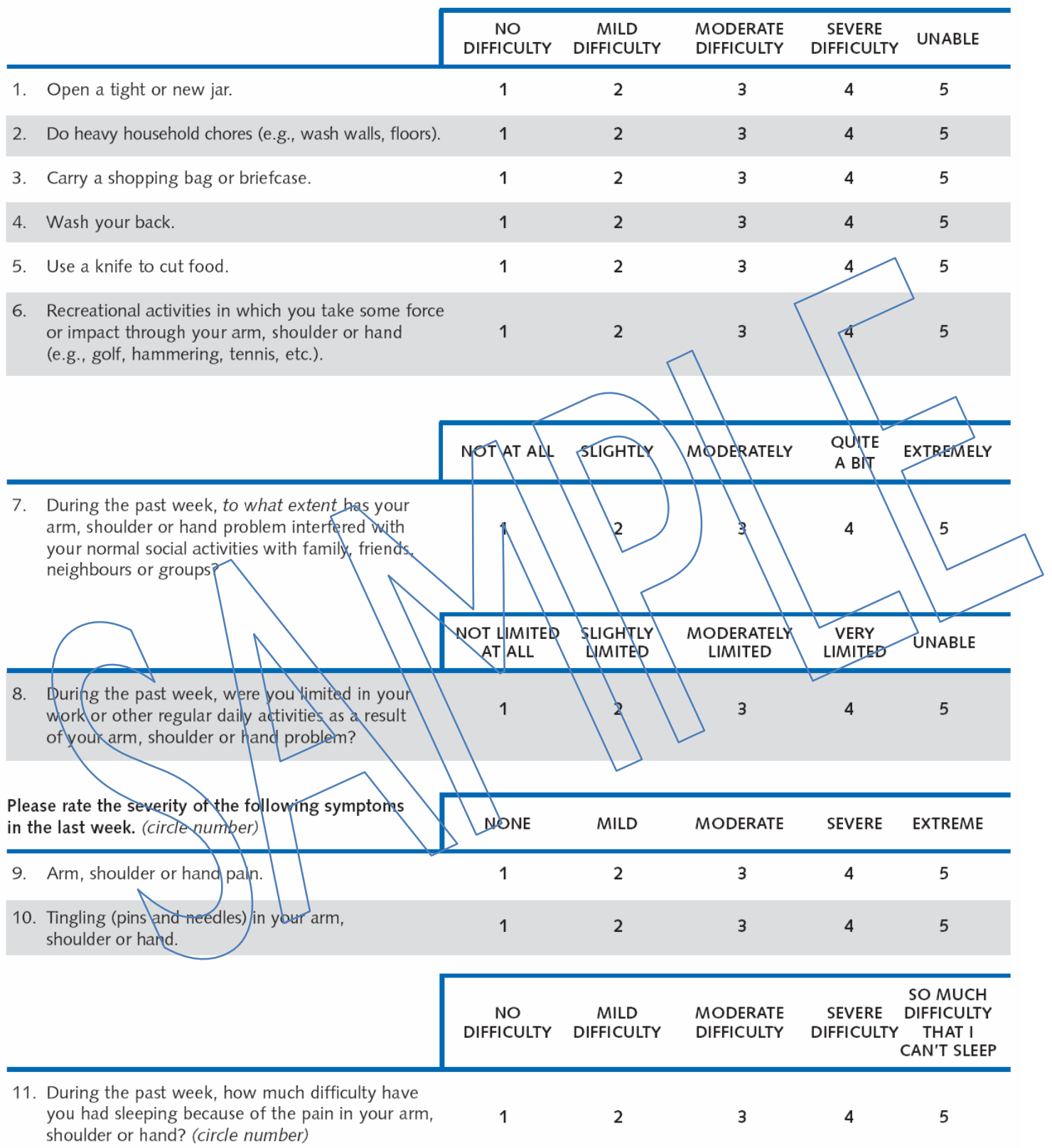

QuickDASH DISABILITY/SYMPTOM SCORE $=\left(\left[\frac{(\text { sum of } n \text { responses })}{n}\right]-1\right) \times 25$, where $n$ is equal to the number
of completed responses.

A QuickDASH score may not be calculated if there is greater than 1 missing item. 


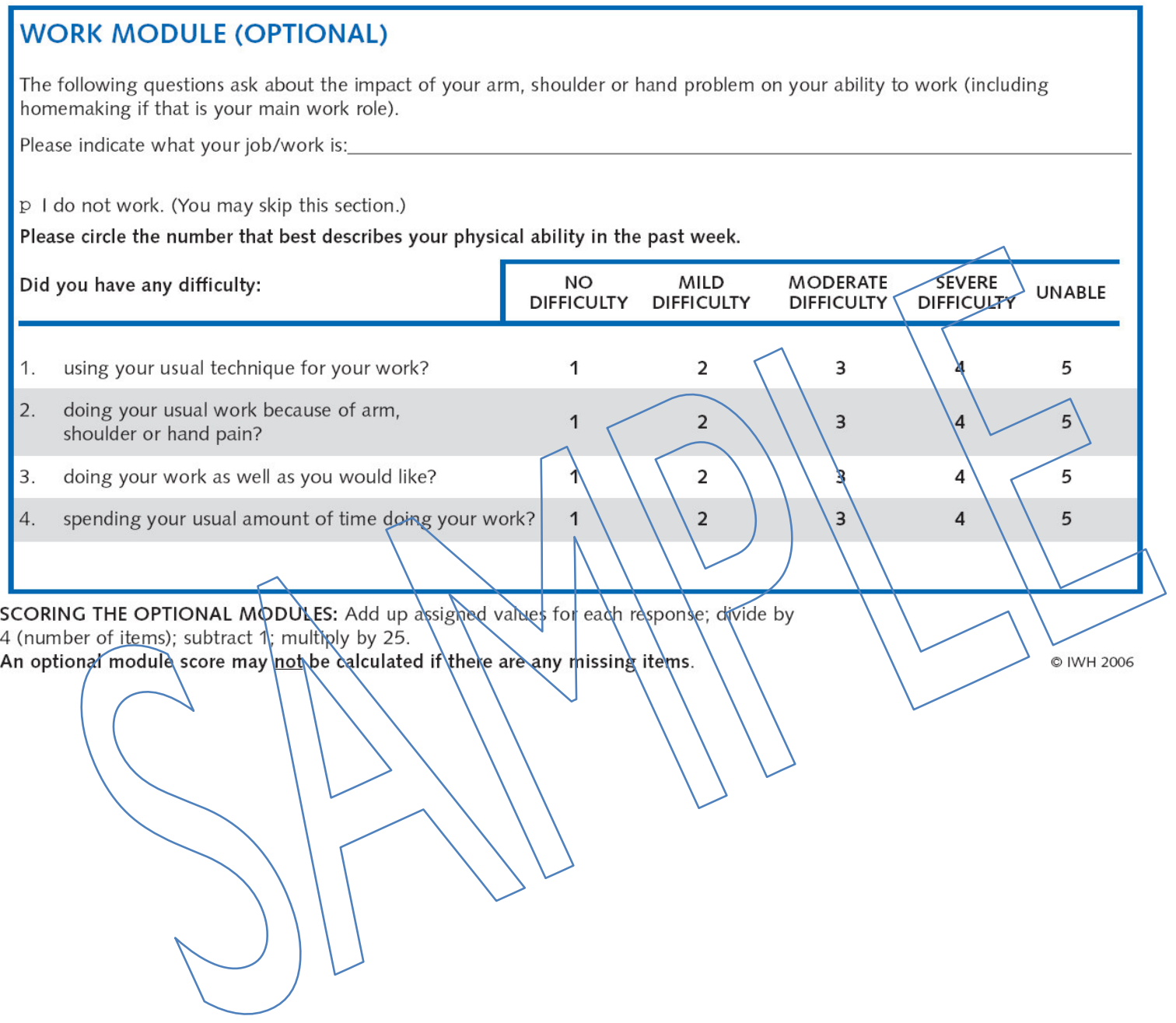




\section{APPENDIX 2. MODEL HEALTH AND SAFETY POLICY FOR SIGN LANGUAGE INTERPRETER PROVIDING SERVICES ON SHORT TERM CONTRACT}

[Interpreting agency / Individual interpreter] is committed to interpreter health and safety as a major prerequisite to the quality and availability of communication access between deaf people and people who do not sign. All clients and individual interpreters must be dedicated to the continuing objective of reducing risk of injury.

In retaining the services of [Interpreting agency / Individual interpreter], [Client / Employer] will make every effort to provide a safe, healthy work environment.

[Client / Employer] is ultimately responsible for worker health and safety of those who work on [its/their] premises, and has knowledge of potential or actual hazards that may be unknown to [Interpreting agency / Individual interpreter]. Accordingly, [Client / Employer] will provide all interpreters with adequate training and information prior to hazard exposures as necessary to protect the interpreter's health and safety, and take every reasonable precaution for the protection of the interpreter.

Specifically, and without limiting the generality of this principle, [Client / Employer] will ensure that the workplace for interpretation is in compliance with established safe work practices and procedures. In addition, [Client / Employer] will ensure that continuous solo interpreting does not last longer than [AVLIC RECOMMENDED MAXIMUM LENGTH OF SOLO INTERPRETING between breaks of at least [time] minutes, during which no sign language communication will be required.

[Individual interpreter / Interpreting agency "and each affiliated interpreter'] will take responsibility to protect [his, her, their] own health and safety by working in accordance with the health and safety policies communicated by [Client / Employer] and laws or regulations pertaining to the workplace as communicated by [Client / Employer] and by adopting the safe work practices and procedures established by the Association for Visual Language Interpreters of Canada (AVLIC).

Working together, [Interpreting agency / Individual interpreter] and [Client / Employer] will promote and practise our highest standards of communication to achieve our mutual health and safety goals.

Signed:

[Client / Employer]

[Interpreting agency / Individual interpreter] 
I2 APPENDIX 3. CANADA'S FOOD GUIDE 


\section{$\begin{array}{ll}\text { Health } & \text { Santé } \\ \text { Canada } & \text { Canada }\end{array}$ \\ Your health and \\ Votre santé et votre \\ safety... our priority. \\ sécurité... notre priorité.}

Eating

\section{Well with}

Canada's

Food Guide
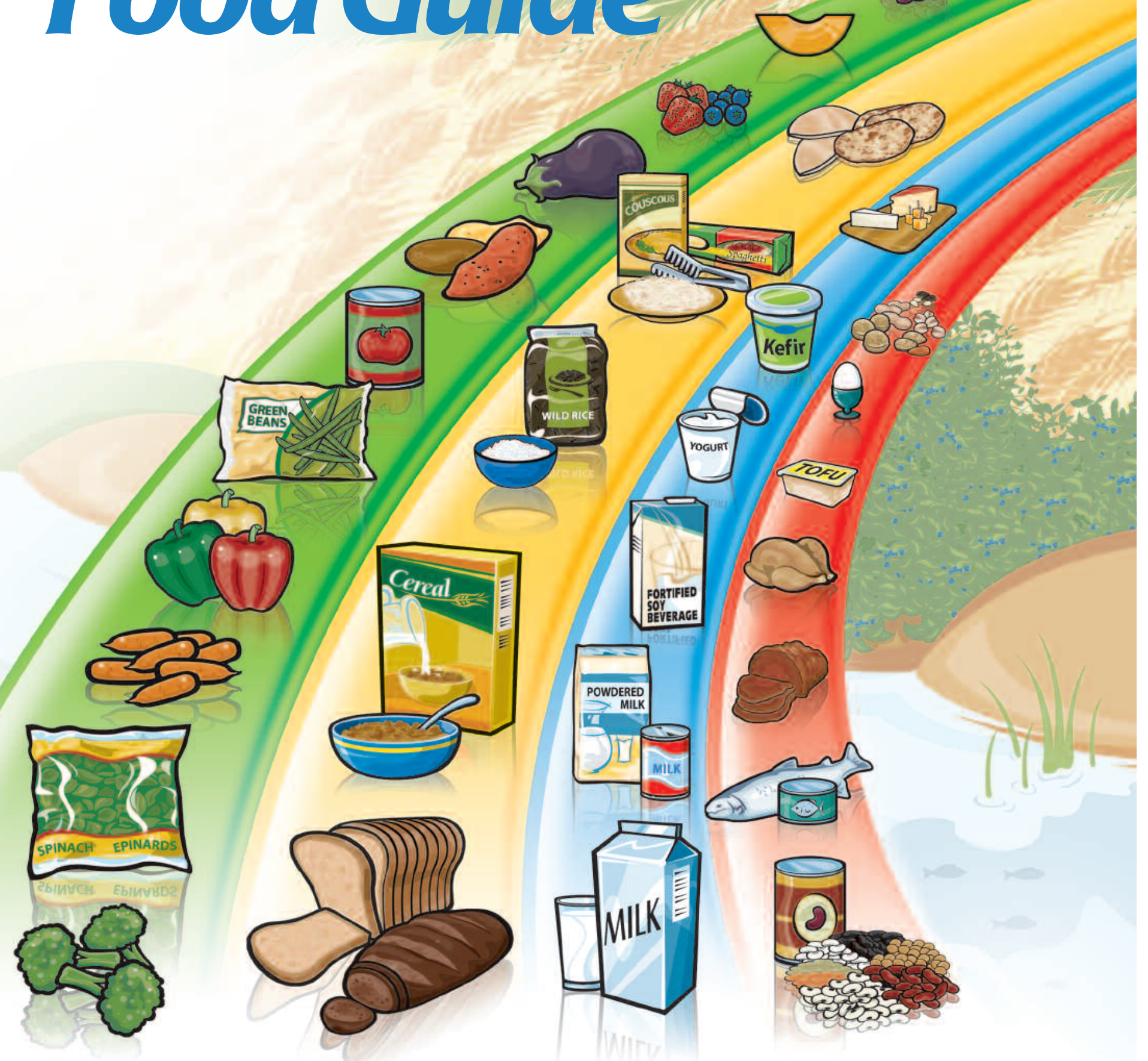


\section{Recommended Number of Food Guide Servings per Day}
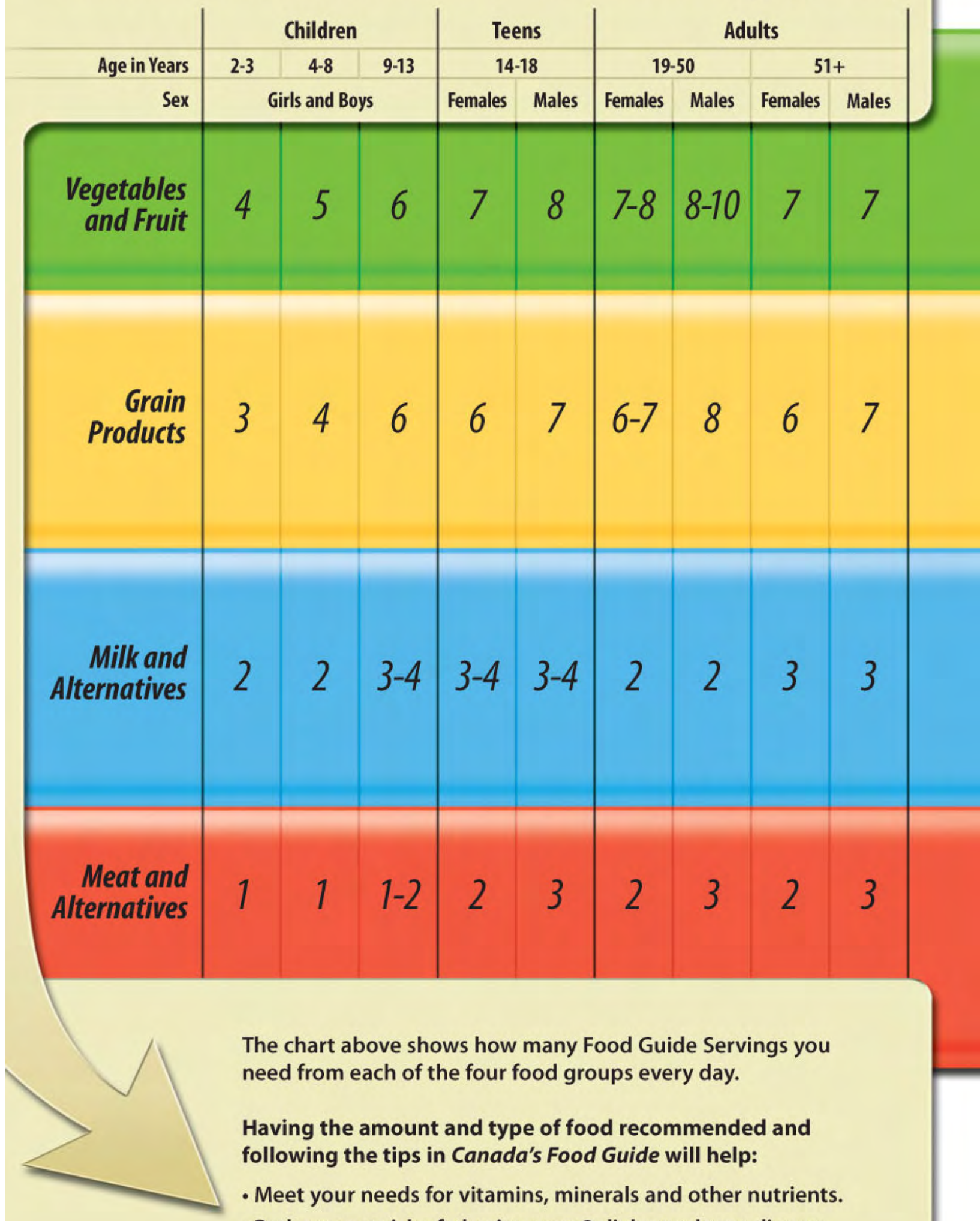

The chart above shows how many Food Guide Servings you need from each of the four food groups every day.

Having the amount and type of food recommended and following the tips in Canada's Food Guide will help:

- Meet your needs for vitamins, minerals and other nutrients.

- Reduce your risk of obesity, type 2 diabetes, heart disease, certain types of cancer and osteoporosis.

- Contribute to your overall health and vitality. 


\section{What is One Food Guide Serving? Look at the examples below.}

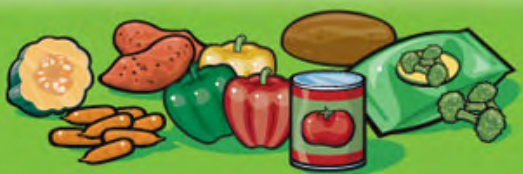

Fresh, frozen or canned vegetables $125 \mathrm{~mL}$ (1/2 cup)

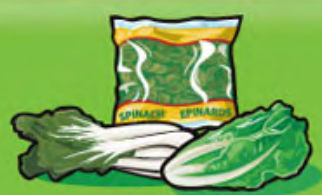

Leafy vegetables Cooked: 125 mL (1/2 cup) Raw: $250 \mathrm{~mL}$ (1 cup) 8

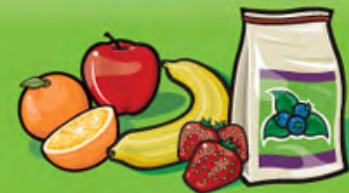

Fresh, frozen or canned fruits

1 fruit or $125 \mathrm{~mL}$ (1/2 cup)

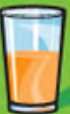

$100 \%$ Juice $125 \mathrm{~mL}$ (1/2 cup)

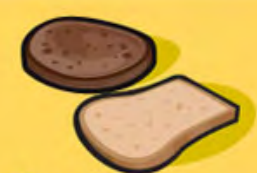

Bread

1 slice (35 g)

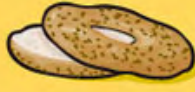

Bagel

$1 / 2$ bagel $(45 \mathrm{~g})$

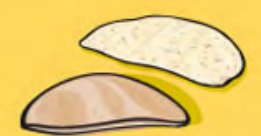

Flat breads

$1 / 2$ pita or $1 / 2$ tortilla $(35 \mathrm{~g})$

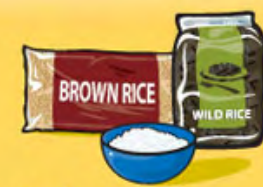

Cooked rice,

bulgur or quinoa $125 \mathrm{~mL}$ (1/2 cup)

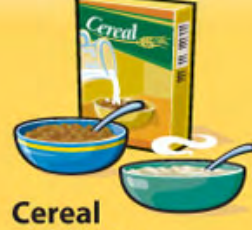

\section{Cereal}

Cold: $30 \mathrm{~g}$

Hot: $175 \mathrm{~mL}$ (3/4 cup)

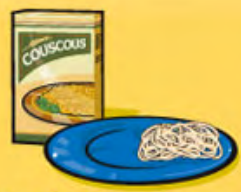

Cooked pasta or couscous $125 \mathrm{~mL}$ (1/2 cup)

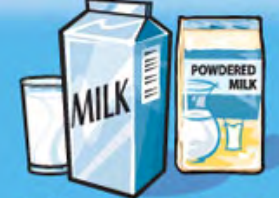

Milk or powdered milk (reconstituted) $250 \mathrm{~mL}$ (1 cup)

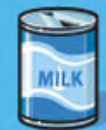

Canned milk

(evaporated)

$125 \mathrm{~mL}$ (1/2 cup)

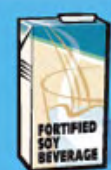

Fortified soy

beverage $250 \mathrm{~mL}$ (1 cup)

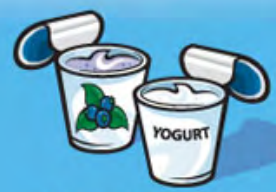

Yogurt

$175 \mathrm{~g}$ ( $3 / 4$ cup)

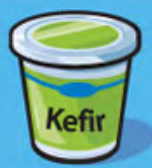

Kefir

$175 \mathrm{~g}$ ( 3 cup)

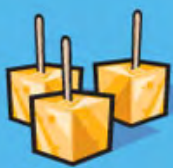

Cheese

$50 \mathrm{~g}\left(1 \frac{1}{2} \mathrm{oz}\right.$.

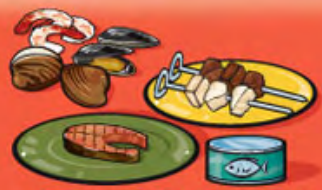

Cooked fish, shellfish, poultry, lean meat $75 \mathrm{~g}(2$ / oz. o. $/ 125 \mathrm{~mL}$ (1/2 cup)

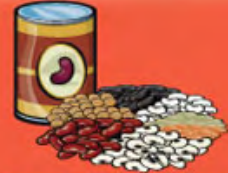

Cooked legumes $175 \mathrm{~mL}(3 / 4$ cup)

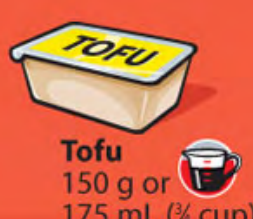

$175 \mathrm{~mL}$ (3/4 cup)

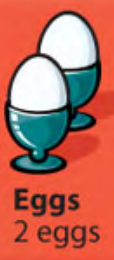

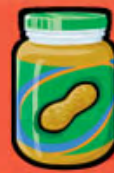

Peanut or nut butters $30 \mathrm{~mL}$ (2 Tbsp)

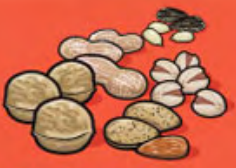

Shelled nuts and seeds $60 \mathrm{~mL}$ (1/4 cup)

\section{Oils and Fats}

- Include a small amount - 30 to $45 \mathrm{~mL}$ ( 2 to $3 \mathrm{Tbsp}$ ) - of unsaturated fat each day. This includes oil used for cooking, salad dressings, margarine and mayonnaise.

- Use vegetable oils such as canola, olive and soybean.

- Choose soft margarines that are low in saturated and trans fats.

- Limit butter, hard margarine, lard and shortening.

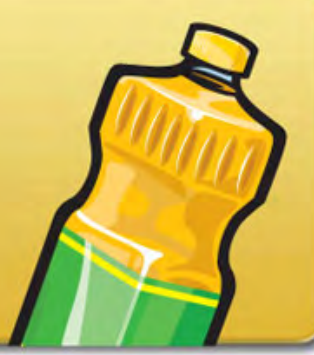




\section{Make each Food Guide Serving count... wherever you are - at home, at school, at work or when eating out!}

\section{- Eat at least one dark green and one orange vegetable each day.}

- Go for dark green vegetables such as broccoli, romaine lettuce and spinach.

- Go for orange vegetables such as carrots, sweet potatoes and winter squash.

- Choose vegetables and fruit prepared with little or no added fat, sugar or salt.

- Enjoy vegetables steamed, baked or stir-fried instead of deep-fried.

\section{Have vegetables and fruit more often than juice.}

\section{- Make at least half of your grain products whole grain each day.}

Eat a variety of whole grains such as barley, brown rice, oats, quinoa and wild rice.

Enjoy whole grain breads, oatmeal or whole wheat pasta.

- Choose grain products that are lower in fat, sugar or salt.

Compare the Nutrition Facts table on labels to make wise choices.

Enjoy the true taste of grain products. When adding sauces or spreads, use small amounts.

\section{- Drink skim, $1 \%$, or $2 \%$ milk each day.}

- Have $500 \mathrm{~mL}$ (2 cups) of milk every day for adequate vitamin D.

- Drink fortified soy beverages if you do not drink milk.

\section{- Select lower fat milk alternatives.}

- Compare the Nutrition Facts table on yogurts or cheeses to make wise choices.

Have meat alternatives such as beans, lentils and tofu often.

- Eat at least two Food Guide Servings of fish each week.*

- Choose fish such as char, herring, mackerel, salmon, sardines and trout.

\section{- Select lean meat and alternatives prepared with little or no added fat or salt.}

- Trim the visible fat from meats. Remove the skin on poultry.

- Use cooking methods such as roasting, baking or poaching that require little or no added fat.

- If you eat luncheon meats, sausages or prepackaged meats, choose those lower in salt (sodium) and fat.
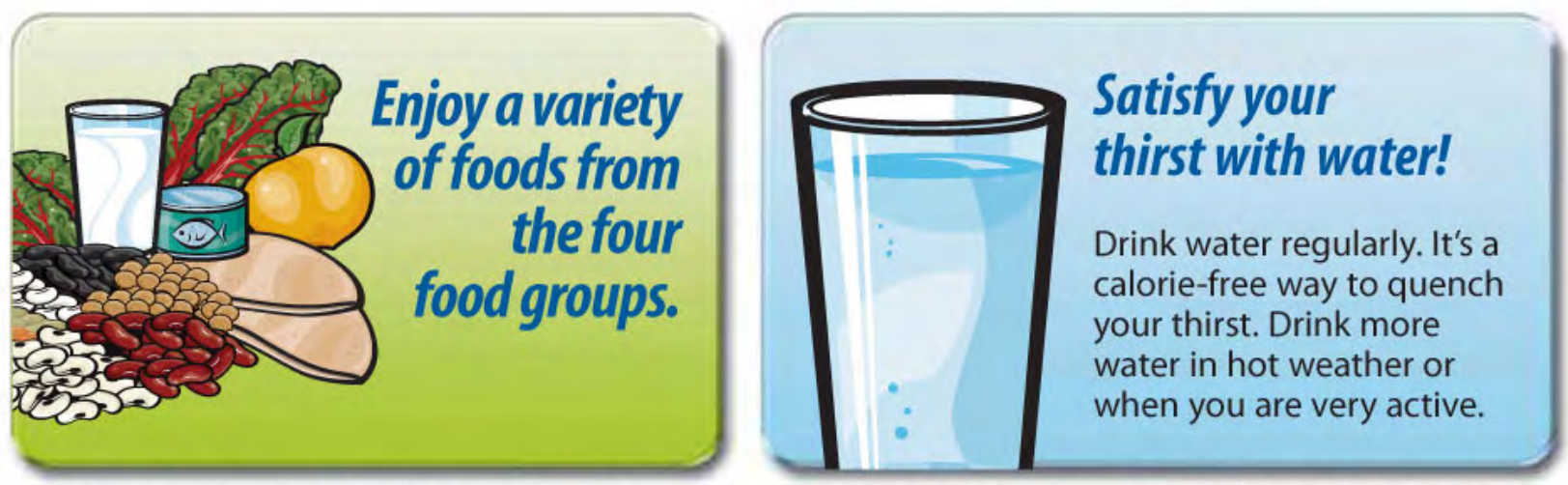

* Health Canada provides advice for limiting exposure to mercury from certain types of fish. Refer to www.healthcanada.gc.ca for the latest information. 


\section{Advice for different ages and stages...}

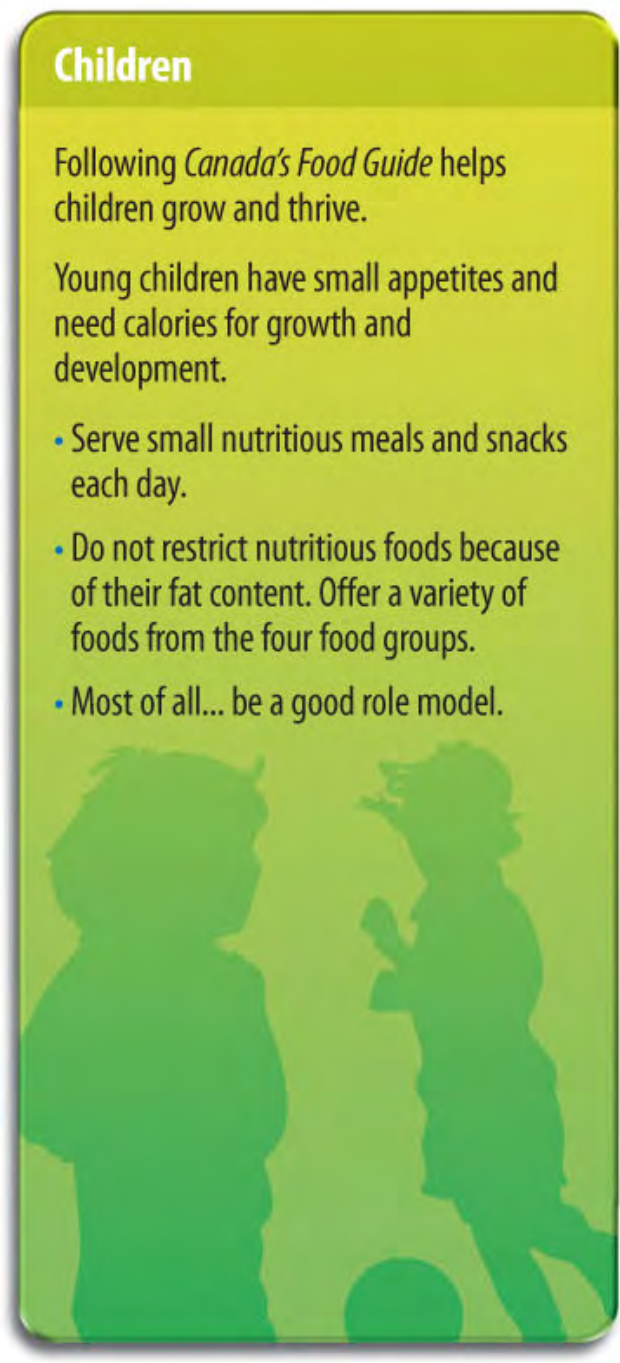

\section{Women of childbearing age}

All women who could become pregnant and those who are pregnant or breastfeeding need a multivitamin containing folic acid every day.

Pregnant women need to ensure that their multivitamin also contains iron. A health care professional can help you find the multivitamin that's right for you.

Pregnant and breastfeeding women need more calories. Include an extra 2 to 3

Food Guide Servings each day.

\section{Here are two} examples:

- Have fruit and yogurt for a snack, or

- Have an extra slice of toast at breakfast and an extra glass of milk at supper.

\section{Men and women over 50}

The need for vitamin D increases after the age of 50 .

In addition to following Canada's Food Guide, everyone over the age of 50 should take a daily vitamin $D$ supplement of $10 \mu \mathrm{g}(400 \mathrm{IU})$.

\section{How do I count Food Guide Servings in a meal?}

\section{Here is an example:}

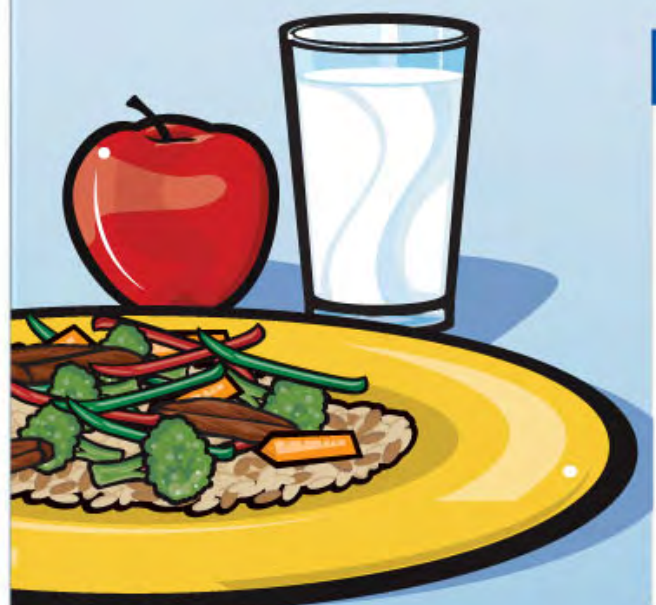

Vegetable and beef stir-fry with rice, a glass of milk and an apple for dessert

$250 \mathrm{~mL}$ (1 cup) mixed broccoli, carrot and sweet red pepper

$=2$ Vegetables and Fruit Food Guide Servings

$75 \mathrm{~g}(2 \mathrm{~K}$ oz.) lean beef $=1$ Meat and Alternatives Food Guide Serving

$250 \mathrm{~mL}$ (1 cup) brown rice $=2$ Grain Products Food Guide Servings

$5 \mathrm{~mL}$ (1 tsp) canola oil = part of your Oils and Fats intake for the day

$250 \mathrm{~mL}$ ( 1 cup) $1 \%$ milk $=1$ Milk and Alternatives Food Guide Serving

1 apple $=1$ Vegetables and Fruit Food Guide Serving 


\section{Eat well and be active today and every day!}

\section{The benefits of eating well and being active include:}

- Better overall health.

- Lower risk of disease.

- Feeling and looking better.

- A healthy body weight.

- More energy.

- Stronger muscles and bones.

\section{Be active}

To be active every day is a step towards better health and a healthy body weight.

Canada's Physical Activity Guide recommends building 30 to 60 minutes of moderate physical activity into daily life for adults and at least 90 minutes a day for children and youth. You don't have to do it all at once. Add it up in periods of at least 10 minutes at a time for adults and five minutes at a time for children and youth.

\section{Start slowly and build up.}

\section{Eat well}

Another important step towards better health and a healthy body weight is to follow Canada's Food Guide by:

- Eating the recommended amount and type of food each day.

- Limiting foods and beverages high in calories, fat, sugar or salt (sodium) such as cakes and pastries, chocolate and candies, cookies and granola bars, doughnuts and muffins, ice cream and frozen desserts, french fries, potato chips, nachos and other salty snacks, alcohol, fruit flavoured drinks, soft drinks, sports and energy drinks, and sweetened hot or cold drinks.

\section{Read the label}

- Compare the Nutrition Facts table on food labels to choose products that contain less fat, saturated fat, trans fat, sugar and sodium.

- Keep in mind that the calories and nutrients listed are for the amount of food found at the top of the Nutrition Facts table.

\section{Limit trans fat}

When a Nutrition Facts table is not available, ask for nutrition information to choose foods lower in trans and saturated fats.

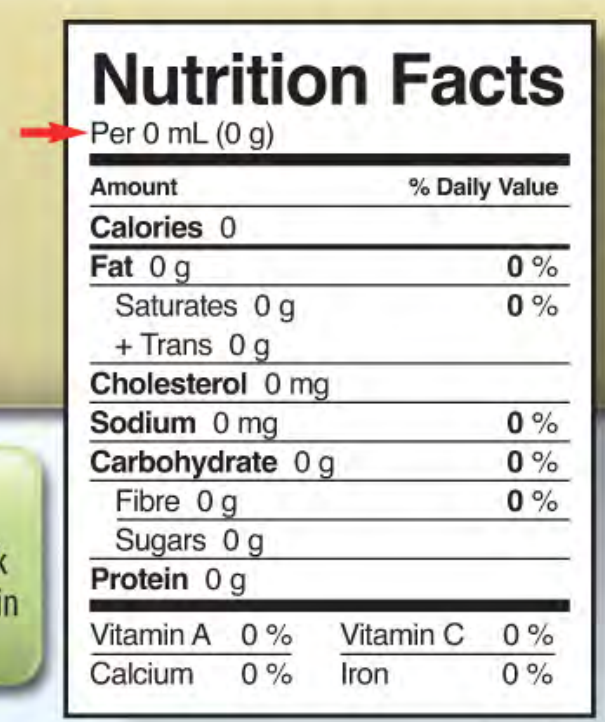

Take a step today...

$\checkmark$ Have breakfast every day. It may help control your hunger later in the day.

$\checkmark$ Walk wherever you can - get off the bus early, use the stairs.

$\checkmark$ Benefit from eating vegetables and fruit at all meals and as snacks.

$\checkmark$ Spend less time being inactive such as watching TV or playing computer games.

$\checkmark$ Request nutrition information about menu items when eating out to help you make healthier choices.

$\checkmark$ Enjoy eating with family and friends!

$\checkmark$ Take time to eat and savour every bite!

\section{For more information, interactive tools, or additional copies visit Canada's Food Guide on-line at: www.healthcanada.gc.ca/foodguide}

\section{or contact:}

Publications

Health Canada

Ottawa, Ontario K1A 0K9

E-Mail: publications@hc-sc.gc.ca

Tel.: 1-866-225-0709

Fax: (613) 941-5366

TTY: 1-800-267-1245

Également disponible en français sous le titre: Bien manger avec le Guide alimentaire canadien

This publication can be made available on request on diskette, large print, audio-cassette and braille. 
Ontario Workplace Safety and Insurance Board Research Advisory Council Grant \#05-23 Occupational Health and Safety Guide for Sign Language Interpreters

Kathryn Woodcock and Steven L. Fischer School of Occupational and Public Health 350 Victoria Street, Toronto Ontario M5B 2K3 www.ryerson.ca/sophe

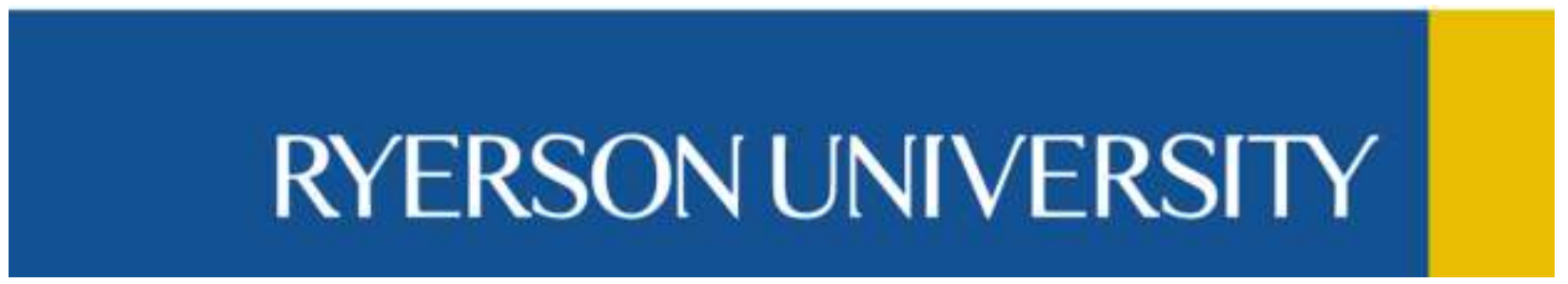

